University of Windsor

Scholarship at UWindsor

\title{
An improved kinetic fluorometric enzymatic coupled assay for the determination of galactose 1-phosphate uridylyltransferase in erythrocytes.
}

\author{
Peter. Catomeris \\ University of Windsor
}

Follow this and additional works at: https://scholar.uwindsor.ca/etd

\section{Recommended Citation}

Catomeris, Peter., "An improved kinetic fluorometric enzymatic coupled assay for the determination of galactose 1-phosphate uridylyltransferase in erythrocytes." (1988). Electronic Theses and Dissertations. 1088.

https://scholar.uwindsor.ca/etd/1088

This online database contains the full-text of PhD dissertations and Masters' theses of University of Windsor students from 1954 forward. These documents are made available for personal study and research purposes only, in accordance with the Canadian Copyright Act and the Creative Commons license-CC BY-NC-ND (Attribution, Non-Commercial, No Derivative Works). Under this license, works must always be attributed to the copyright holder (original author), cannot be used for any commercial purposes, and may not be altered. Any other use would require the permission of the copyright holder. Students may inquire about withdrawing their dissertation and/or thesis from this database. For additional inquiries, please contact the repository administrator via email (scholarship@uwindsor.ca) or by telephone at 519-253-3000ext. 3208. 


\section{It+1}

Canadian Theses Service Service des thèses canadiennes .

Otawa. Canada

KIA ON4

The quality of this microtom is heavily dependent upon the quality of the original thesis submitted for microfilming. Every effort has been made to ensure the highest quality of reproduction possible.

If pages are missing, contact the university which granted the degree.

Some paiyes may have indistinct print especially if the original pages were typed with-a poor typewriter ribbon or if the university sent us an inferior photocopy.

Previously copyrighted materials (journal articles, pubdished tests, etc.) are not filmed.

Reproduction in full or in part of this microform is governed by the Canadian Copyright ACt. R.S.C. 1970, C. C-30.

\begin{abstract}
AVIS
La qualité de cette microforme dépend grandement de la qualité de la thèse soumise au microfilmage. Nous avons tout fait pour assurer une qualité supérieure de reproduc. tion.

S'il manque des pages, veuillez communiquer avec luniversité qui a contéré le grade.

La qualité d'impression de certaines pages peut laisser à désirer, surtout si les pages originales ont été dactylographiées à l'aide d'un ruban usé ou si l'université nous a lait parvenir une photocópie de qualité inférieure.

Les documents qui tont déjà l'objet d'un droit d'auteur (articles de revue, tests publiés, etc.) ne sont pas microfilmés.

La reproduction, même partielle, de celte microlorme est soumise à la Loi canadienne sur le droit d'auteur, SAC 1970, c. C.30.
\end{abstract}


AW IMPROVED KTIETIC FLUOROMETRIC ENZYMATIC COUPLED ASSAY

FOR THE DETERMINATION OF

GALACTOSE 1-PHOSPHATE URIDYLYLTRANSFERASE

IN ERYTHROCYTES

by

PETER CATOMERIS
A THESIS
Submitted to the Faculty of Graduate Studies through the Department of Chemistry and Biochemistry in
Partial Fulfillment of the Requirements for the Degree of Master of Science at the
University of Windsor

Windsor, Ontario, Canada

1987 
Permission has been granted to the National Iibrary of Canada to microfilm this thesis and to lend or sell copies of the film.

The author (copyright owner) has reserved other publication rights, and neither the thesis nor extensive extracts from itmay be printed or otherwise reproduced without his/her written permission.
L'autorisation a été accordée à la Bibliothèque nationale du Canada de microfilmer cette thèse et de prêter ou de vendre des exemplaires du film.

L'auteur (titulaire du droit d'auteur) se réserve les autres droits de publication: ni la these ni de longs extraits de celle-ci ne doivent être imprimés ou autrement reproduits sans son autorisation écrite.

$$
\text { ISBN } \quad 0-315-43734-0
$$


-. $\quad$ MIII $964 M^{-}$

40

(C) Peter Catomeris 1987

$-$
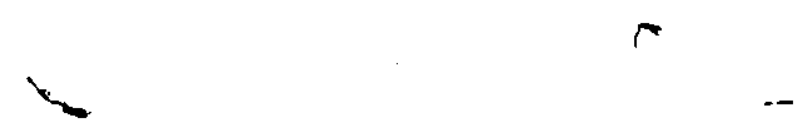
ABSTRACT

AN IMPROVED KINETIC FLUOROMETRIC ENZYMATIC COUPLED ASSAY FOR THE DETERMINATION OF GALACTOSE 1-PHOSPHATE URIDYLYLTRANSFERASE IN 
Due to the high native fluorescence of resorufin (100-ford greater than that of WADPE), low levels of GALT activity can be measured continuously and quickly. This has a distinct advantage over UDPG-consumption and radiochemical methods, which require three steps, and other kinetic methods which require a long pre-incubation period (15 to 20 minutes) to generate enough product to be measured. In contrast the present coupled assay has a lag phase of only 3 to 4 minutes.

GALT activity at pH $8.7,37^{\circ} \mathrm{C}$ was determined, using a $10-\mu \mathrm{I}$ sample of hemolysate, by monitoring the rate of increase in fluorescence ( $n_{\text {excitation }}=$ $520 \mathrm{~nm}, \lambda_{\text {emission }}=585 \mathrm{~nm}$ ) with time.

The present method correlated well $(r=0.977)$ with the reference UDPGconsumption method for GAIT, and clearly differentiated between deficient and normal samples. GALI activities for normal patients ranged from 240-456 U/ kg hemoglobin.

Also described is the optimization of the resazurin/diaphorase reaction for the determination of dehydrogenase activity. Onder the new conditions, improved standard curves were generated and lower levels of dehydrogenase activity were determined. 


\section{ACKNOWLEDGEMENTS}

I would first like to thank my supervisor, Dr. Roger Thibert, for giving me the opportunity to be in the Clinical Chemistry Programme_and to work with him. At several times during my.M.Sc., he displayed great patience and was constantly encouraging.

I would also like to express my appreciation to other members of the committee (Drs. Draisey, Mutus and Virgo) for taking the time to critique this paper.

I am forever indebted to Miss Maeve Doyle, not only for the time and effort she has spent typing this document, but also for the moral support she has given me during some of the more difficult times.

Gerardo Castillo and Gheorghe Brotea must be mentioned for helping to tie up some of the loose ends (and creating some new ones) in the "Resorufin Story".

To members of the faculty, staff and students, I thank you for your suggestions, help and friendship.

Lastly, I would like to say that none of this would have been possible if not for my parents, who constantly stressed the importance of education to me. I hope that this"makes them as proud of me as I am of them. 
$+$

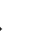

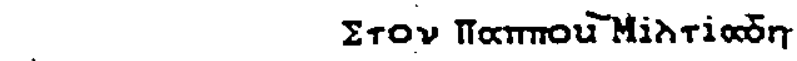

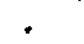

$\checkmark$

$\infty$

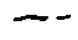




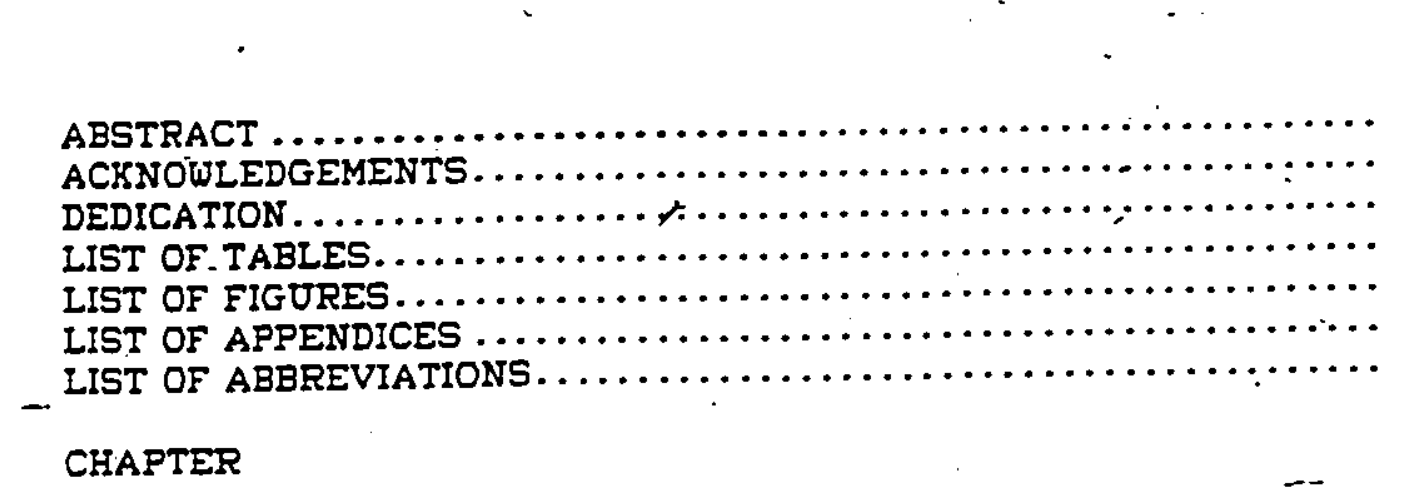

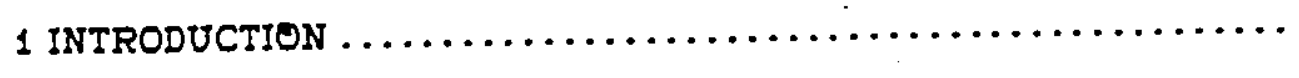

1.1 Galactose 1-Phosphate Uridylyltransferase.$\ldots \ldots \ldots \ldots \ldots$

- 1.1 .1 Role in Galactose Metabolism ................

1.1.2 Galactosemia..........................

1.1.2.1 Prevalence........................

1.1.2.2 Clinical Symptoms and

Bicchemical Basis ................... 4

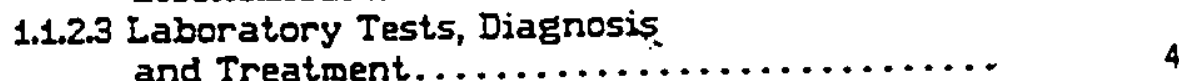

1.1.3 Properties of the Erythrocyte Enzyme .......... 5

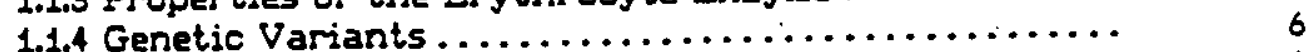

1.1 .5 Methods of Analysis ...................... 6

1.1.5.5 UDPG-Consumption Method............ 7

1.1.5.2 Methods Based on the

Generation of Glucose 1-Phosphate........ 8

1.1.5.3 Radiochemical Methods ................

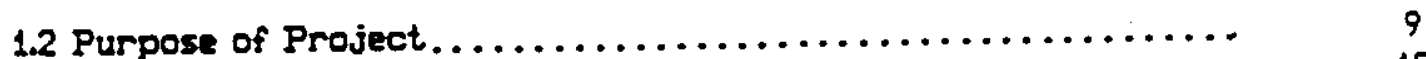

1.3 The Resazurin/Diaphorase System ................ 10

2 MATERIALS AND METHODS . . . . . . . . . . . 13

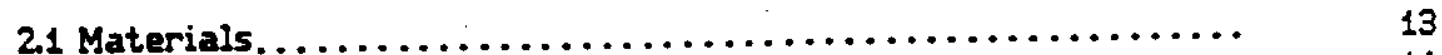

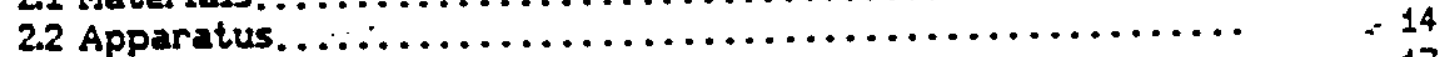

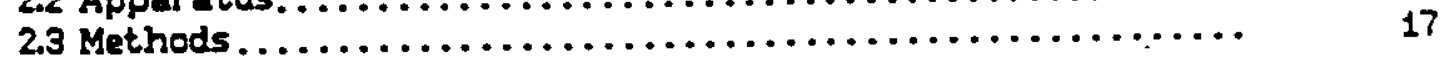

2.3.1 Study of Resazurin/Diaphorase System .......... 17

2.3.1.1 Reagents ........................ 17

2.3.1.2 Procedures........................ 18

$\mathbf{v i}$ 
2.3 .2 Measurement of GAII in Hemolysates ..........., 21

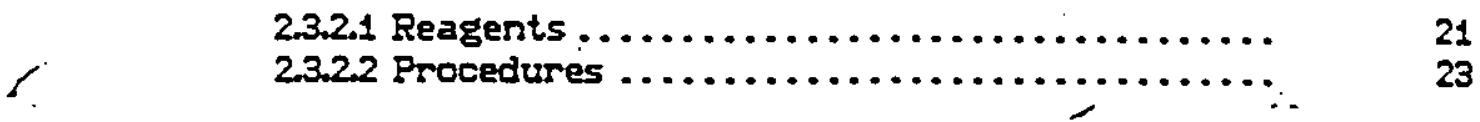

3. RESULTS AND DISCUSSION . . . . . . . . . . . . $\ldots \ldots \ldots \ldots \ldots \ldots$

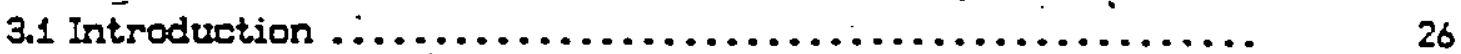

3.2 The Resazurin/Diaphorase System................. . . 26

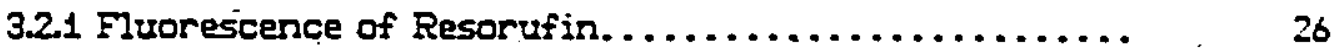

3.2 .2 Preliminary Studies ...................................

3.2.3 Reaction Kinetics of Diaphorase/Resazurin System... 31

3.2.4 Calibration Curves ........................ 38

3.25 Stability of Resazurin in Water............... 45

3.3 Determination of GALT Activity is Erythrocytes.......... 45

3.3.1 Preliminary Studies ...................... 45

3.3 .2 Optimization of GALT Assay.................. 53

3.3.2.1 Sample Size $\ldots \ldots \ldots \ldots \ldots \ldots \ldots \ldots \ldots \ldots \ldots \ldots . . \ldots \ldots \ldots$

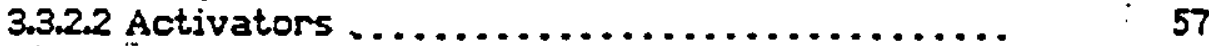

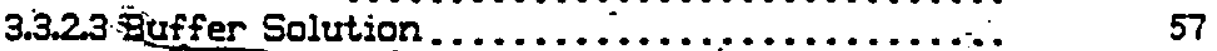

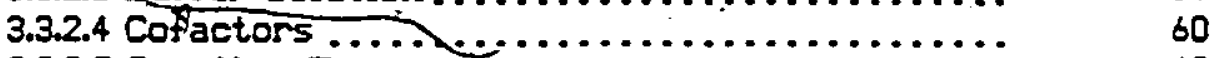

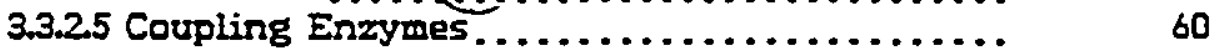

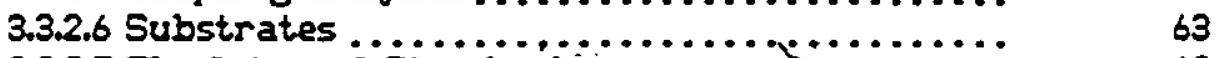

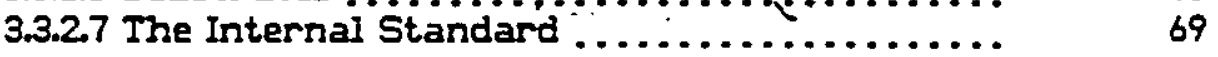

3.3.3 Linearity of GALT Assay .................... 79

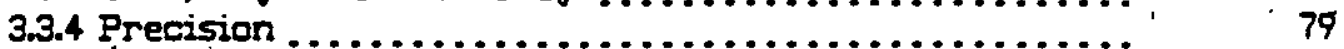

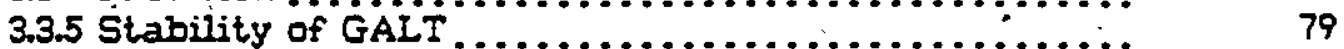

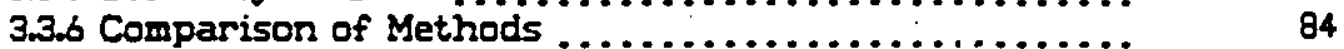

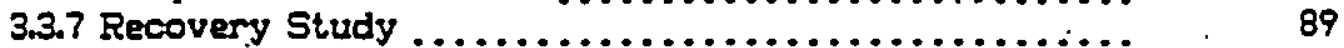

3.3 .8 Reference Range of $\mathrm{GAIT}$ in Erythrocytes .......... 91

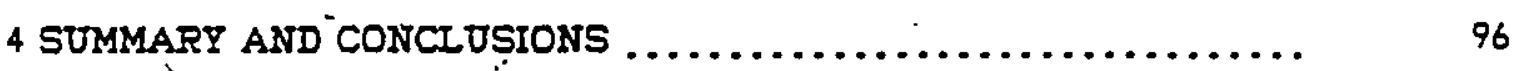

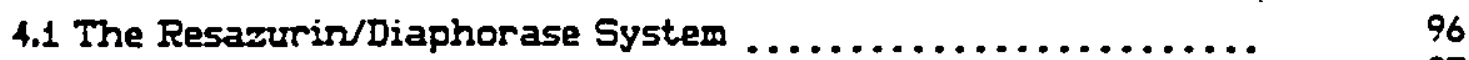

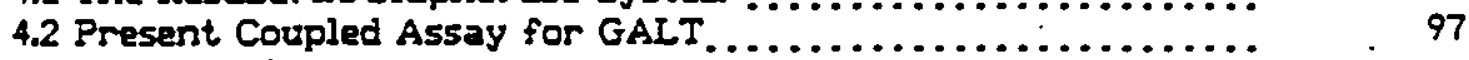

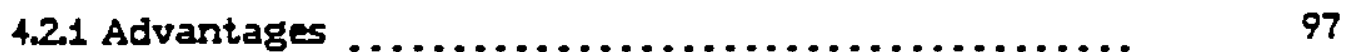

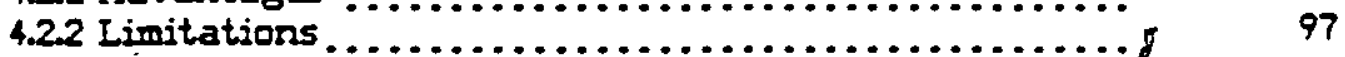

APPENDIX A $\therefore$

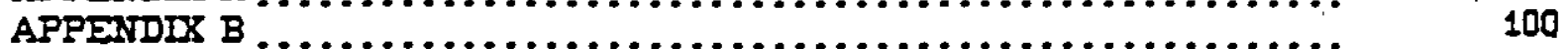

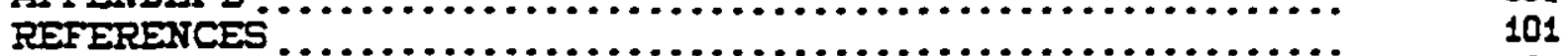

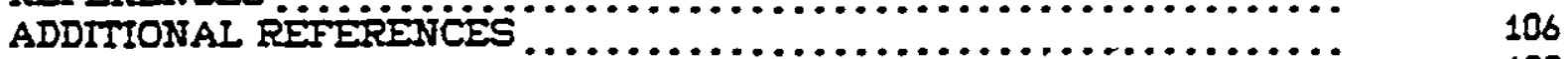

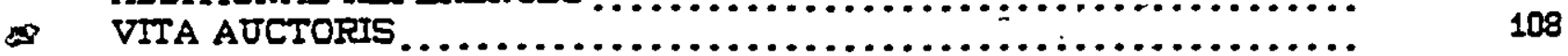

vii

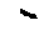




\section{IIST OF TABLES}

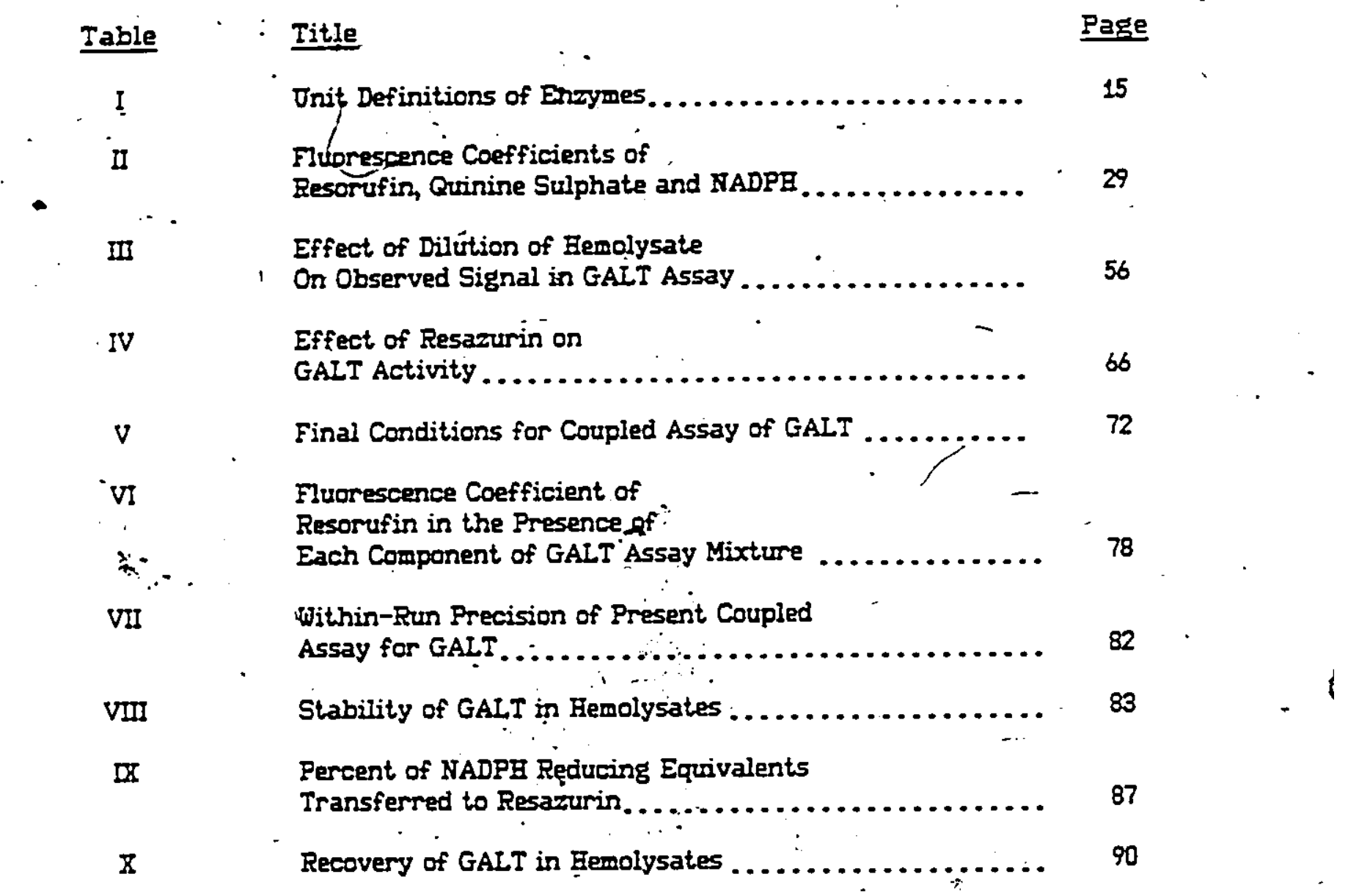




\section{LIST, OF FIGURES}

Figure

$1 \rightarrow$

2

3

4

7

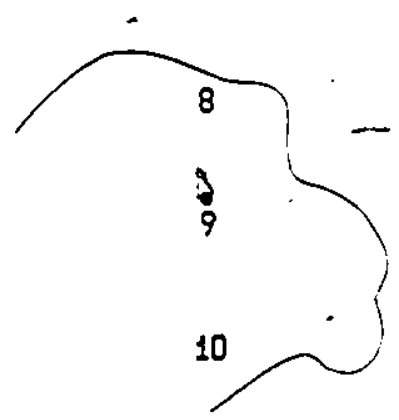

11

12 .

13

14

15

16

17
Title

Page

Pathway of Galactose Metabolism............... 3

Diaphorase-Mediated Reduction

of Resazurin .......................... 12

Fluorescence Spectra of Resorufin $\ldots \ldots \ldots \ldots \ldots \ldots \ldots .28$

Effect of Resazucimon Rate of .

Reduction (0) served $\Delta$ Fluorescence

Signals) Using Diaphorase and NADPH

33

Quenching of Fluorescence of

Resorufin by Resazurin ..................... 35

Lineweaver-Burk Plot of Diaphorase
Activity with Respect to Resazurin ...

37

Hanes-Woolf Plot of Diaphorase

Activity with Respect to NADPH

Comparison of Resazurin and DCPIP

As Stbsțrates for Diaphorase................. 42

Calibration Curve of $\Delta$ Fluorescence/min Versus

Glucose 6-Phosphate Dehydrogenase Activity ..........

Absorption Spectra of

Resorufin and Resazurin .................... 47

Stability of Resazurin Solution. .............. 49

Absorption Spectrum of Hemolysate ............. 52

Fuorescence Spectra of Resorufin in the

Presence of Eemolysate and Resazurin............ 55

pH Study of GALT Activity ................. 59

Effect of $\mathrm{MgCl}_{2}$ on GALT Activity ............... 62

Effect of Diaphorase on GALT Activity ........... 65

Eanes-Woolf Plot of GALT Activity

vith Respect to Galactose 1-Phosphate

68 
Hanes-Woolf Plot of GAIT

Activity with Respect to ODPG................. 71

19

Effect of Adding Resorufin to

Assay Mixture on GALI Activity................ 75

20

Effect of Adding Resorufin to

Assay Mixture on Diaphorase Activity............ $\pi$

21

Linearity of GALT Coupled Assay

81

22

Comparison of Present Coupled

Assay with UDPG-Consumption Method............ 86

23

Time Course of Coupled Assay of GAIT............ 93

24

Distribution of GALT Activity in Patients. .

95 


\section{LIST OF APPENDICES}

Appendix

A

B
Title

Correcting Observed Fluorescence intensities on Perkin-Elmer

Fluorescence Spectrophotometer ................

Calculation of GALI Activity

Using An Internal Standard
Page

99

100

$\varepsilon$

on

6

、

$c$

$x i$ 


\section{LIST OF ABBREVIATIONS}

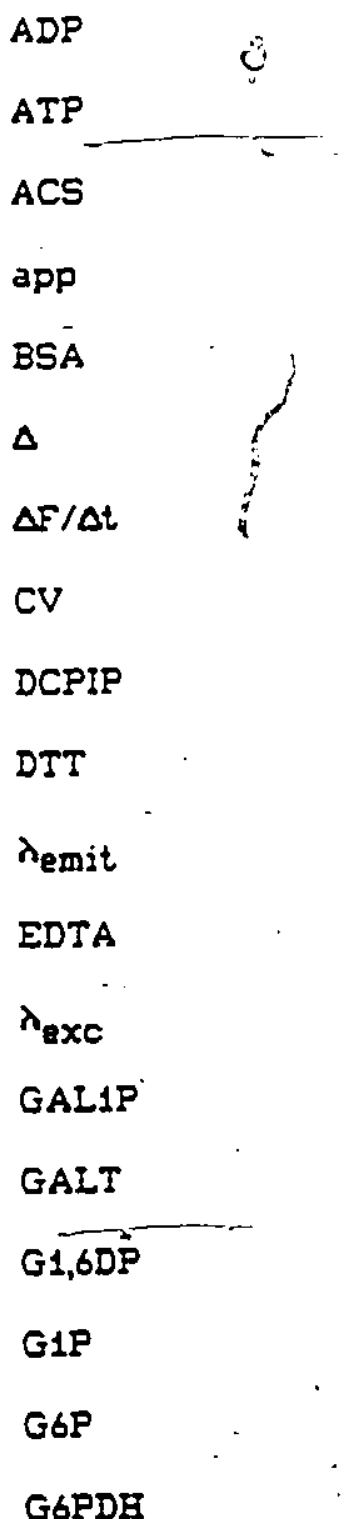

G6PDE

$\mathrm{Hb}$

$K_{m}$ adenosine 5'-diphosphate

adenosine 5'-triphosphate

American Chemical Society

apparent

bovine serum albumin

change in

change in fluorescence/change in time

coefficient of variation

2,6-dichlorophenol-indophenol

dithiothreitol

emission wavelength

,

ethylenediaminetetraacetic acid

excitation wavelength

galactose 1-phosphate

galactose 1-phosphate uridylyltransferase

glucose 1,6-diphosph hate

glucose 1-phosphate

glucose 6-phosphate

Glucose 6-phosphate dehydrogenase

hemoglobin

Michaelis constant 


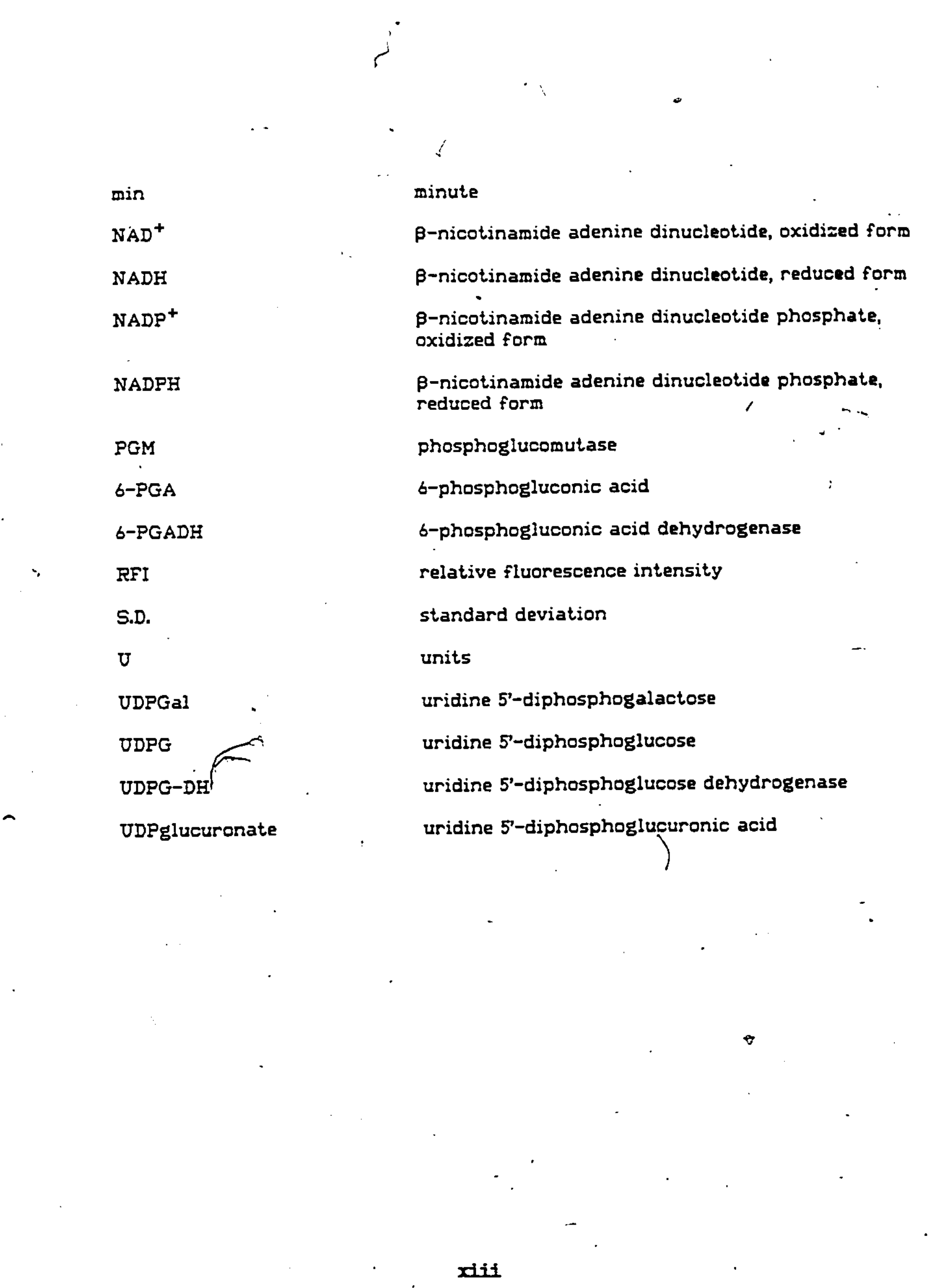


CHAPTER 1

\section{INTRODUCTION}

\subsection{Galactose 1-Phosphate Uridylyltransferase}

\subsubsection{Role in Galactose Metabolism}

Galactose is primarily obtained by the hydrolysis of lactose (the sugar of milk) in the intestine and converted to glucose in the liver (1). The pathway by which this is done involves three steps and is shown in Figure 1.

In the first reaction, galactokinase transfers a phosphate from ATP to galactose to produce galactose 1-phosphate. GAIT hydrolyzes UDPG, liberating glucose 1-phosphate, and transfers the uridylyl moiety to galactose 1-phosphate, forming UDPGal. It is in this nucleotide-containing form that galactose is converted to glucose, using UDPGal 4-epimerase. The glucose is eventually released in the form of glucose 1-phosphate, after incorporation into glycogen and phosphorolysis.

It should be noted that the third reaction is freely reversible, allowing the conversion of glucose into galactose (1). For this reason, galactose is not essential in the diet.

\section{1 .2 Galactosemia}

\subsubsection{Prevalence}

Galactosemia is the general term which refers to the inability to metabolize galactose, and casesthave been reported involving deficiencies of each of the three enzymes discussed (2-4). 


\section{FIGURE 1}

\section{PATEUAY OF GALACTOSE METABOISM}

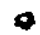

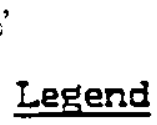

The key steps in converting galactose into glucose are those marked (9), (3), and(3), involving the enzymes galactokinase, GAIT, and UDPGal 4-epimerase. Deficiency of any of these three enzymes leads to the condition known as galactosemia, or the inability to metabolize galactose.

(Borrowed, without permission, frow Earper's Review of Biochemistry, 19th ' edition (1883) Martin, D.w. Jr., Mayes, P.A. and Rodwell, V.w. (editors). Lange Medical Publications, Los Altos.) 
FIGURE 1

,

2

galactose

ATP TAPACTOKINABE (1)

GALACTOSE (2) GLUCOSE

GLUCOSE it 2 UDP

$\therefore$ (3) GLUCOSE

$-0$

Dimonosioink

arospinoonactoss

To

$\int$

UDP-

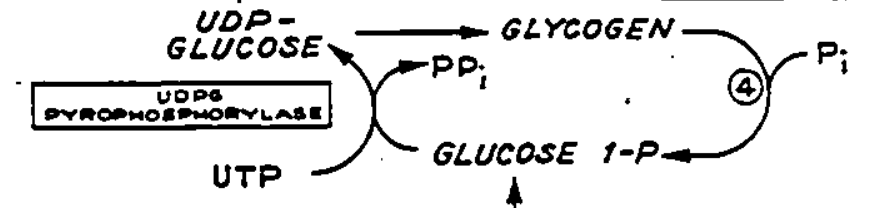

UTP

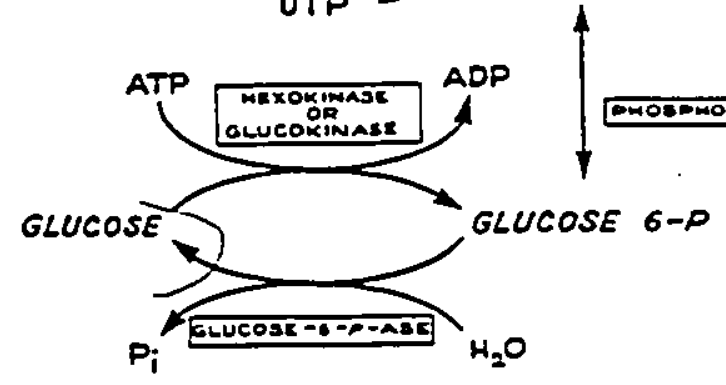

PMOSMMORYLAER 
The transferase (GALT)-deficient or "classical" galactosemia is the most common of the three. The prevalence of the disease has varied from 1:18,000 to $1: 81,600$ depending on the population studied (5-6). A more comprehensive study (7) involving several counitries, indicates that the prevalence is about 1:75,000 overall.

\subsubsection{Clinical Symptoms and Biochemical Basis}

Symptoms of the disease appear within a few days of the birth of the child, usually a few days after its first feedings of milk (2-5). The child develops diarrhea, vomiting and dehydration and hyperbilirubinemia is seen for sevaral days. If not diagnosed early and treated properiy, the child develops cataracts, renal and hepatic dysfunction, and mental retardation. In severe cases, the outcome is fatal.

Due to the deficiency of GALT, there is an accumulation of galactose 1-phosphate in the lens, liver, kidney and brain. It is believed that this causes depletion of inorganic phosphate in these tissues, causing their dysfunction $(1,4)$. In addition, galactitol, the sugar alcohol of galactose, accumulates in the lens, drawing water into it, and causes the formation of cataracts.

\subsubsection{Laboratory Tests, Diagnosis and Treatment}

Galactosemia should be considered in cases where the neonate develops jaundice, diarrhea, vomiting and failure to thrive while receiving lactose in' the diet. A preliminary test on the urine will show high levels of galactose. However, it is not uncommon to find galactosuria in newborns with low weight, who have immature renal glucose-galactose transport systems (4).

Diagnosis of GALT-deficient galattosemia can, therefore, only be made definitively by assay of the enzyise itself. Although GALT is present in a variety 
of cells and tissues (8), for clinical purposes, it is measured most often in red blood cells. Several workers (9-11) have also assayed for the enzyme in cultured amniotic cells, for use in the prenatal diagnosis of galactosemia.

There is effective treatment, i.e., removal of galactose from the diet, for the disease. In GALT-deficient patients, the epimerase is present in sufficient amounts to provide the necessary quantity of galactose required by the body. Because of this fact, and because of the severity of the disease, it is important that a proper diagrosis be made early in the patient's life.

$-$

\subsubsection{Properties of the Erythrocyte Enzyme}

The enzyme is composed of two similar or identical subunits with combined molecular weight of 88,000 (11). Kinetic studies (12) have shown that the reaction catalyzed by GAII proceeds by a ping-pong mechanism, in which a covalent uridylyl-enzyme intermediate is formed.

GALT, in general, can be stabilized and activated by the thiol reagents: 2-mercaptoethanol, cysteine, and dithioerythritol/dithiothreitol (12). The effect is more pronounced in leukocytes than erythrocytes, which have relatively high concentrations of reduced glutathione to stabilize the enzyme (13).

The reported pF optimum of the enzyme rajges from $8.5(2,12)$ to $8.7(8,14,15)$. The pH most commonly used for the assay of GAIT is 8.7 at $25^{\circ} \mathrm{C}$.

Due to the low activity of GAII in erythrocytes, it is assayed at $37^{\circ} \mathrm{C}$.

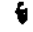

- Chloride ions have been shown to inhibit GAIT (14). Tris-acetate and glycine-NaOE solutions are generally accepted as the buffers of choice.

One study (16) has reported that GAIT is also inhibited by glisose 1-phosphate, glucose 6-phosphate, UDPG, ATP and ADP, but this has not been 
confirmed by other workers.

\section{1 .4 Genetic Variants}

GALI-deficient galactosemia is an autosomal recessive cisorder, in which the affected individual is completely devord of, or markediy deficient in, GALT activity. The basis of the abnormality is believed to be a structural gene mutation, resulting in the replacement of an amino acid at or near the catalytic site $(17,18)$.

I A variant of galactosemia has been described (19) in which GAIT was almost completely inhibited by glucose 1-phosphate at a concentration within the range of stationary G1P concentration if the liver. It is suggested that the product inhibition is responsible, in this case, for the impaired galactose metabolism in the patient.

Several other catalytically impaired variants, in which GAII activity is 30-65\% of normal, have also been described (5). Patients with the more severe of these variants present the clinical symptoms related to classical galactosemia.

On the other hand, the Los Angeles variant (20) is associated with greater than normal GAIT activity and is not linked to any clinical disorder.

\subsection{Methods of Analysis}

The reaction catalyzed by GALT is:

UDPG + Galactose 1-Phosphate (GAL1P) $\rightarrow$ UDPGal + Glucose 1-Phosphate (G1P)

The methods of analysis can be summarized as the UDPG-consumption methods, those based on the generation of GIP, and the radiochemical methods. 


\subsubsection{UDPG-Consumption Method}

The UDPG-consumption assay is the method selected by the American Association for Clinical Chemistry for the determination of GALI in erythrocytes (5), and the assay was first described by Anderson et al. (21).

UDPG and GAL1P are first allowed to incubate in presence of GAIT for a fixed period of time, after which the reaction is stopped. After centrifugation, the amount of UDPG remaining is determined using uridine 5'-diphosphoglucose dehydrogenase (UDPG-DE) in the following system:

$$
\mathrm{UDPG}+2 \mathrm{NAD}+\stackrel{\mathrm{UDPG}-\mathrm{DH}}{\longrightarrow} \text { UDPglucuronate }+2 \mathrm{NADE}+2 \mathrm{~F}^{+}
$$

The increase in absorbance at $340 \mathrm{~nm}$ is measured and is proportional to the amount of UDPG present. When subtracted from the amount of UDPG originally added (determined frow the blank), the UDPG consumed is determined and is porportional to the GAIT activity present.

The main problem associated with this method is the fact that the concentration of UDPG used-is a compromise $(5,14)$. Early versions of the-assay s.

$(21,22)$ used low concentrations of UDPG, and suffered from the fact that the relationship between GAIT activity and rate of UDPG-consumption departed from linearity. This is a result of the depletion of UDPG in the latter portion of the incubation period, leading to slower reaction rates. As a conseguence, the procedures could not differentiate between carriers and normals with any degree of certainty. (14).

- Later versions of the assay $(5,14)$ have increased the amount of UDPG used to improve linearity, but have the disadvantage of producing high absorbance values for tests and blanks. GAIT activity must be calculated from two large numbers, differing. only slightly from one another. This has led to 
a procedure which is less precise.

r

From a practical point of view, the reference UDPG-consumption method has several drawbacks in that it requires:

a. a 15-minute iscubation period;

b. that the reaction to be stopped by placing the assay mixture in a boiling water bath;

c. a 20-minute centrifugation step;

d. an end-point assay for ODPG which is lengthy (20 to 30 minutes).

It should also be noted that UDPGal 4-epimerase, if/ active, interferes with this test, by providing a means for ODPGal to be converted back to UDPG (23). Thus, it is necessary to inactivate the enzyme by heating the sample (hemolysate) to destroy NAD+, a co-factor for the enzyme.

\subsubsection{Methods Based on the Generation of Glucose 1-phosphate}

These methods monitor the amount of G1P formed using the ceipled assay below (Scheme 1):

G1P $\stackrel{P G M}{\longrightarrow}$ Glucose 6-Phosphate (G6P)

$\mathrm{G} 6 \mathrm{P}+\mathrm{NADP}+\stackrel{\mathrm{G} 6 \mathrm{PDE}}{\longrightarrow}$ 6-Phosphogluconate(6-PGA) + NADPE + $\mathrm{H}^{+}$

$6-P G A+N A D P^{+} \stackrel{6-P G A D E}{\longrightarrow}$ Ribulose 5-Phosphate $+\mathrm{CO}_{2}+\mathrm{NADPH}+\mathrm{H}^{+}$

A multitude of assays for GAIT have been developed, based on the above principle.

A manometric technique (24) incorporates methylene blue to transport electrons from NADPE to molecular oxygen, and GALT is measured as the rate of oxygen consumption. The method, however, is tedious and requires large amounts of blood. 
Fluorometric assays, based on the fluorescence of NADPH, have been used for qualitative (5) and quantitative (6) determination of GAIT. These require incubation periods of 1 to 2 hours.

Spectrophotometric assays, of note, are those of Pesce et al. (25) and Schutgens et al. (26), which both follow the increase in absorbance at $340 \mathrm{~nm}$. The first involves only one step, but requires a 20-minute incubation period to generate enough product to be measured and the increase in absorbance. must be followed for 9 minutes. In addition, it requires a spectrophotometer with extremely high sensitivity, since the observed absorbance changes range from 0.0005 to 0.006 per minute. The latter assay producks greater absorbance changes, but requires the same basic steps (incubation, stopping reaction, centrifugation, and end-point assay) associated with UDPG-consumption methods.

\subsubsection{Radiochemical Methods}

A number of radioisotopic methods have been developed, using either $\left[{ }^{14}\right.$ C]GAL1P $(23,27)$ or $\left[{ }^{32}\right.$ PJGAL1P $(28)$. The assays are sensitive, but require an addditional step to separate substrate from product before measurement. .

\subsection{Purpose of Project}

We set out to deyelop a sensitive fluorometric, continuous enzymatic coupled assay for GALT in which the electrons from NADPE, generated as in Scheme 1, are transferred to resazurin, forming a fluorescent product, resorufin.

The aim was to eliminate the drapbacks of other methods discussed" previously, namely:

1. large sample volumes; 


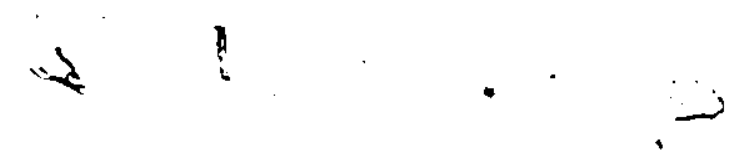

2. separation steps, associated with UDPG-consumption and radiochemical methods;

3. long incubation periods.

The first is an important consideration, since the patients affected by this disease are neonates, from whom very little blood may be drawn. The and third are important from a practical point of view, i.e., reduction of technologist time required to perform the assay.

\subsection{The Resazurin/Diaphorase System}

Electrons from NADPF (or NADF) are enzymatically trasnferred to nonfluorescent resazurin in the presence of diaphorase to produce resorufin, a highly fluorescent molecule (Figure 2).

The use of the resazurin/diaphorase system for the determination of dehydrogenase activity was first proposed by Guilbault and Kramer (29). They ... indicated that as low. as $10^{-4}$ units of enzyme activity could be determined, making this procedure several orders of magnitude more sensitive than spectrophotometric procedures (30). In addition, enzyme activity can be determined rapidiy and directly by this method, which is a distinct advantage over the procedure of Lowry et al. $(31,32)$. The latter assay, based on the fluorescence of $\mathrm{NAD}^{+}$, requires that the NAD ${ }^{+}$be heated with $6 N$ sodium hydroxide for 5 to 30 minutes, before a measurement can be made.

Due to its sensitivity and simplicity, the resazurin/diaphorase system has been exploited in a number of assays (31-37) which genérate NADE or NADPH. For these same reasons, we proposed to use it for the determination of GALT activity.

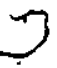


11

FIGURE 2

DIAPHORASE-MEDIATED REDUCTION OF RESAZURIN

Legend

Non-fluorescent resazurin is enzymatically reduced to the highly fluorescent resorufin, using diaphorase and NADH or NADPH.

6

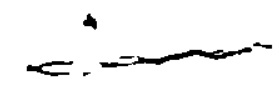

1

$\therefore$ 
FIGURE 2

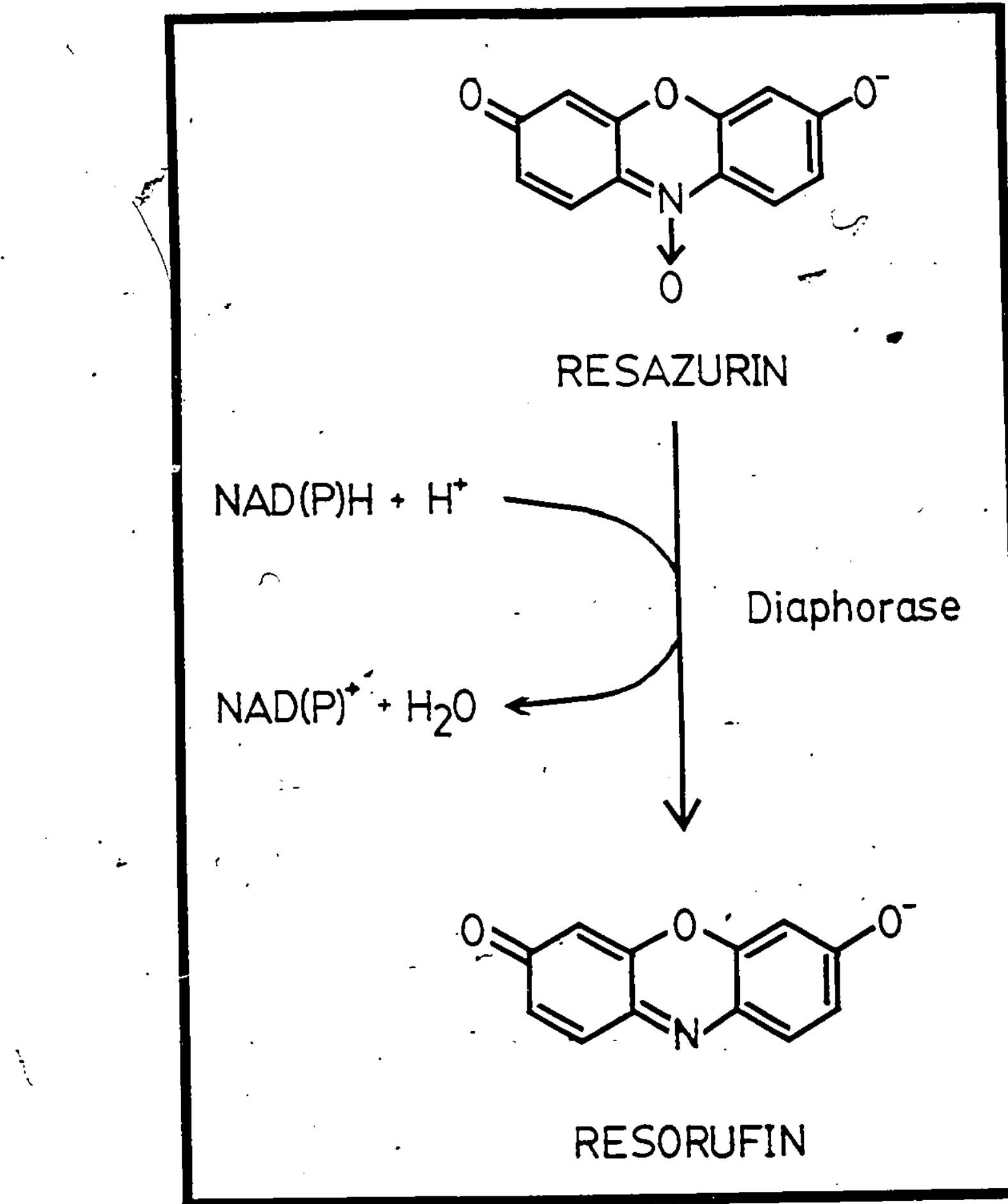




\section{CHAPTER 2}

\section{MATERTALS AND METHODS}

\section{Materials}

Bovine serum, albugin. (Eraction $V$ ), citric acid. (free acid), 2,6-dichlorophenol-indophenol, DL-dithiothreitol, flavin mononucleotide (sodium salt), glucose 1,6-diphosphate [tetra(cyclohexylammonium)salt], glucose 1-phosphate (disodium salt), glucose 6-phosphate (monosodium salt), glycine (free base), NAD' (free acid), NADH (disodium salt), NADP+ (sodium salt), NADPH (tetrasodium salt), 6-phosphoghwconic acid (tri(cyclohexplammonium)salt), Trizma base, Triton X-100 and UDPG (sodium salt) were purchased from Sigma Chemical Company (St. Louis, MO).

Galactose 1-phosphate (dipotassium salt) was generously donated by Biosynth Ag (Skokie, Ml), courtesy of Dr. C. Patel.

All of the following enzymes were purchased from Sigma Chemical Company: Diaphorase [NADE: lipoamide axidoreductase (EC 1.6.4.3) from Clastridium kiuryuerz.

Galactose 1-phosphate uridylyltransferase [UDPG: $\propto-D$-galactose 1-phosphate uridylyltrasferase (EC 27.7.12) from galactose adapted yeast]

Glucose 6-phosphate dehydrogenase [D-glucose 6-phosphate: NADP+ oxidoreductase (EC 1.1.149) from Bakers yeastl.

Phosphoglucomutase [ $\alpha-D$-glucose 1,6-diphosphate: $\alpha$ D-glücose 1-phosphate phosphotransferase (EC 2.7 .5 .1 ) from rabbit muscle]. 
6-Phosphogluconic dehydrogenase 66-phospho-D-gluconate: NADP ${ }^{+}$oxidoreductase (EC 1.1.1.44) from yeast].

UDPG dehydrogenase [UDPG: $\mathrm{NAD}^{+}$6-oxidoreductase (EC 1.1.1.22) from bovine liver].

Unless otherwise indicated, the unit definitions of the enzymes used throughout this thesis are those quoted in Table I. The enzymes were assayed using the manufactarer's bulletins (38-42) to ensure that the activities were those claimed.

GALT Deficient Control and Hemoglobin Standard were purchased from Sigma Chemical Company.

Resazurin (sodium salt) and resorufin were purchased from Aldrich Chemical Company, Inc. (Milwaukee, wI).

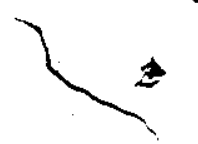

Acetic acid, ethoxyethanol, hydrochloric acia snd sulphuric acid were all ACS grade and purchased from 3DF Chemicals (Toronta, Ontario).

EDTA (disodium salt), magnesium chloride hexahydrate, potassium cyanide, potassium ferricyanide, potassium phosphate monobasic, quinine sulphate, spdium chloride and sodium hydroxide were purchased from Fisher Scientific Co. (Canada) and were of analytical grade.

Distilled de-ionized water was obtained by passing water from a distillation apparatus through a reverse osmosis Xenopure $\mathbb{B}_{\text {system. }}$

\subsection{Apparatus - -}

A fluorescence spectrophotometer (Model 204) equipped with a xanon power supply (Model 150) and a recorder (Model 56), all manufactured by Perkin Elmer . Corporation (Norwalk, Conn.), was used for all fluorometric studies. The cuvette holder was connected to a water bath (Haake Corp; Berlin, Germany) for 
TABLE I

\section{ONIT DEFINITIONS OF ENZYMES}

Enzyme $\quad$ Unit definition

Diaphorase

$+$

Galactose 1-phosphate uridylyltransferase

Glucose 6-phosphate dehydrogtnase

Phosphoglucomutase

6-Phosphogluconate dehydrogenase
- One DCPIP unit will oxidize 10 pmole of $\bar{\beta}-$ NNADE per minute at 7 $p$ H 7.5 at $25^{\circ} \mathrm{C}$, with the corresponding reduction of 2,6-dichlorophenal-indophenol. ।

One resazurin unit will convert 1.0 umole of resazurin to resorufin per minute in the presence of NADPE at $\mathrm{pE} 8.7$ at $25^{\circ} \mathrm{C}$. and $37^{\circ} \mathrm{C}$

One unit will oxidize 10 mole of glucose 6-phosphate to 6-phosphogluconate per minute in the presence of NADP' at pH 7.4 at $25^{\circ} \mathrm{C}$.

One unit will convert 1.0 prole of glucose 1-phosphate to glucose 6-phosphate per minute at $\mathrm{pH} 7.4$ at $30^{\circ} \mathrm{C}$.

One unit will oxidize 10 pmole of 6-phosphogluconate to D-sibulose 5-phosphate and $\mathrm{CO}_{2}$ per minute at $\mathrm{pH} 7.4$ and $37^{\circ} \mathrm{C}$. 
experiments performed at $37^{\circ} \mathrm{C}$. Unless otherwise indicated, 2 1.0-mL fluorometric quartz cuvette (1.00-cī pathlength), from Hellma (Canada) Limited (Concord, Ontario), was used. A small plastic platform was placed in the cuvette holder to elevate the cuvette.

Ultraviolet/visible readings and recordings, taken at room temperature, wëre obtained using a Shimadzu spectrophotometer (Model UV-240) and printer (Model PR-1) made by Tekscience kkville, Ontario). A Model 35 recording spectrophotometer, with temperature-controlled cuvette holder, (Beckman Instruments, Inc.; Palo Alto, California) was usged for experiments requiring temperatures higher than $25^{\circ} \mathrm{C}$.

Other equipment included: .

1. TJ-6 table-top centrifuge, with $T H-4$ rotor and $T J-R$ refrigeration unit (Beckman Instruments Inc.);

2. Thermolyne Dri-bath heater (Sybron, Boston, MA);

3. Mettler P1000 balance for masses greater than one gram and Type H16 is balance for less than one gram masses (Fischer Scientific Co; Toronto, Ontario);

4. Gilson Pip̧etman variable-volume pipetters (Mandel Scientific Co., Ltd.; Ville St. Pierse, Quebec) and Oxford fixed-volume pipettors and pipette tips (Canadian Laboratbry Supplies, Ltd.; Toronto, Ont.);

5. Fisher Accumet (3) pH meter (Fisher Scientific Co.; Toronto, Ont.);

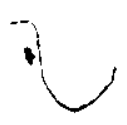

6. Borosilicate glass culture tubes KFisher Scientific Co.; Toronto, Ont.); 
23 Methods

\subsubsection{Study of Resazurin/Diaphorase System .}

\subsubsection{Reagents}

1. Glycine Buffer ( $100 \mathrm{mM})$, pE 8.7 at $25^{\circ} \mathrm{C}$ : Glycine (3.8 grams) was dissolved in about $450 \mathrm{~mL}$ of water and $\mathrm{pH}$ was adjusted to 8.7 at $25^{\circ} \mathrm{C}$ with $\mathrm{NaOH}$. The solution was diluted to $500 \mathrm{ml}$ with water and stored at $4^{\circ} \mathrm{C}$.

2. BSA Solution (1\% $w / v)$ : BSA (100 mg) was dissolved in $10.0 \mathrm{mI}$ of glycine buffer.

T

3. Diaphorase: Solutions were prepared fresh on day of use by dissolving material in 1\% 8SA.

4. Resorufin: Solutions were prepared fresh by dissolving appropriate amounts of material in water.

8

5. Resazurin: Solutions were prepared fresh by dissolving appropriate amounts of material in water.

6. NADPH: Solutions were prepared fresh by dissolving appropriate amounts of material in water. Exact concentrations were determined using a molar extinction coefficient of $6.3 \times 10^{3} \mathrm{~cm}^{-1} \times \mathrm{M}^{-1}$ at $340 \mathrm{~nm}$ (43).

7. Glucose 6-Phosphate Dehydrogenase: Solutions were prepared when required by dissolving material in $1 \%$ BSA solution.

8. NADP+ Solution $(0.03 \mathrm{M}): \mathrm{NADP}^{+}(8.3 \mathrm{mg})$ was dissolved in $500 \mu \mathrm{ll}$ water. Exact concentration was determined using a molar extinction coefficient of $17.4 \times 10^{3} \mathrm{~cm}^{-1} \times \mathrm{M}^{-1}$ at $340 \mathrm{sm}$ (44). 
(2)

9. Glucose 6-Phosphate Solution (0.034 M): G6P (6.0 mg) was dissolved in 500 $\mu L$ of water.

10. Quinine Sulphate Solution ( $1.0 \mathrm{\mu g} / \mathrm{mL})$ : Quinine sulphate $(0.100 \mathrm{~g})$ was dissolved in $1.0 \mathrm{I}$ of $0.1 \mathrm{~N} \mathrm{H}_{2} \mathrm{SO}_{4}$ solution. This solution (10 mI) was then diluted to $1.0 \mathrm{I}$ with $0.1 \mathrm{~N}$ acid solution (45).

\subsubsection{Procedures}

a. Generation of Fluorescence Spectra

The procedure followed was that outlined in the manual (46) which accompanies the fluorescence spectrophotometer. The emission spectra were generated first by exciting with light of all wavelengths. The wavelength giving the highest emission, was then used to generate the excitation spectra.

b. Fluorescence Coefficient of Compounds

Appropriate solutions of resorufin and NADPH, in glycine buffer, and quinine sulphate were made and their relative fluorescence intensity (RFI) were measured at the corresponding $\lambda_{\text {exc }}$ and $\lambda_{\text {emit }}$ for each compound. The settings on the fluorometer at which each measurement was made was also noted.

For the determination of the fluorescence coefficient of resarufin in the presence of resazurin, the following procedure was followed: Solutions of varying resazurin concentration were made by. serially diluting a stock $20 \mathrm{mM}$ solution with water. A resorufin solution was made to be $3.1 \mu \mathrm{M}$. Solutions were made up as described below and their iprI measured. 
3.0-mi cuvette

$\begin{array}{ccccc} & \text { Blank } & \text { Sample } & \text { Blank } & \text { Sample } \\ \text { Buffer } & 2.90 \mathrm{~mL} & 2.90 \mathrm{~mL} & 0.48 \mathrm{~mL} & 0.48 \mathrm{~mL} \\ \mathrm{~B}_{2} \mathrm{O} & 0.05 \mathrm{~mL} & - & 0.01 \mathrm{~mL} & - \\ \text { Resazurin } & 0.05 \mathrm{~mL} & 0.05 \mathrm{~mL} & 0.01 \mathrm{~mL} & 0.01 \mathrm{mI} \\ \vdots & - & 0.05 \mathrm{~mL} & - & 0.01 \mathrm{~mL}\end{array}$

A control was prepared, in each case, by replacing resazurin with water.

c. Determination of Diaphorase Activity

Diaphorase activity, using DCPIP as a substrate, was determined according to the manufacturer's bulletin (38)

Diaphorase activity, using resazurin as a substrate, was determined by monitoring the rate of increase in fluorescence $\left(\lambda_{\text {exc }}=568 \mathrm{~nm}, \lambda_{\text {emit }}=582\right.$ $\mathrm{nm}$ ) at $25 \mathrm{C}$. The general procedure was to add resazurin and diaphorase to - glycine buffer, and initiate the reaction with NADPH. The non-enzymatic reduction of resazurin by NADPE, in all cases was determined by replacing the diaphorase with an appropriate aliquot of $1 \%$ BSA.

The study of the effect of resazurin on diaphorase activity was carried out in a 3.0-mL cuvette. The assay mixture consisted of $2.88 \mathrm{~mL}$ of glycine buffer, $20 \mu \mathrm{L}$ diaphorase $(1.7 \mathrm{U} / \mathrm{mL}) 50 \mu \mathrm{L}$ of resazurin (ranging from $51 \mu \mathrm{M}$ up to 20 $\mathrm{mM}$, and $50 \mu \mathrm{L}$ of NADPE $(4.7 \mathrm{mM})$.

The study of the effect of NADPE on diaphorase activity was carried out in a 1.0-mi cuvette, using two different concentrations of resamurin. The assay mixture consisted of $470 \mu \mathrm{L}$ of glycine buffer, $10 \mu \mathrm{L}$ of diaphorase (0.9 $\mathrm{J} / \mathrm{mL}), 10 \mu \mathrm{L}$ of resazurin $(0.34 \mathrm{mM}$ or $1.7 \mathrm{mM}$ ) and $10 \mu \mathrm{L}$ of NADPE (ranging 
from $47 \mu \mathrm{M}$ up to $1.5 \mathrm{mM}$.

- The "linearity of diaphorase activity" study was carried out in a $1.0 \mathrm{~mL}$ cuvette. Seriel two-fold dilutions of a stock diaphorase solution (3.2 DCPIP U/ mI) were made with 1\% BSA, and assayed. The assay mixture consisted of 470 $\mu L$ of glycine buffer, $10 \mu \mathrm{L}$ of diaphorase, $10 \mu \mathrm{I}$ of resazurin $(1.7 \mathrm{mM})$ and 10 $\mu$ II Of NADPH (1.1 mM).

d. Determination of Glucose 6-phosphate Dehydrogenase Activity

G6PDE activity at $25^{\circ} \mathrm{C}$ was first determined spectrophotometrically by monitoring the rate of increase in absorbance at $340 \mathrm{~nm}$, due to the reduction of NADP' to NADPE. The reaction was initiated by adding $20 \mu L$ of G6PDE to a solution containing $940 \mu \mathrm{L}$ of glycine buffer, $20 \mu \mathrm{L}$ of $\mathrm{NADP}^{+}(0.03 \mathrm{M})$ and $20 \mu \mathrm{L}$. of glucose 6-phosphate $(0.034 \mathrm{M})$.

Serial two-fold dilutions of the G6PDH solution were made and then assayed, using the resazurin/diaphorase system, by monitoring the rate of increase of fluorescence $\left(\lambda_{\text {exc }}=568 \mathrm{~nm}, \lambda_{\text {emit }}=582 \mathrm{~nm}\right)$ at $25^{\circ} \mathrm{C}$. The reaction was initiated by adding $10 \mu \mathrm{L}$ of G6PDH to a solution containing $450 \mu \mathrm{L}$ of glycine buffer, $10 \mu \mathrm{L}$ of NADP ${ }^{+}(0.03 \mathrm{M}), 10 \mu$. of G6P (0.034 M), $10 \mu \mathrm{L}$ of resazurin and 10 $\mu$ diaphorase. G6PDH was assayed in this way under two different conditions, ' - in which the working solutions of resazurin and diaphorase were: i) $1.7 \mathrm{mM}$ and $16.5 \mathrm{DCPIP} \mathrm{J} / \mathrm{mL}$, respectively; ij) $0.34 \mathrm{mM}$ and $0.67 \mathrm{DCPIP} \mathrm{V} / \mathrm{mL}$, respectively.

\section{e. Stability of Resazurin}

A solution of resazurin $(0.85 \mathrm{mM})$ was made by dissolving $11.0 \mathrm{mg}$ in 50.0 mL of water and kept at room temperature in an amber glass bottle. The absorbance of a dilute solution (50 $\mu$. of stock solution added to $5.0 \mathrm{~mL}$ of water) was read (in duplicate) at $600 \mathrm{~nm}$ on 11 occasions over a period of 40 
days.

\section{3 .2 Measurement of GAIT in Hemolysates}

\subsubsection{Reagents}

1. NaCl Solution $(0.9 \% \mathrm{w} / \mathrm{v})$ : $\mathrm{NaCl}(9.0 \mathrm{mg})$ was dissolved in $1.0 \mathrm{~L}$ of water. The solution was stored at $4^{\circ} \mathrm{C}$.

1 2. Modified Drabkin's Reagent: Potassium ferricyanide (200 mg), potassium cyanide (500 mg), potassium phosphate monobasic (140 mg), and Triton X$100(1.0 \mathrm{~mL}) \cdot$ were dissolved in water and diluted to $1.0 \mathrm{~L}$. The solution was kept in an amber glass bottle-in the dark at room temperature and was stable for several months.

3. Hemoglobin Standard: Lyophilized powder was reconstituted with $50.0 \mathrm{~mL}$ of Drabkin's reagent. Concentration of hemoglobin in this solution was

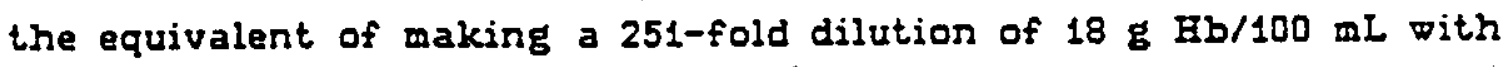
Drabkin's reagent.

4. Glycine Buffer $(100 \mathrm{mM})$ with EDTA (0.5 mM), vpH 8.7 at $25^{\circ} \mathrm{C}$ : Giycine $(3.75$ g) and EDTA $(92.5 \mathrm{mg})$ vere dissolved in about $450 \mathrm{~mL}$ of water and the pF was adjusted to 8.7 with $\mathrm{NaOH}$. The solution was diluted to $0.50 \mathrm{I}$ and kept at $4^{\circ} \mathrm{C}$.

5. BSA Solution (1\% $y / v)$ ) BSA (50 mg) was dissolved in $5.0 \mathrm{~mL}$ of buffer.

6. Phosphogluasmutase (15 $\mathrm{J} / \mathrm{mL}$ ): On day of assay, a PGM-solution (15 U/ mL) was made by an appropriate dilution of stock PGM with 1\% BSA.

7. Glucose 6-Phosphate Dehydrogenase (200 $\mathrm{J} / \mathrm{mL})$ L Lyophilized powder was reconstituted with sufficient $0.005 \mathrm{M}$ citrate buffer, pE 7.5 to make a 200 U/mL solution. Aliquọts were kept at $-20^{\circ} \mathrm{C}$. 
8. Diaphorase $(8.9 \mathrm{~J} / \mathrm{mL})$ : Solution was prepared fresh on day of assay by dissolving appropriate amounts of material in $450 \mu$ of $1 \%$ BSA.

9. ODPG Solution (27.5 mM): ODPG (27 mg) was dissolved in $1.0 \mathrm{~mL}$ of water. The absorbance of a $1000 x$ dilution, in water, was read at $260 \mathrm{~nm}$. Based on the extinction coefficient of $9.9 \times 10^{3} \mathrm{~cm}^{-1} \times \mathrm{M}^{-1}$ (47), the exact concentration of the solution was calculated and adjusted, if necessary, by dilution with water. Aliquots were stored at $-20^{\circ} \mathrm{C}$.

10. Galactose 1-Phosphate Solution ( $0.17 \mathrm{M})$ : GAI1P (73 mg) was dissolved in $1.0 \mathrm{~mL}$ of water. Aliquots were stored at $-20^{\circ} \mathrm{C}$.

11. NADP+ Solution $(35.2 \mathrm{mM}): \mathrm{NADP}^{+}(28 \mathrm{mg})$ was dissolveqin $1.0 \% \mathrm{~mL}$ of water. Aliquots were stored at $-20^{\circ} \mathrm{C}$.

12. Glucose 1,6-Diphosphate Solution (1.0 mM): G1,6DP (1.5 mg) was dissolved in $2.0 \mathrm{~mL} \mathrm{~B}_{2} \mathrm{O}$. Aliquots were stored at $-20^{\circ} \mathrm{C}$.

13. Resazurin Solution $(0.85 \mathrm{mM})$ : Resazurin (10.9 mg) was dissolved in $50.0 \mathrm{ml}$ water. The solution was kept at room temperature in an amber glass bottle and was stable for about one month.

14. Resorufin Solution (0.21 'mM): On day of assay, about $5.0 \mathrm{mg}$ (exact mass was noted) of resorufin vere dissolved in $100 \mathrm{~mL}$ water.

15. GAIT: Solutions were prepared fresh as needed by dissolving appropriate amounts of material in $1 \%$ BSA.

16. GAIT Deficient Control: Lyophilized powder was reconstituted, as needed, with $500 \mu$ I of water. 


\subsubsection{Procedures}

a. Preparation of Bemolysates

1. On the day of collection, venous blood samples in EDTA Vacutainers? were transferred to $13 \times 75 \mathrm{~mm}$ plastic tubes and washed as described $+$ by Ibbatt (5).

2. Hemolysates of the packed erythrocyte were made by adding an equal volume of cold water and freeze/thawing in a solid $\mathrm{CO}_{2}^{5}$ /acetone bath. The freeze/thaw procedure was repeated three times as recommended by Schutgens et al. (26).

3. For those samples to be used in the comparison of methods study, the hemolysates were incubated at $37^{\circ} \mathrm{C}$ for ten minutes (5).

4. Hemoglobin concentrations in hemolysates were determined by method described below.

5. Hemolysates were stored at $4^{\circ} \mathrm{C}$ until assayed.

b. Determination of Eemgglobin Concentration

Hemcglobin, concentration was determined with the use of the Eemoglobin Standard by the cyanmethemoglobin method recommended by the International Committee for Standardization in Hematology $(48,49)$.

\footnotetext{
$\mathcal{H}$

c. Coupled Assay of GAIT
}

1. $410 \mu \mathrm{L}$ of buffer solution were pipetted into $10 \times 75 \mathrm{~mm}$ glass tubes ( 6 for each sample to be analyzed). Test tubes were covered with parafilm and placed in a $37^{\circ} \mathrm{C}$ dry-bath heater. 
2. PGM (15 $\mathrm{U} / \mathrm{mL})$, diaphorase $(8.9 \mathrm{U} / \mathrm{mL})$ and resorufin $(0.21 \mathrm{mM})$ were prepared.

3. "Enzyme" solution was prepared by adding $25 \mu \mathrm{L}$ of PGM and 25 $\mu L$ of G6PDE (200 $\mathrm{O} / \mathrm{mL})$ to the diaphorase solution.

4. "Substrate" solution was prepared by mixing $75 \mu L$ each of GAL1P $(0.17 \mathrm{M}), \mathrm{NADP}^{+}(35.2 \mathrm{mM})$ and $G 1,6 D P(1.0 \mathrm{mM})$.

5. To the buffer $\left(\right.$ at' $37^{\circ} \mathrm{C}$ ) were added $10 \mu$ f of hemolysate, $20 \mu$ of resazurin (0.85 mM), $20 \mu$ of UDPG (27.5 mM), $20 \mu L$ of "enzymes" and $20 \mathrm{\mu L}$ of "substrates". The solution was transferred to a 1.0-mL cuvette and allowed to incubate at $37^{\circ} \mathrm{C}$ for three minutes, after which the increase in fluorescence $\left(\lambda_{\text {exc }}=520 \mathrm{~nm}, \lambda_{\text {emit }}=585 \mathrm{~nm}\right)$ was recorded for three minutes.

6. Step 5 was repeated for the blank with the exception that $20 \mu$, of water were used instead of UDPG.

7. An intersal standard was set up for each run in the following manner: To $410 \mu$ ll of buffer solution were added $10 \mu$ I of hepolysate, $20 \mu \mathrm{l}$ resazurin and $50 \mu \mathrm{L}$ of water. The solution was transferred to a 1.0-mi cuvette and allowed to incubate at $37^{\circ} \mathrm{C}$ for three minutes. Its RFI was adjusted to read "zero" at the same settings used for steps 5 and $6.10 \mu \mathrm{L}$ of resorufin $(0.21 \mathrm{mM})$ were added; the solution was mixed (by inversion, using parafilm) and its RFI was cecorded.

8. Steps 5, 6 and 7 were performed twice for each sample assayed. 
For the comparison of methods study, hemolysates were also analyzed using the reference UDPG-consumption method of Ibbott (5). For this study, some samples were prepared as described in "Preparation of Sample" (Section 2.3.2.2 a., p. 23), while others were produced by mixing normal samples with GALI Deficient Contral in various ratios.
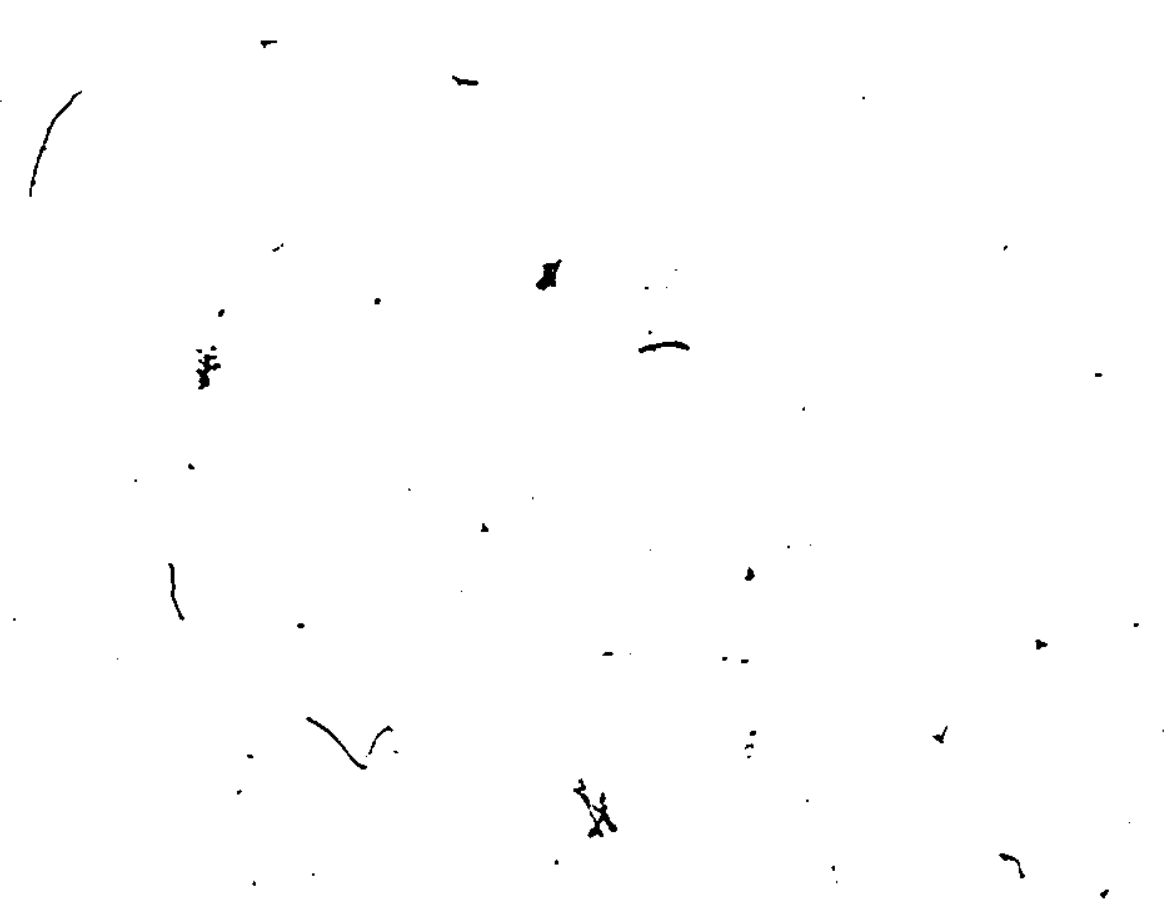


\section{CHAPTER 3}

\section{RESULTS AND DISCUSSION}

\subsection{Introduction}

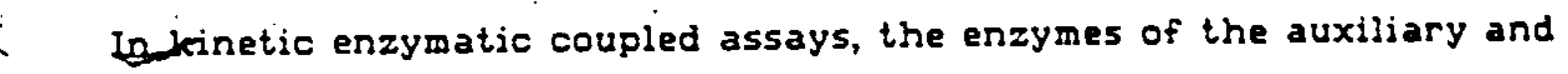
indicator reactions must be present in sufficient amounts in order to not be rate-limiting (50-52). Our preliminary investigation into the resazurin/diaphorase system suggested that the amount of diaphorase used by Guilbault and Kramer $(29,31)$ would always be rate-limiting in their kinetic assay for the determination of dehydrogenases. These initial observations led us to investigate the resazurin/ diaphorase system more thoroughly.

\subsection{The Resazurin/Diaphorase System}

\subsubsection{Fluorescence of Resorufin}

The excitation and emission wavelengths for resorufin were found to vary between 565-570 $\Omega \mathrm{m}$ and 580-585 nm, respectively (Figure 3).

Relative fluorescence intensity (RFi) was proportional to resorufin concentration up to about $5 \times 10^{-6} \mathrm{M}$ (Table II) with an average "fluorescence coefficient" of $8.4 \times 10^{6}$. Fluorescent coefficients were calculated by dividing the corrected RFI and dividing by, the molar concentrations. Resorufin has a native fluorescence on the same order as quirine sulphate and an order of 100 times that of NADPF. It is obvious then that assays based on the fluorescence of resorufin are much more sensitive than those based on NADPH fluorescence. 
FTGURE 3

\section{FLUORESCENCE SPECTRA OF RESORUFIN}

\section{Legend}

Shown are the excitation and emission spectra of resorufin at pH 8.7 at $25^{\circ} \mathrm{C}$. The emission spectrum was generated first by using exciting light 568 - nig. The excitation spectrum was then generated by monitoring the fluorescence At 582 nm (wavelength of peak fluorescence). 
FIGURE 3

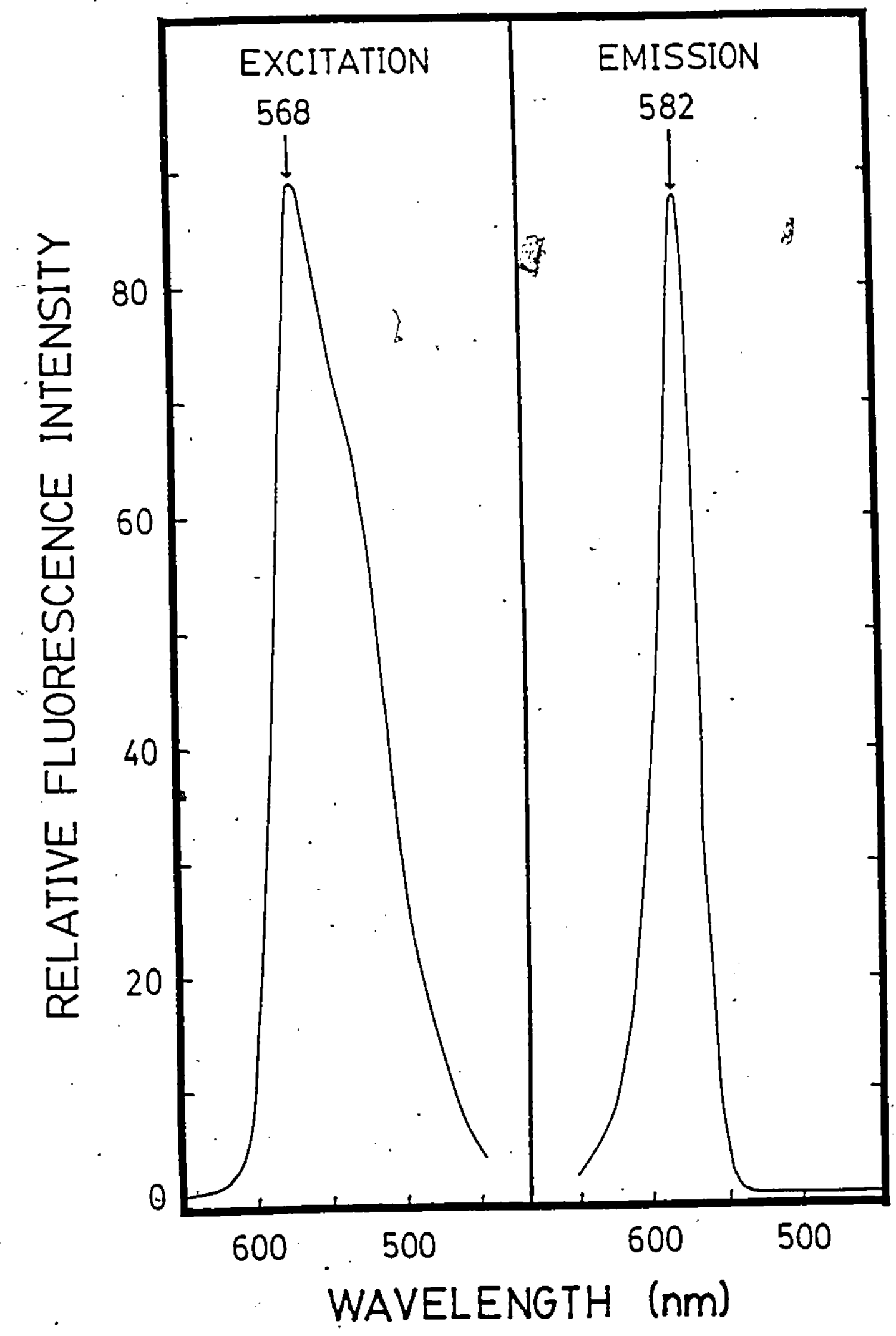


TABLE II

FLUORESCENCE COEFFICIENTS OF RESORUFIT, QUINIE SULPEATE AND IADPR

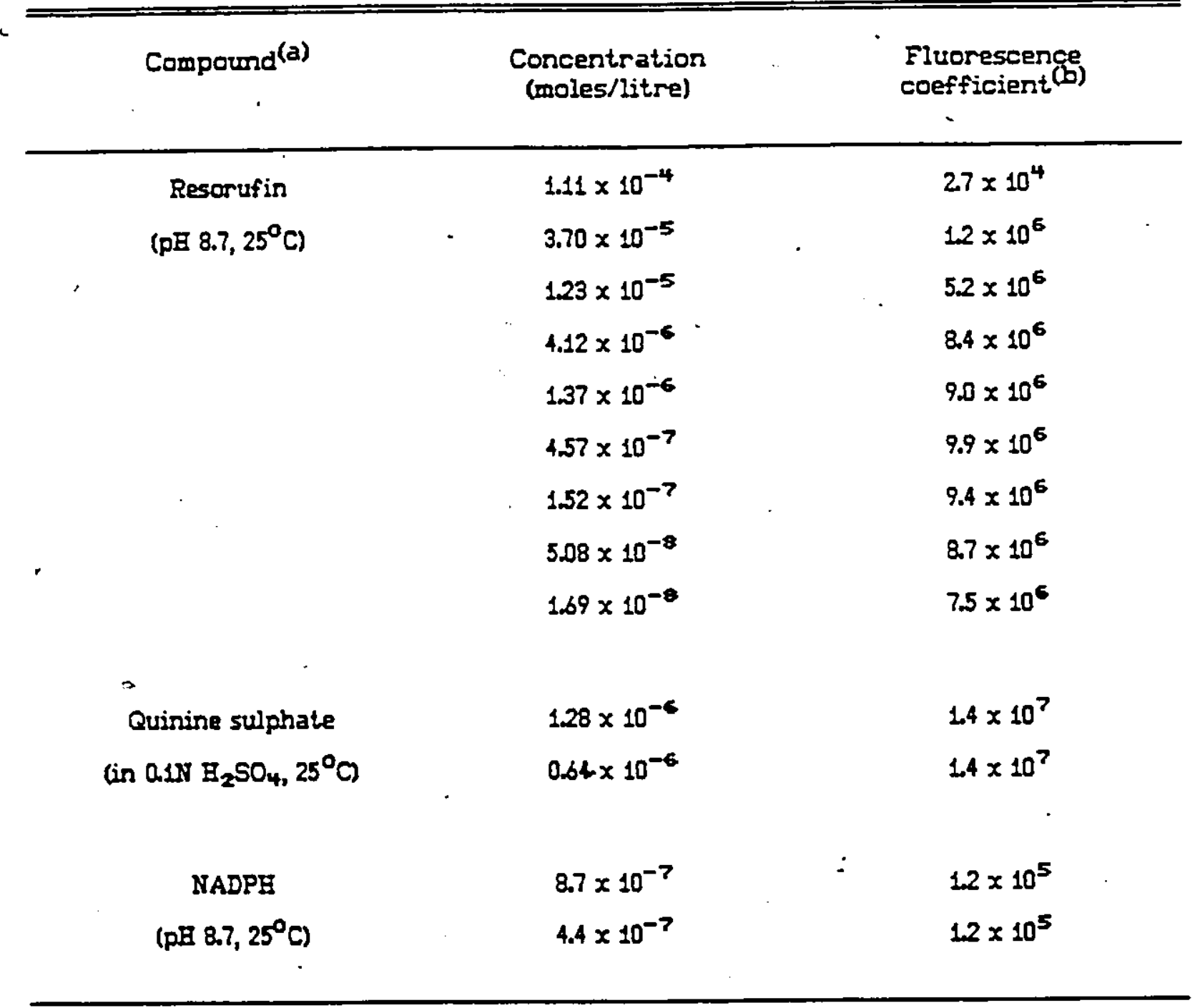

(a) $\lambda_{\text {exc }}$ and $\lambda_{\text {emit }}$ were respectively: $568 \mathrm{~nm}, 582 \mathrm{~nm}$ (resorufin); $350 \mathrm{~nm}, 450$ nm (quinine sulphate); $365 \mathrm{~nm}, 450 \mathrm{~mm}$ (NADPE2.

(b) These were determined by correcting the observed fluorescence intensities to a common setting of 1 (sensitivity control), $x 1$ (selector control) [see $A P P E N D D X I$ and dividing by the molar concentration. 


\subsubsection{Preliminary Studies}

Our preliminary studies indicated that the specific activity of diaphorase, using resazurin ( $6.7 \mu \mathrm{M})$ as a substrate, was oniy about $2 \times 10^{-3}$ that using 、 2,6-dichlorophenol-indophenol (DCPIP) as a substrate. This sharply differs from the findings of Guilbault et al. (53), who found the "resazurin specific activity" to be about $5, \times 10^{-2}$ that of the "DCPIP specific activity".(a) Although they used NADH as the redcing agent for resazurin, hile we used NADPH, we have found that the rates of reactions are only slightly slower when using NADPH, and this would not account for the huge discrepancy between our findings. One important point which they neglected to mention is that the non-enzymatic rate of reduction of resazurin by NADH or NADPH is significant when these are present in concentrations greater than $1 \times 10^{-5} \mathrm{M}$ (Guilbault et al. (53) used $\left.2 \times 10^{-4} \mathrm{M} \mathrm{NADH}\right)$.

In their assay for dehydrogenase, Guilbault et al. (29) claim that the rate of reaction is dependent only upon the dehydrogenase concentration, between $4.7 \times 10^{-4}$ and 0.4 units/mL. In the assay, diaphorase is present in 0.08 "old" DCPIP units/mL, which according to our results, is only about $3 \times 10^{-5}$ resazurin units/mL. It seems, therefore, that diaphorase should always be rate-limiting in their assay. This was supported by the finding that in other assays $(32,33)$,

(a) The "new" DCPIP unit of diaphorase activity is givan in Table I. It should be noted that in the papers of Guilbault et al. $(29,31,53)$, the old definition of a DCPIP unit was used, in which "one unit equals a decrease in absorbance of $1.00 / \mathrm{min}$, using the dye DCPIP and the coenzyme NADH, at $25^{\circ} \mathrm{C}$. Six "old" DCPIP units are equal to one "new" DCPIP unit. 
$\Delta$

calibration curves were generated in which rates of reaction were proportional to the logarithm of analyte concentration, not the analyte concentration itself.

It seemed obvious that procedure of Guilbault and Bramer $(29,31)$ could be improved by ensuring that the indicator reaction (resazurin/diaphorase) is not rate-limiting.

\subsubsection{Reaction Xinetics of Diaphorase/Resazurin System}

Guilbault et al. (53) show a Iineweaver-Burk plot which passes through the origin. Concentrations of resazurin up to about $5.0 \times 10^{-6} \mathrm{M}$ were used, indicating that the $\mathrm{K}_{\mathrm{m}}$ of this substrate must be much higher than $5.0 \times 10^{-6} \mathrm{M}$. Considering this fact, it was not cleas why Guilbault et al. chose to use a resazurin concentration of $6.6 \times 10^{-6} \mathrm{M}^{\prime}$ in their assays for the determination of dehydrogenase activity.

The effect of resazurin concentration on diaphorase activity was, therefore, studied and the results are shown in Figure 4. Maximum.signal (AF) At) was obtained at concentration of resazurin between $6.7 \times 10^{-6}$ and $13.4 \times$ $10^{-6} \mathrm{M}$ and a decrease in signal was seen at concentrations above that.

It had been noted in our studies, however, that resazurin had an absorption maximum $(600 \mathrm{~nm})$ near the excitation and emission wavelengths of resorufin and quenched the fluorescence signal of resorufin. The quenching effect of resazurin on the flurescence of resorufin is shown in Figure 5.

$$
\sim
$$

Diaphorase activities were calculated by dividing the $\Delta F / \Delta t$ (from Figure 4) by the corresponding fluorescence coefficient of resorufin in the presence of different amounts of resazurin. Tho data is shown in Figure 6 as a Lineweaver Burk plot, and indicates that diaphorase activity is first order with respect to resazurin concentration up to $34 \mu \mathrm{M}$. 
32

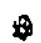

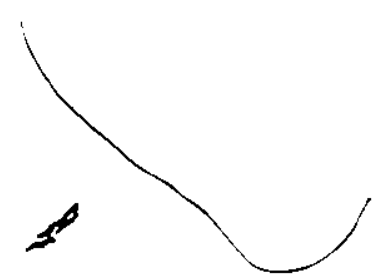

FIGURE 4

EFFECT OF RESAZURIN ON RATE OF REDUCTION COESERVED $\triangle$ FLUORESCENCE SIGNALS) USING DIAPFORASE AND NADPF

\section{Legend}

The reduction of resazurin by NADPH was followed by monitoring the change in fluorescence $\left(\lambda_{\text {exc }}=568 \mathrm{~nm}, \lambda_{\text {emit }}=582 \mathrm{~nm}\right)$. Reactions were carried out in a $3.0-\mathrm{mI}$ cuvette at $\mathrm{pH} 8.7$ and $25^{\circ} \mathrm{C}$, using $0.011 \mathrm{DCPIP} \mathrm{U} / \mathrm{mI}$ diaphorase and $7.8 \times 10^{-5} \mathrm{M}$ NADPF. Nen-enzymatic rate of reduction of resazurin by NADPH was followed using 1\% BSA instead of diaphorase and was substracted from the total rate (enzymatic + non-enzymatic). 
FIGURE *

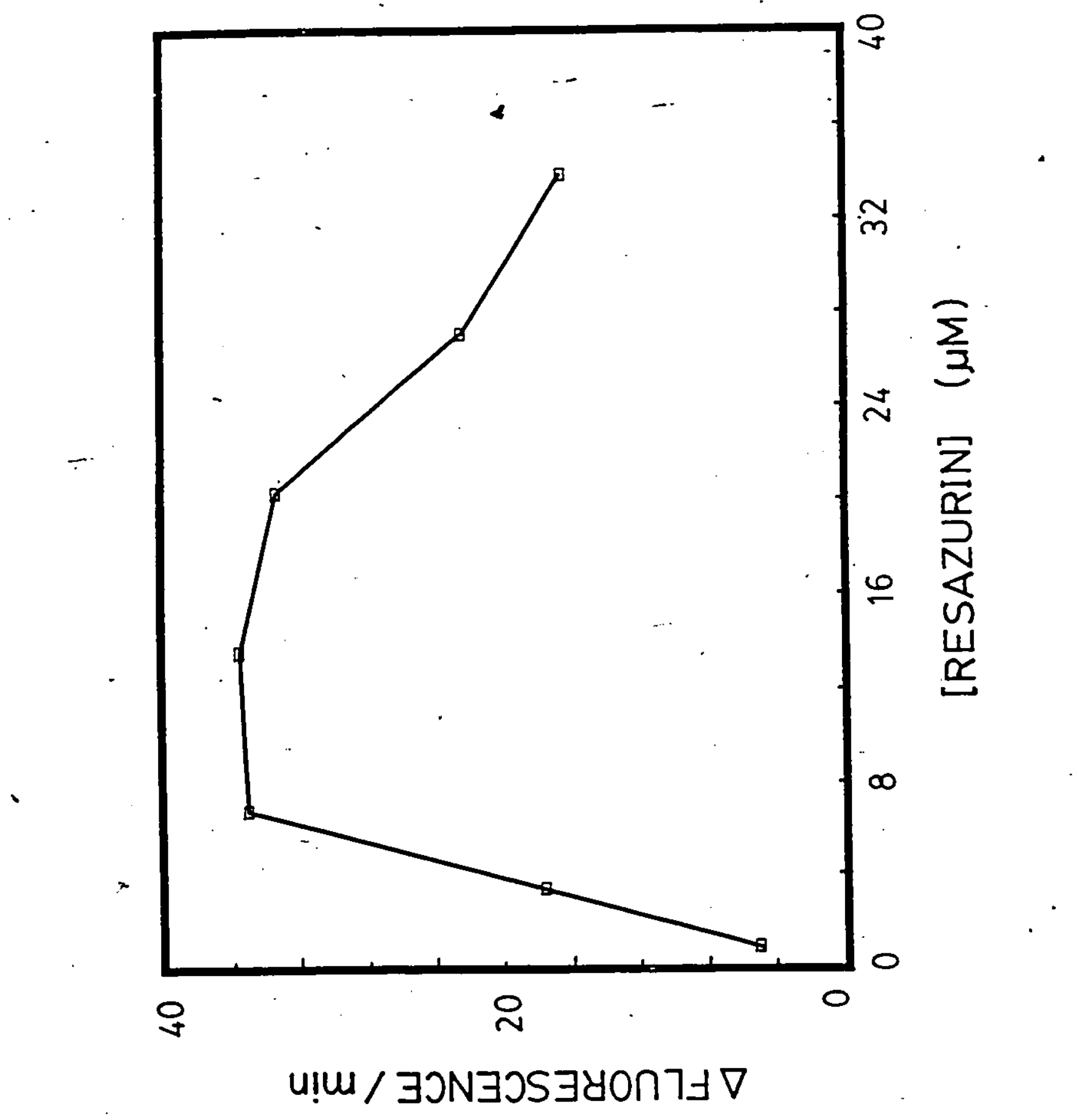


34

FIGURE 5

QUENCHING OF FLUORESCENCE OF RESORUFIN BY RESAZURIN

Legend.

The relative fluorescence intensity of resorufin $\left(3.1 \times 10^{-6} \mathrm{M}\right)$ was measured in duplicate in the presence of various amounts of recazurin, and compared to that in the absence of resazurin. Blank values (RFI of resazurin in absence of resorufin) were subtracted. Measurements were made in a $3.0-\mathrm{ml}(a)$ and $1.0 \mathrm{~mL}(\Delta)$ cuvette, at $25^{\circ} \mathrm{C}, \mathrm{pH} 8.7$. 
FIGURE 5

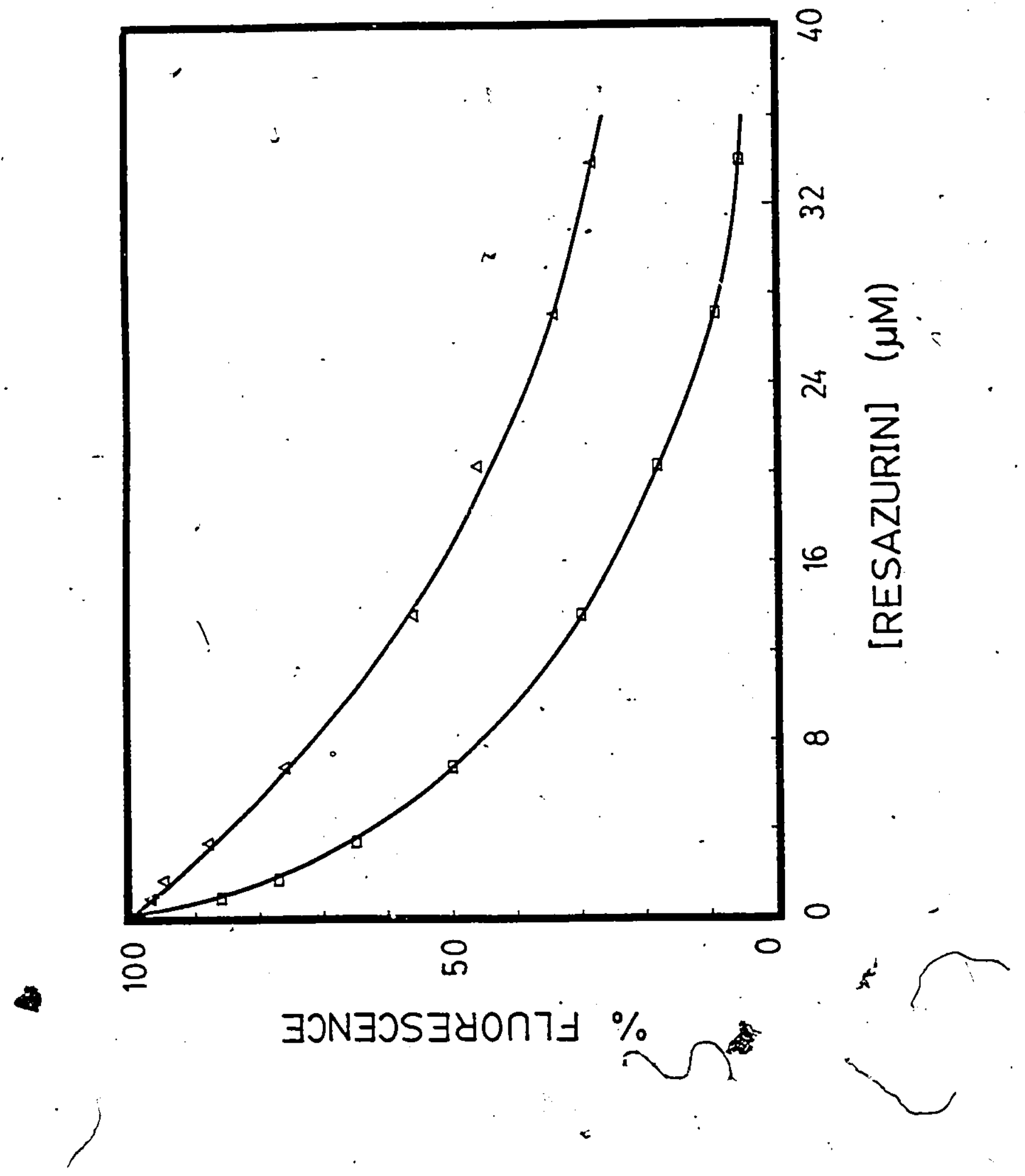




\section{FIGURE 6}

IINEUEAVER-BURK PIOT OF DIAPEORASE ACTIVITY WITH RESPECT TO RESAIURIN

\section{Legend}

Rates of reaction were followed by monitoring change in fluorescence i $n_{\text {exe }}$ $\left.=568 \mathrm{~nm}, \lambda_{\text {emit }}=582 \mathrm{~nm}\right)$. Reactions were carried out in a $3.0-\mathrm{mL}$ cuvette at $\mathrm{pH} 8.7$ and $25^{\circ} \mathrm{C}$, using $0.011 \mathrm{DCPIP} \mathrm{U} / \mathrm{mL}$ diaphorase and $7.8 \times 10^{-5} \mathrm{M}$ NADPH. Non-enzymatic rate of reduction of resazurin by NADPH was followed using $1 \%$ BSA instead of diaphorase, and was subtracted from the total rate (enzymatic + non-enzymaticl.

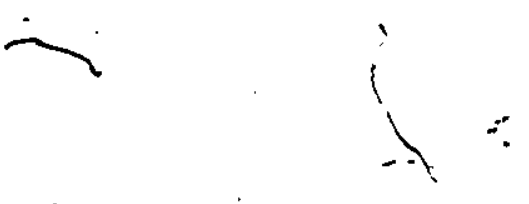


FIGURE 6

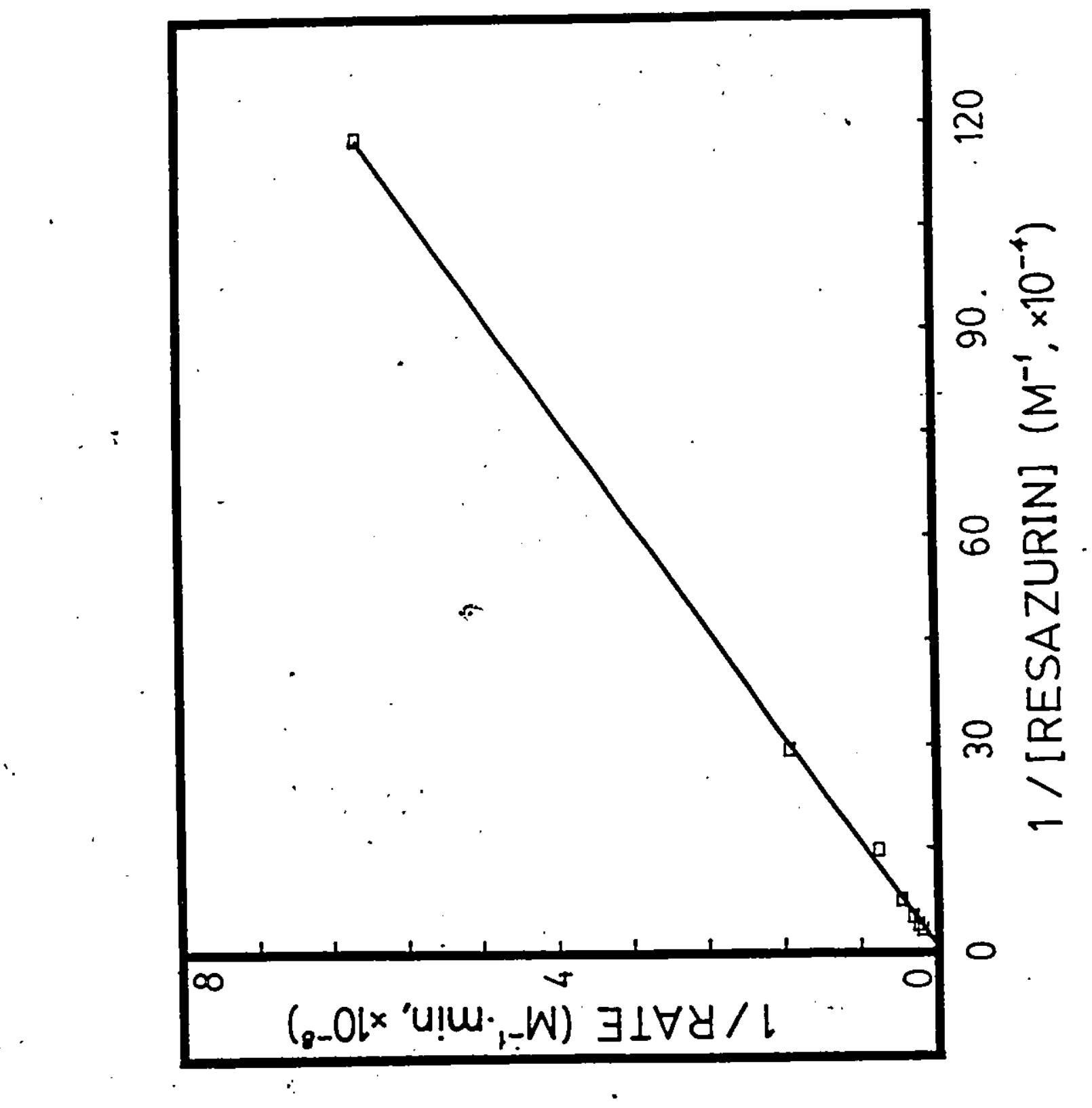


The lower signals at high concentrations of, resazurin (Figure 4) can be explained in terms of increased rates of reaction and increased quenching as the amount of resazurin is increased. When a 10-mL cuvette was used, hopever, the quenching effect was reduced (see Figure 5). As a result, higher $\Delta F / \Delta t$ signals were observed at $34 \mu \mathrm{M}$ resazurin than at $6.8 \mu \mathrm{M}$. The use of higher resazurin concentrations can, therefore, be justified by this fact.

The effect of NADPH concentration on diaphorase activity was studied at two different concentrations of resazurin. From the Hanes-Woolf plot (Figure 7), the $\left(\mathrm{K}_{\mathrm{m}}\right)_{\text {app }}$ of NADPH were found to be $1.31( \pm 0.04) . \mu \mathrm{M}$ and $0.78( \pm 0.04)$ $\mu M$ at $34 \mu M$ and $6.8 \mu M$ resazurin, respectively. This differs from the findings of Guilbault et al. (53) who found diaphorase activity to be independent of NADH concentration at 6.8 / $\mathrm{M}$ resazurin. They, however, worked in an NADE concentration range, appraximately 8 to 80 times the $K_{i m}$ we determined, i.jp, zero reder with respect to substrate.

Diaphorase. activity, at $34 \mu \mathrm{M}$ resazurin, was linear up to $1.4 \times 10^{-3}$ units/ $m L$ (Figure 8). In this range, the specific activity using resazurin is on the order of 100 times less than that using DCPIP as a substrate.

\subsection{Calibration Curves}

Curve $B$ of Figure 9 is a calibration curve of $\Delta F / \Delta t$ versus glucose 6-phosphate dehydrogenase (G6PDH) activity, using the conditions suggested by, Guilbault et al $(29,31)$ i.e.e, $6.8 \mu \mathrm{M}$ resazurin and diaphorase at 0.013 DCPIP units/ mL. In no part of the graph is the $\Delta F / \Delta t$ directly proportional to the amount of G6PDH.

Curve $A$ is a second calibration curve using higher amojnts of both resazurin and diaphorase ( $34 \mu \mathrm{M}$ and 0.33 DCPIP units/mL, respectively). This curve gives a better separation of points and is clearly proportional up to $6 \times 10^{-4}$ unitsiml of G6PDE. In addition, the higher signals make the assay more 
FIGURE 7

HANES-WOOLF PLOT OF DIAPFORASE ACTIVITY WITH RESPECT TO NADPE

\section{Iegend}

Rates of reaction were followed by monitoring change in fluorescence $\left(\lambda_{\text {exc }}=568 \mathrm{~nm}, \lambda_{\text {emit }}=582 \mathrm{~nm}\right)$. Reactions were carried out in a 1.0-mi cuvette at $\mathrm{pH} 8.7$ and $25^{\circ} \mathrm{C}$, using $0.018 \mathrm{DCPIP} \mathrm{U} / \mathrm{mL}$ diaphorase and two different concentrations of resazurin $[6.7 \mu \mathrm{M}(\square)$ and $34 \mu \mathrm{M}(\Delta)$. Non-enzymatic rate of reduction of resazurin by NADPF was followed using 1\% BSA instead of diaphorase, and was subtracted from the enzymatic rate. 
FIGURE ?

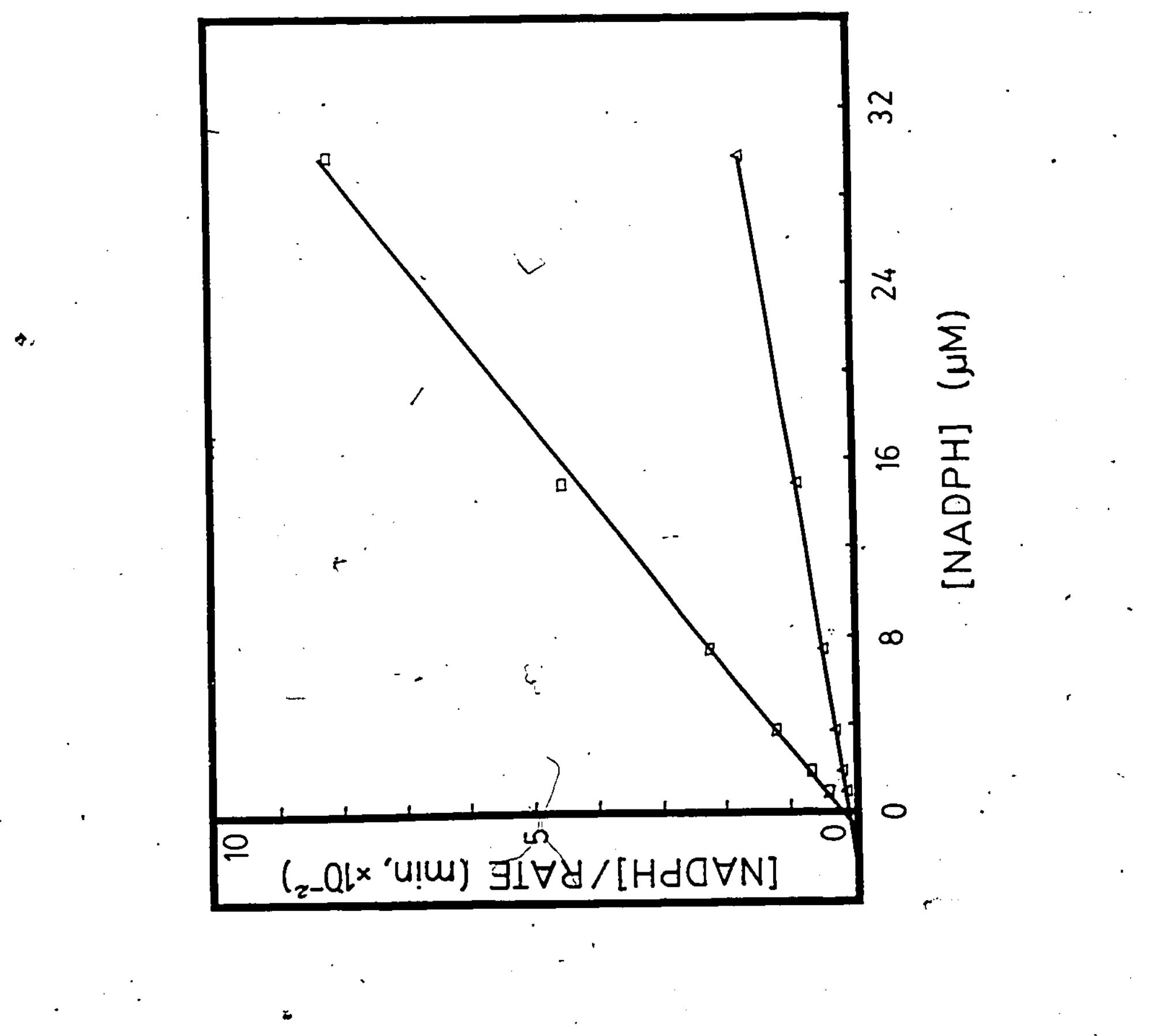


41

\section{FIGURE 8}

COMPARISON OF RESAZURIN AND DCPIP AS SUESTRATES FOR DIAPHORASE .

\section{- Legend}

Diaphorase activity using DCPIP as a substrate was determined by following decrease in absorbance at $600 \mathrm{~nm}$. Reactions were carried out at pH 7.5 and $25^{\circ} \mathrm{C}$, using $39 \mu \mathrm{M} \mathrm{DCPIP}$ and $0.2 \mathrm{mM} \mathrm{NADH}$. Non-enzymatic rates of reduction were subtracted.

Diaphorase activity using resazurin as a substrate was determined by monitoring the increase in fluorescence $\left(\lambda_{\text {exc }}=568 \mathrm{~nm}, \lambda_{\text {emit }}=582 \mathrm{~nm}\right)$. Reactions were carried out at $\mathrm{pH} 8.7$ and $25^{\circ} \mathrm{C}$, using $34 \mu \mathrm{M}$ resazurin and $22 \mu \mathrm{M}$ NADPH. Non-enzymatic rates of reduction were subtracted. 
FIGURE 8 .

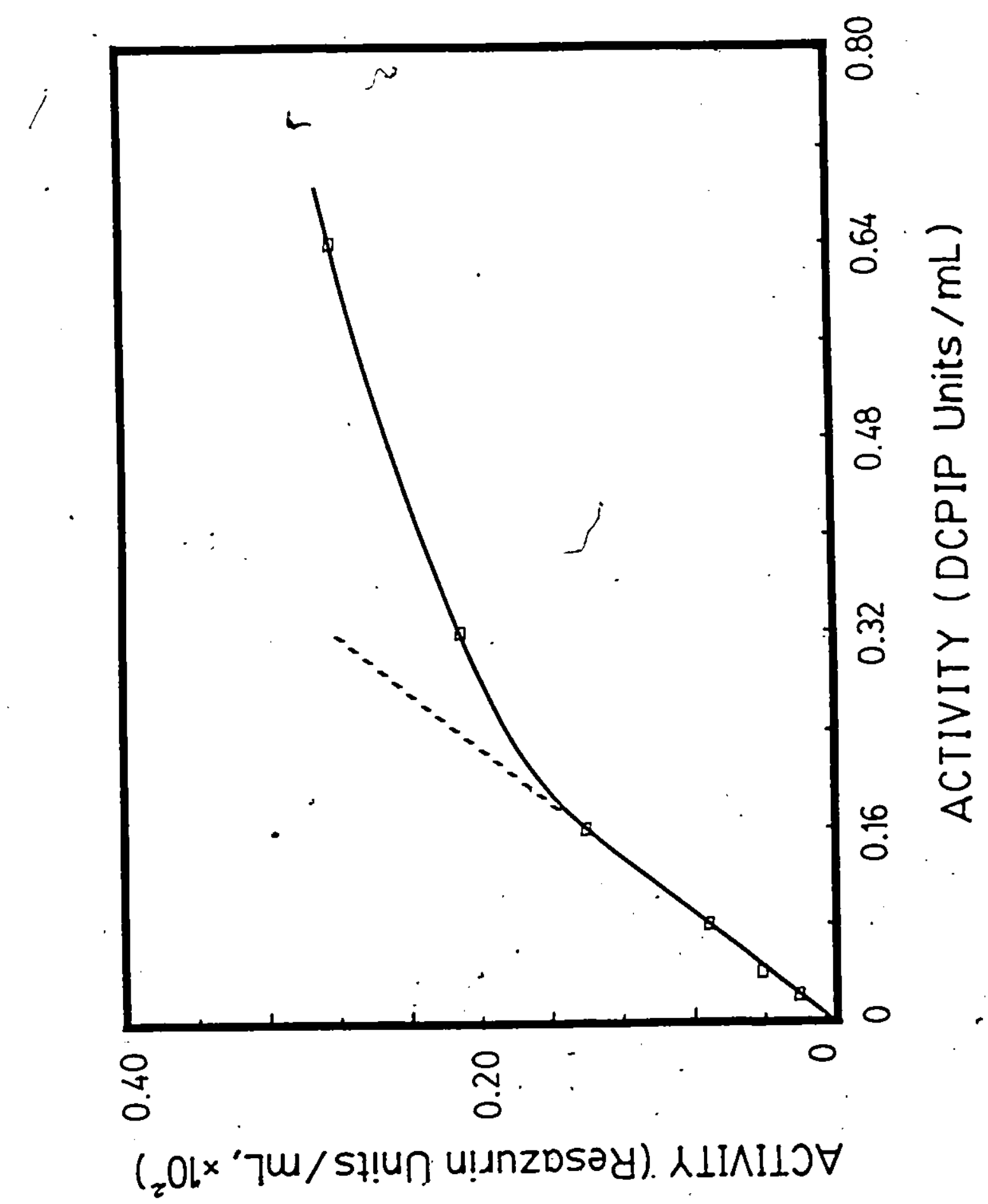




\section{FIGURE ?}

CALIERATION CURVE OF A FLUORESCENCE/MIN VERSUS GLUCOSE 6-PHOSPHATE DEEYDROGENASE ACTIVTIY

\section{Legend}

Dilutions of G6PDH were made in 1\% BSA and assayed by monitoring the increase in absorbance at $340 \mathrm{~nm}$. Reactions were carried out at $\mathrm{pH} 8.7$ and $25^{\circ} \mathrm{C}$, using $0.6 \mathrm{mM} \mathrm{NADP}{ }^{+}$and $0.68 \mathrm{mM}$ glucose 6-phosphate.

G6PDE solutions were re-assayed in duplicate by coupling the NADPE -produced to the diaphorase/sesazurin system and monitoring the increase in fluorescence $\left(\lambda_{\text {exc }}=568 \mathrm{~nm}, \lambda_{\text {emit }}=582 \mathrm{~nm}\right)$. Two calibration curves were generated, one using $34 \mu \mathrm{M}$ resazurin and 0.33 DCPIP $\delta / m L$ diaphorase (Curve A), and the other using $6.8 \mu \mathrm{M}$ resazurin and 0.013 DCPIP U/mL (Curve B). Reactions were carried out at $\mathrm{pH} 8.7$ and $25^{\circ} \mathrm{C}$, using $0.6 \mathrm{mM} \mathrm{NADP}$ and 0.68 ouM glucose 6-phosphate. 
FIGURE ?

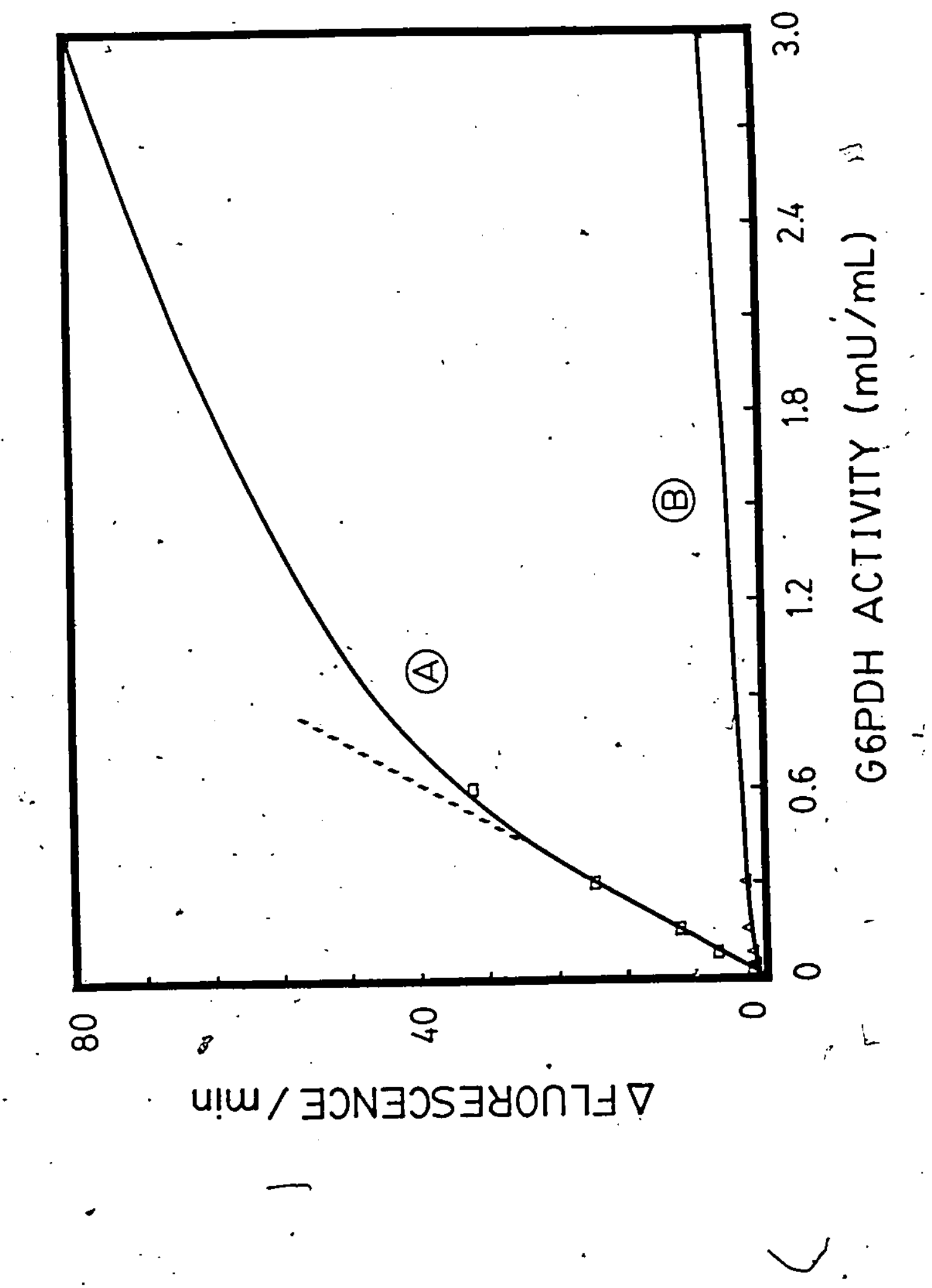


sensitive, ‥e., able to detect as low as $2 \times 10^{-5}$ units/mL. Typically, Guilbault's assay of dehydrogenases (31) can detect on the order of $10^{-4}$ units/ml.

\subsubsection{Stability of Resazurin in Water}

Previous workers $(29,32)$ have prepared resazurin solutions in cellosolve. Since this solvent is a teratogen, the possibility of using water as a solvent was'inyestigated. It was first noted that resazurin has a higher solubility in water than cellosolve, allowing the more concentrated solution required for our procedure to be made.

The stability of resazurin in water was then investigated. Figure 10 illustrates the absorption spectra of freshly prepared equimolar ( $8.5 \mu \mathrm{M})$ resazurin and resorufin, and resazurin which had been kept in a brown bottle in the dark for sixkweeks. Resazurin has a peak at $600 \mathrm{~nm}$, the wavelength chosen for the stability study. It would appear from the spectrum of the old resazurin, that it undergoes a slow cońversion to resorufin in solution.

Although a decrease in absorbance of the resazurin solution over time was observed, the conversion of resazurin is slow enough (Figure 11) to allow the solution to be used for up to one month.

3.3 Determination of GALT Activity in Erythrocytes

\subsubsection{Preliminary Studies}

In the course of preliminary studies of the coupled assay for GAIT, a significant, reagent blank pas discovered. By the process of elimination, it was discovered that it was substantially due to galactose 1-phosphate (GAL1P) and to a lesser extent, glucose 1,6-diphösphate (G1,6DP). Sigma Chemical Company confirmed that their GAL1P was contaminated with glucose 1-phosphate and 
462

is

FIGURE 10

ABSORPTION SPECTRA OF RESORUFIN AND RESAIURIN

Legend

Spectra were generated using $8.5 \mu \mathrm{M}$ solutions of resazurin and resorufin in water at $25^{\circ} \mathrm{C}$. Freshly prepared resazurin solution ( resazurin solution $(-\infty-\infty$ and freshly prepared resorufin solution $(-, \infty$.

,

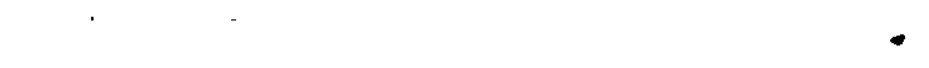

$\checkmark$

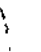

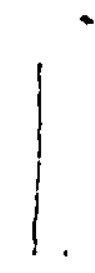

$r$

1

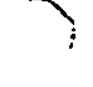

So 
FIGORE 10

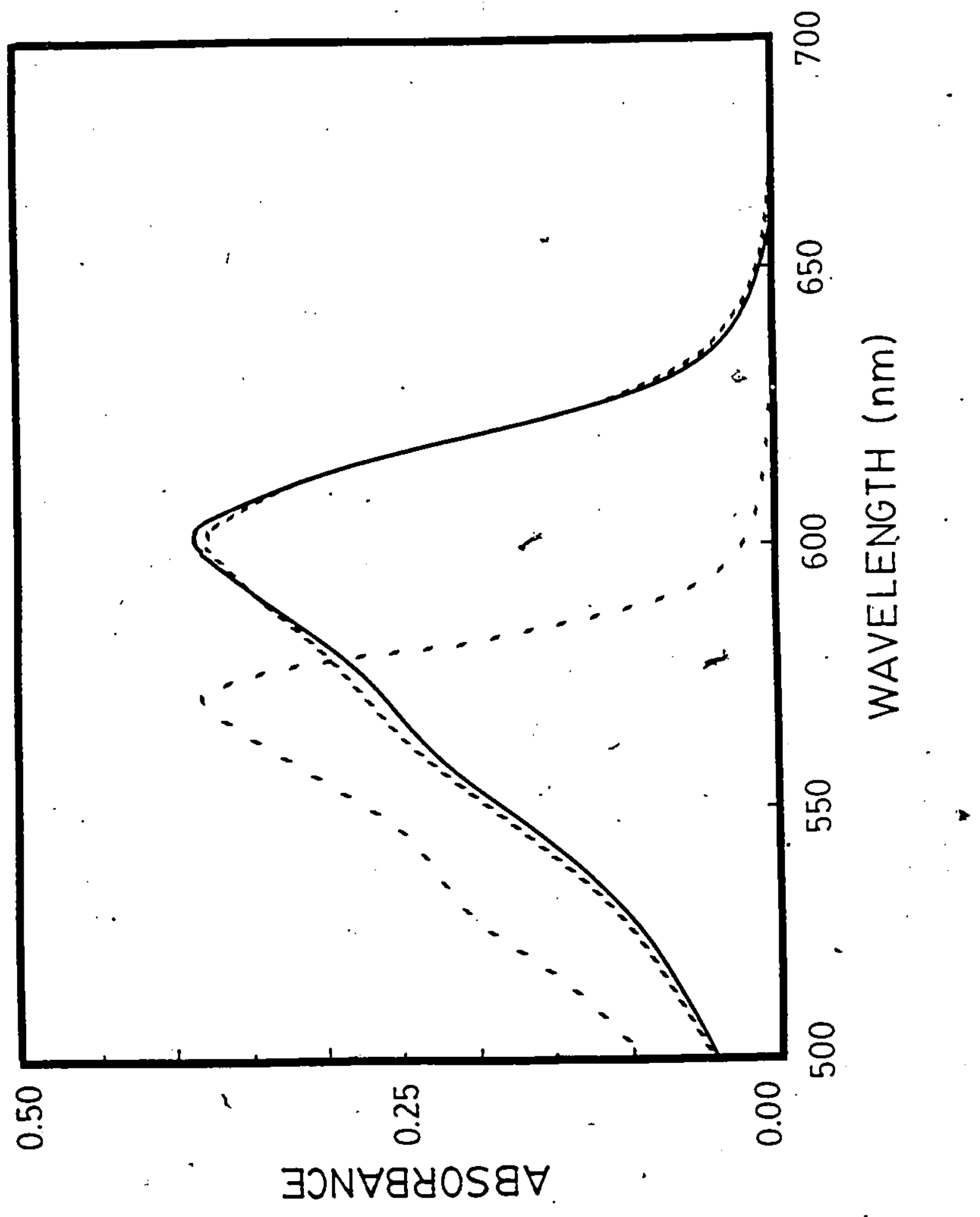


48

FIGURE 11 .

STABILITY OF RESAZURIN SOLUTION

Legend

The absorbance of resazurin $(50 \mu$ of a $0.85 \mathrm{mM}$ solution added to 5.0 $\mathrm{mI}$ of water) was read at $600 \mathrm{~nm}$. Absorbance are the average of duplicate readings and are represented as a percentage of the absorbance reading on the day of preparation of the stock solution. 
-

FIGURE 11

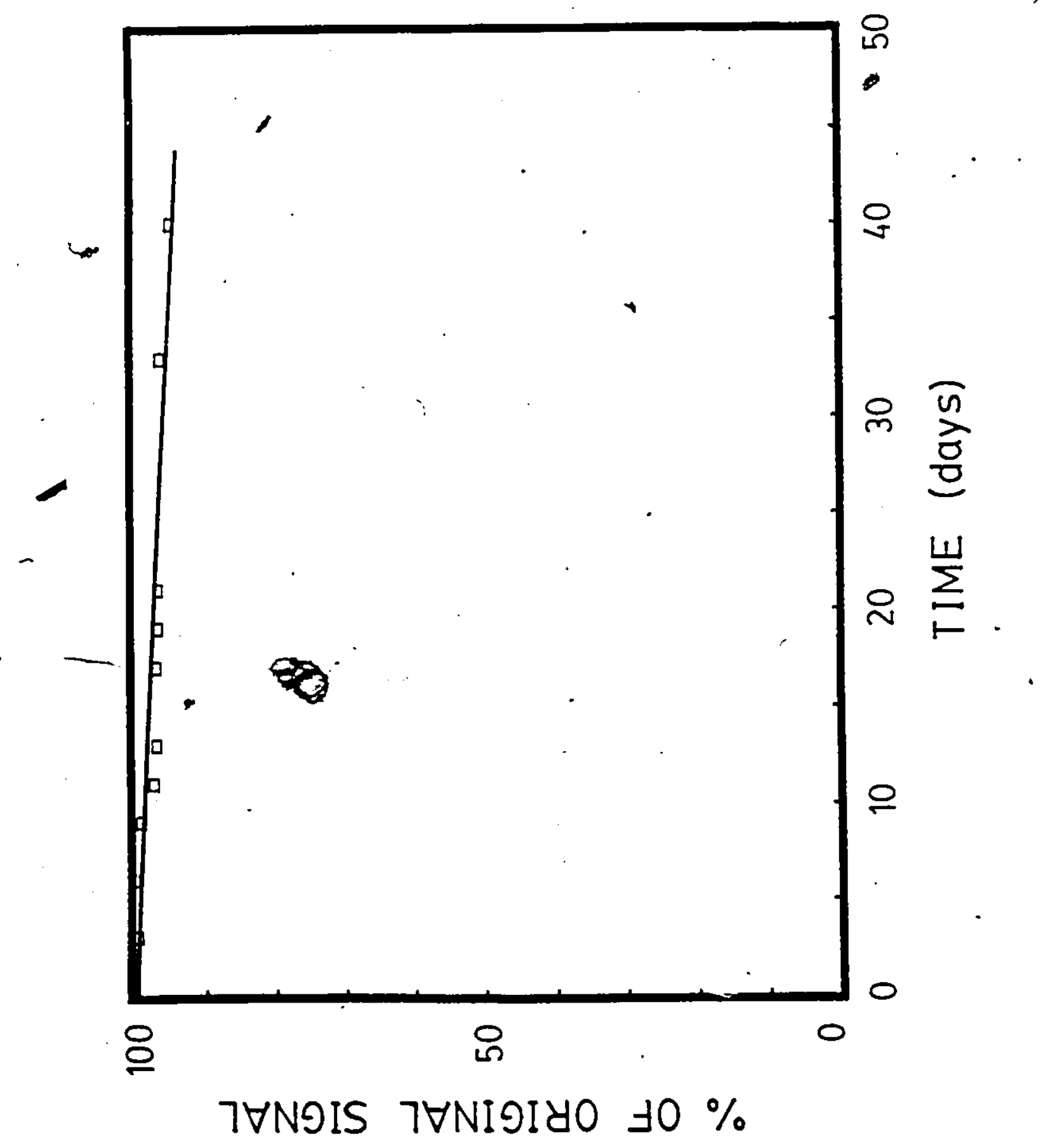


glucose 6-phosphate, which can trigger the sccond and third reactions of the coupled assay as shown in Scheme 2 below:

SCHEME 2: Proposed Coupled Assay for GALT

Galactose 1-Phosphate + UDPG $\stackrel{\text { GAIT }}{\longrightarrow}$ Glucose 1-Phosphate + UDPGal

17 .

Glucose 1-Phosphate $\underset{\text { Glucose 1,6-Diphosphate }}{\stackrel{\text { Phosphoglucomutase }}{\longrightarrow}}$ Glucose 6-Phosphate

Glucose 6-Phosphate + NADP+ $\stackrel{\text { G6PDH }}{\longrightarrow}$ 6-Phosphogluconate + NADPH + $\mathrm{H}^{+}$

6-Phosphogluconate + NADP $\stackrel{\text { 6-PGADH }}{\longrightarrow}$ Ribulose 5-Phosphate + NADPH + H+

2 Resazurin $+2 \mathrm{NADPH}+2 \mathrm{H}+\stackrel{\text { Diaphorase }}{\longrightarrow} 2$ Resorufin $+2 \mathrm{NADP}^{+}+2 \mathrm{H}_{2} \mathrm{O}$

Synthetic galactose 1-phosphate was obtained at a later date from Biosynth Ag., in the hopes of eliminating the problem of the reagent blank. However, it was found that this preparation was also contaminated, and for all future studies it was necessary to include a blank, in which UDPG was omitted from the reaction mixture. .

Preliminary studies using hemolysates produced $\Delta F / \Delta t$ signals which were lower than anticipated and the possibility of quenching by the hemolysate was investigated. The fluorescence coefficient of resorufin was found to be lower in the presence of hemolysate. Figure 12 shows the absorption spectrum of hemolysate. There is a double peak at $540 \mathrm{~nm}$ and $576 \mathrm{~nm}$, in the region of both the excitation and emission spectra of resorufin. The fact that the peaks correspond to oxyhemoglobin (54) raised the problem of variable quenching from sample to sample, since each sample would have different amounts of hemoglobin. 
51

FIGURE 12

ABSORPTION SPECTRUM OF HEMOLYSATE

\section{Legend}

A dilute solution was made by adding $10 \mu$ of $1: 1$ hemolysate $(14.9 \mathrm{~g} \mathrm{Fb/}$ $100 \mathrm{~mL}$ ) to $1.0 \mathrm{ml}$ of glycine buffer, $\mathrm{pH}$ 8.7. Spectrum was recorded at $25^{\circ} \mathrm{C}$. 


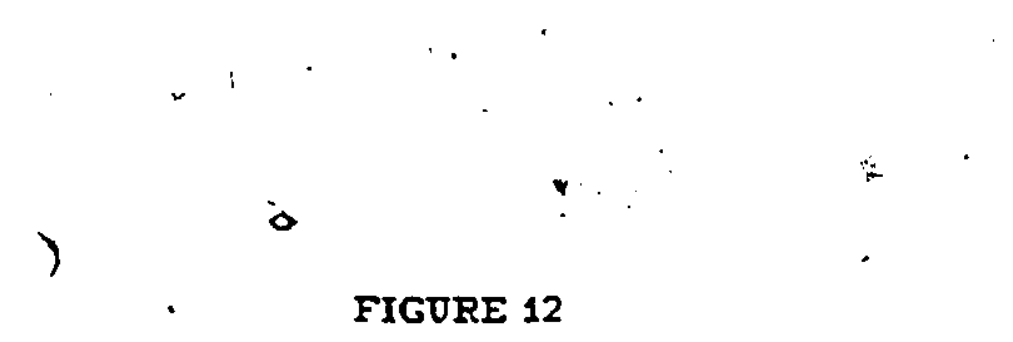

FIGORE 12

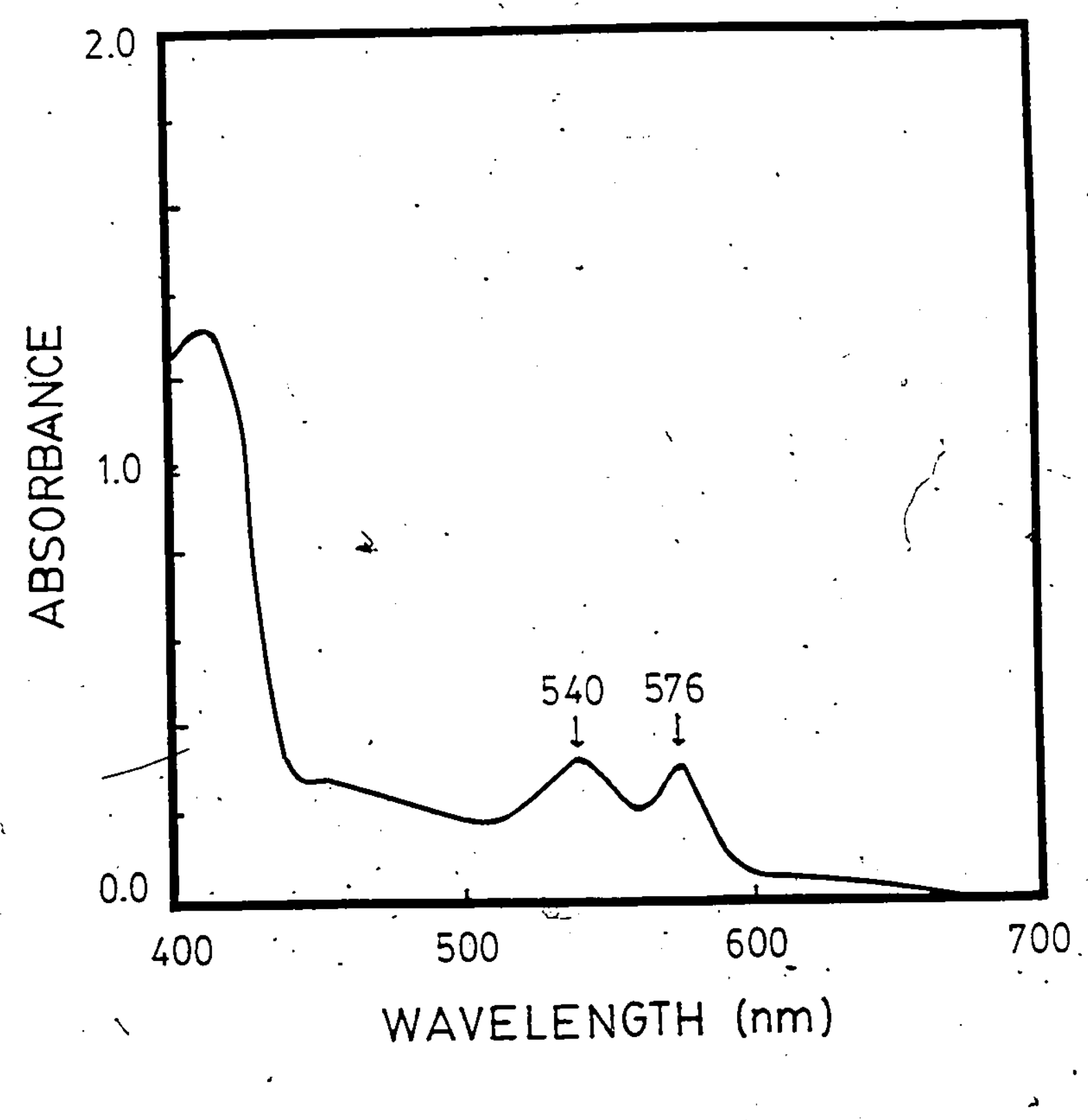


It was, therefore, decided that a calibration curve not be used for the determination of GAIT activity. Rather, the fluorescence coefficient of resorufin would be determined for each sample with the use of an internal standard, i.e., a known amount of resorufin is added to reagent mixture containing buffer, resazurin and sample and its fluorescence intensity is measured. The internal standard is subsequently used in the calculation of GAIT activity. (See APPENDIX c B.)

Figure 13 indicates that the emission spectrum of resorufin is not changed in the presence of hemolysate and resazurin. However, the excitation spectrum is altered, showing two peaks, one at $520 \mathrm{~nm}$ and one at $565 \mathrm{~nm}$.

\subsubsection{Optimization of GALT Assay}

Optimization was carried out on hemolysates prepared from pooled venous blood samples. The "optimum" soncentration of each component of the assay was determined by holding all others constant. Each optimum found was then used in the optimization of the next component. A temperature of $37^{\circ} \mathrm{C}$ was used throughout.

\subsubsection{Sample Size}

Table III lists the change in fluorescence signal observed when various amounts of hemolysate pere analyzed. Maximum rate was observed when $10 \mu$ of 1:1 hemolysate $(14.2 \mathrm{~g} / 100 \mathrm{~mL})$ was used. This amount constitutes a compromise between greater amounts of GAII and increased quenching, with increasing sample size.

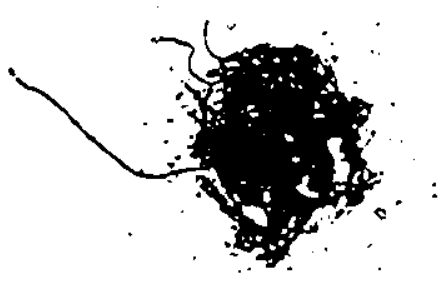


54

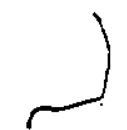

FIGURE 13

FLUORESCENCE SPECTRA OF RESORUFIN IN THE PRESENCE OF HEMOLYSÀTE AND RESAZURIN

\section{Legend}

Fluorescence spectra of resorufin in the presence of $20 \mathrm{\mu L}$ 1:1 hemolysatel ⿷ $\mathrm{mL}$, and $34 \mathrm{MM}$ resazurin (-). Spectra of hemolysate and resazurin trot.

The emission spectra were generated first using exciting light of $520 \mathrm{~nm}$. The excitation spectra were then generated by monitoring the fluorescence at $585 \mathrm{~nm}$.

All spectra were generated at pH 8.7 and $37^{\circ} \mathrm{C}$.

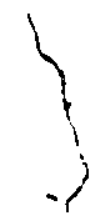




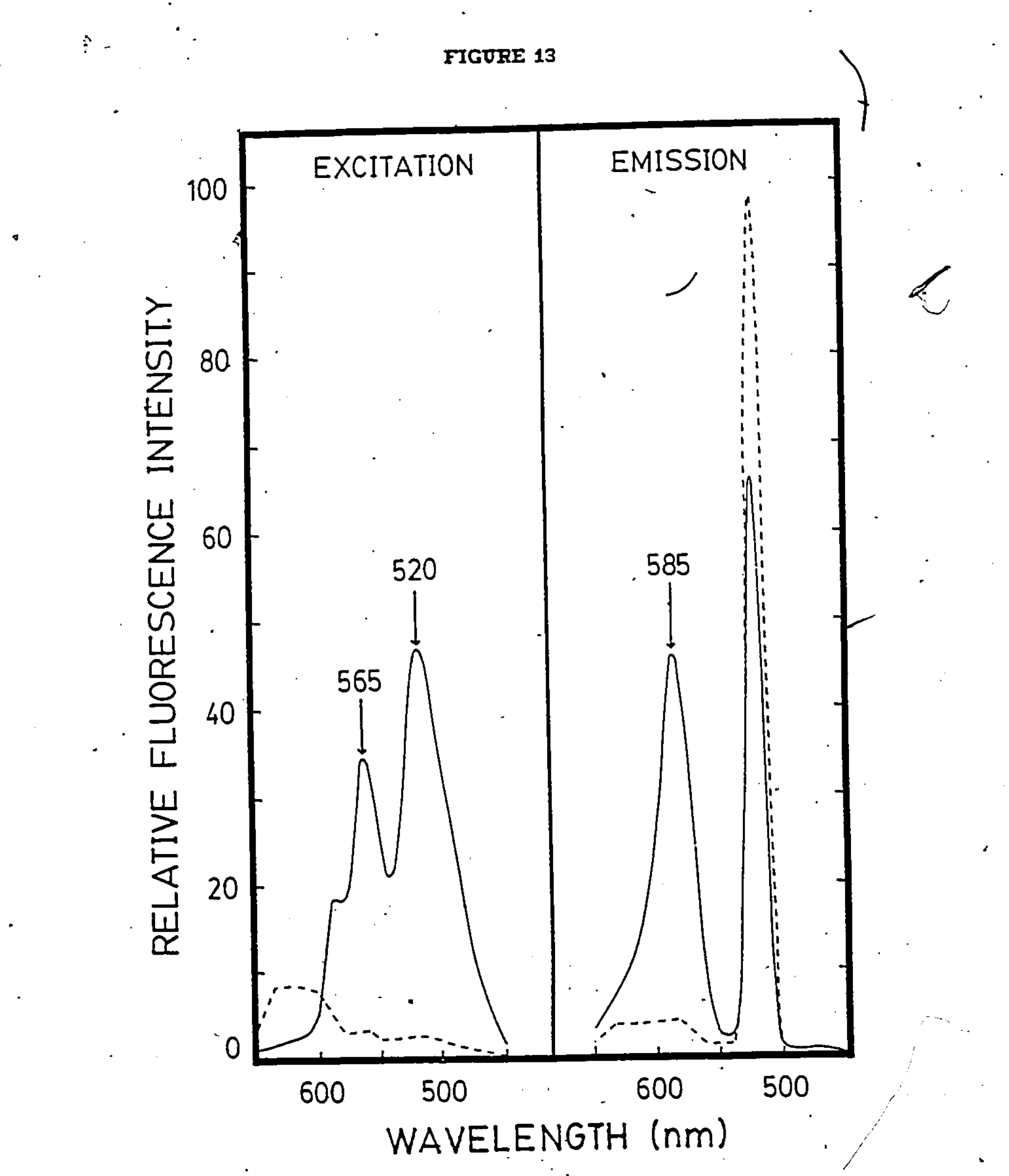


TABLE III

EFFECT OF DILUTION OF HEMOLYSATE ON OBSERVED SIGNAL IX GALT ASSAT

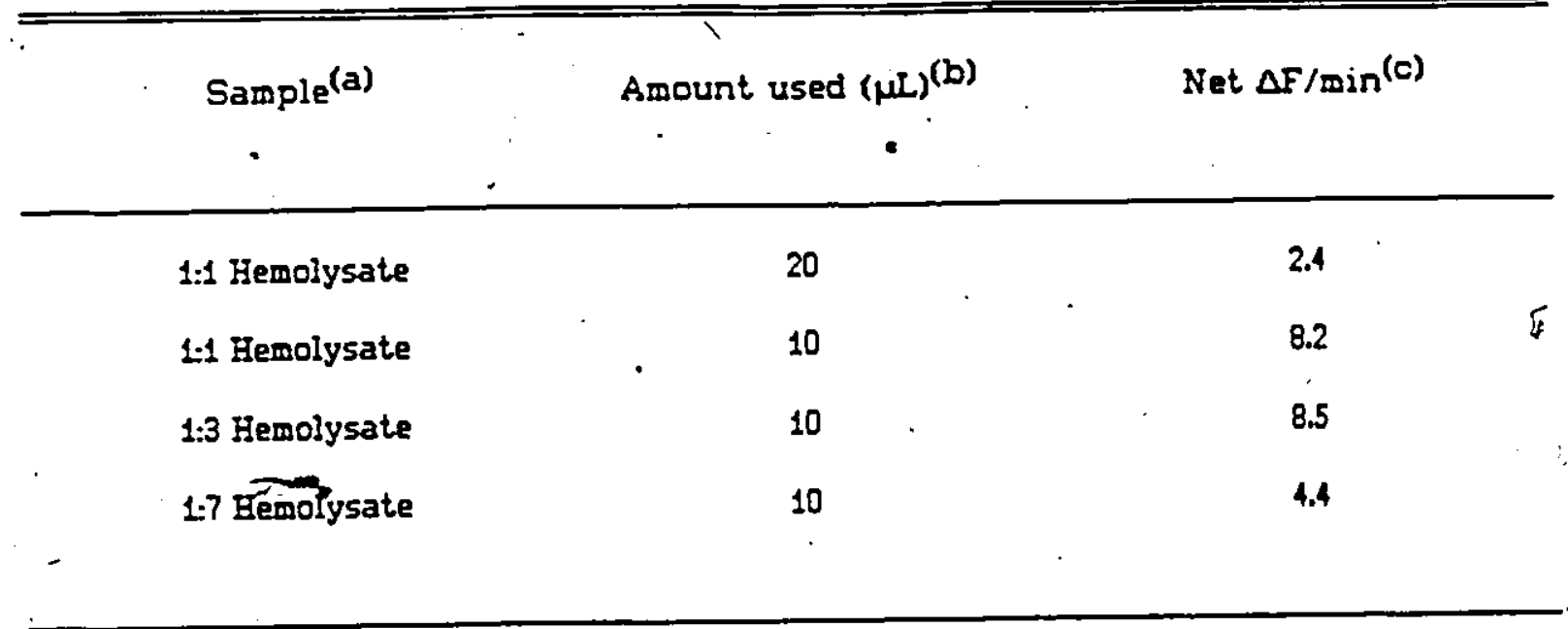

(a) Ratio refers to erythrocyte volume: water volume.

(b) In a total of $500 \mu$ assay mixture.

(c) Deterinined in duplicate $\Delta F_{\text {sample }}-\Delta F_{\text {blank }}$ 


\subsubsection{Activators}

Reviewers of the reference method (5) suggested that the hemolysates be pre-incubated with $26 \mathrm{mM}$ dithiothireitol (DTI) to reactivate GAIT. When this procedure was tried with the present assay, an increase in the blank was observedilt was consequently discovered that the DTT could non-enzymatically reduce resazurin to produce resorufin. It was decided, therefore, to omit this pre-incubation step.

Williams et al. (12) found that the stability of GAII from erythrocytes was about the same in the absence of DTI as that in its presence up to about eight minutes of incubation at $37^{\circ} \mathrm{C}$. Since our assay requires only six to seven minutes, omission of DTT reactivation does not pose a serious problem.

In addition, if the samples are assayed soon enough, GAII retains most of its activity (see Section 3.3.5) and does not require reactivation.

\subsubsection{Buffer Solution}

The buffer solution was comprised of three components: glycine, EDTA and $\mathrm{MgCl}_{2}$. Buffer solutions were prepared by dissolving appropriate amounts of each component in water, adjusting the $\mathrm{pH}$ at $25^{\circ} \mathrm{C}$ with $\mathrm{NaOH}$ and making up to volume.

The effect of $\mathrm{pH}$ of the buffer was first studied. A broad peak (Figure 14) was observed, with maximum activity between $p \# 8.3$ and 8.7 . A pE of 8.7 was chosen due to the fact that this is the one most often quoted for GALI activity in erythrocytes.

Concentrations of up to $200 \mathrm{mM}$ glycine in the buffer solution were used ane maximum activity was found at about $100 \mathrm{mM}$. 
FIGORE 14

PH STUDY OF GALI ACTIVITY

\section{Legend}

All buffer solutions. were made to be $100 \mathrm{mM}$ glycine, $3.3 \mathrm{mM} \mathrm{MgCl} 2$ and $2.0 \mathrm{mM}$ EDTA, and adjusted to appropriate pH values at $25^{\circ} \mathrm{e}$

GAIT activity in a pooled hemolysate sample was determined in duplicate by the present coupled assay. To $410 \mu \mathrm{I}$ of buffer solution at $37^{\circ} \mathrm{C}$ were added $10 \mu L$ of hemolysate, $20 \mu L$ of resazurin $(0.85 \mathrm{mM}), 20 . \mu L$ of UDPG $(27.5 \mathrm{mM})$ and $20 \mu \mathrm{L}$ of enzyme solution $1.0 \mathrm{~J} / \mathrm{mL}$ PGM, 9.0 U/mL G6PDF, 16 DCPIP U/mL diaphorase). The fluorescence of this solution was set to "zero", after which $10 \mu \mathrm{ll}$ of resorufin (0.20 mM) was added and the RFI recorded. The GAIT reaction was initiated by adding 10 . 1 of substrate solution (0.12 M GAL1P 0.02M NADP', $1.0 \mathrm{mM} G 1,6 D P$, and followed at $37^{\circ} \mathrm{C}$ by monitoring the rate of increase of fluorescence $\left(\lambda_{\text {exc }}=565 \mathrm{~nm}, \lambda_{\text {emit }}=585 \mathrm{~nm}\right)$. Blank rates were determined by replacing ODPG with water, and were subtracted.' 
FIGURE 14

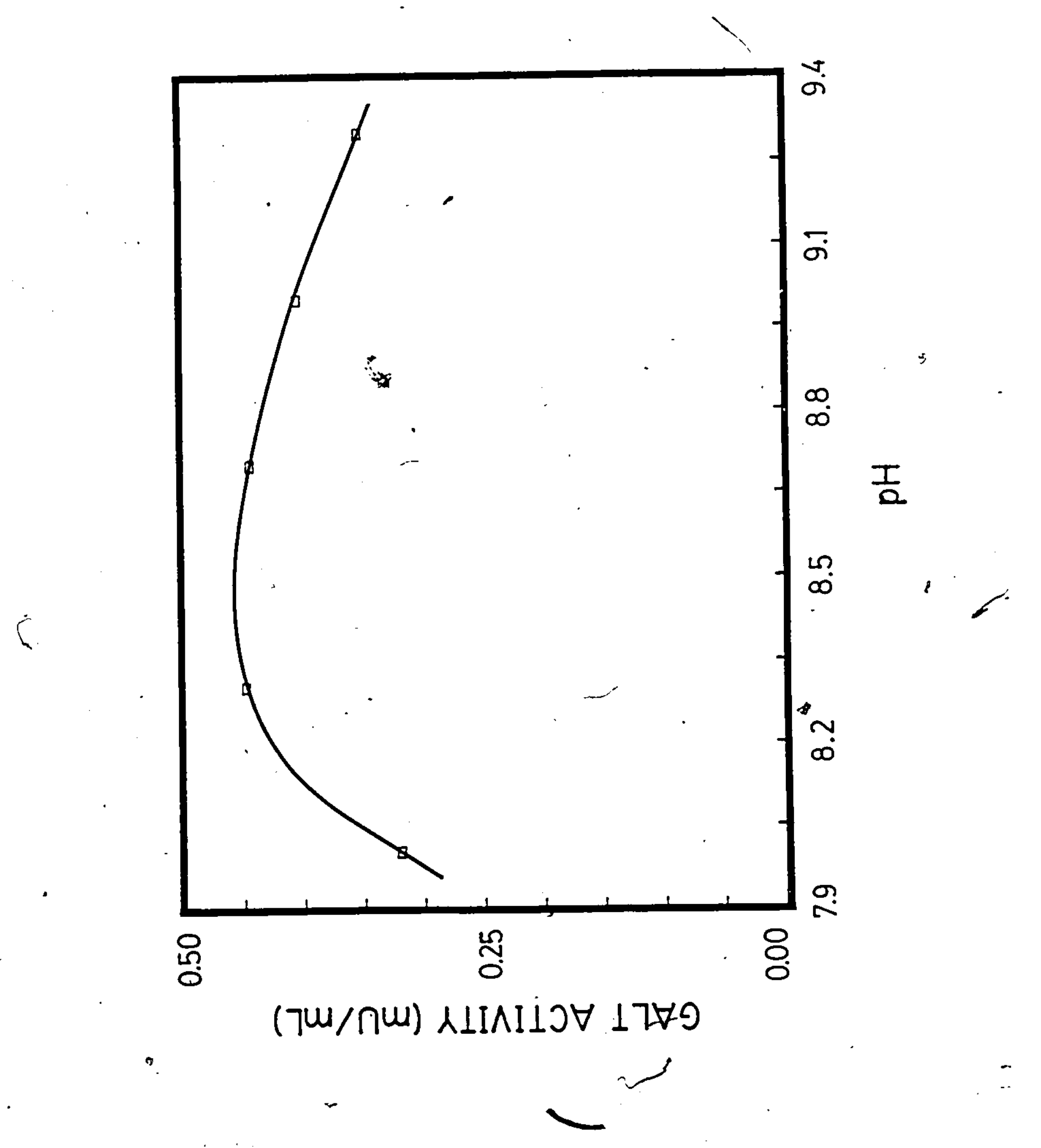


EDTA concentration in the buffer solution was varied between 0 and 2.0 with $0.5 \mathrm{mM}$ EDTA in the buffer, GAIT activity was maximum.

Figure 15 shows the effect of $\left[\mathrm{MgCl}_{2}\right]$ on $\mathrm{GAIT}$ activity. Inhibition of GAIT activity was seen at all concent,rations of $\mathrm{MgCl}_{2}$, and it was, therefore, omitted from the assay mixture.

\subsubsection{Cofactors}

The effect of glucose 1,6-diphosphate concent-ations, up to $52 \mu \mathrm{M}$, was studied. Maximum GAIT activity was seen at concentrations between 6.5 and 13 $\mu \mathrm{M}$. At concentrations above $13 \mu \mathrm{M}$, activity decreased.

\subsubsection{Coupling Enzymes}

Due to the low specific activity of diaphorase, the reagent blank had to be kept to a minimum. This was done by decreasing the concentrations of phosphoglucomutase and glucose b-phosphate dehydrogenase. This resulted in decreased blanks but longer lag phases. The compromise between unacceptable lag phases ( $>4 \mathrm{~min}$ ) and intolerable blanks gave rise to the concentrations chosen for these two auxiliary enzymes (PGM and G6PDH).

Pesce et al. (25) discussed the problem of adding extraneous 6-PGADE to their coupled assay for GALT. (This assay scheme is identical to ours except that it lacks the last reaction.) They indicated that 6-PGADE should not be added since it causes an inhibition of GALT activity. However, they 80 on to. argae that in normal erythrocytes, and even in 6-PGADH-deficient samples, the activity of 6-PGADH is sufficient to produce the second mole of NADPE.

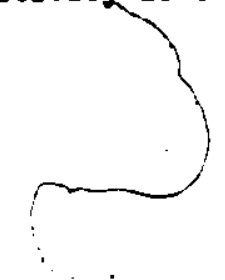


61

FIGURE 15

EFFECT OF $\mathrm{MgCl}_{2}$ ON GAIT ACTIVITY

Legend

Buffer solutions were-made to be $100 \mathrm{mM}$ glycine, $0.5 \mathrm{mM}$ EDTA and contained varying amounts of $\mathrm{MgCl}_{\mathbf{2}}$. Concentrations shown are those in the final assay mixture.

GALT activity in a pooled hemolysate sample was determined in duplicate by the present coupled assay. To $410 \mu$ of buffer solution at $37^{\circ} \mathrm{C}$ were added $10 \mu$ of hemolysate, $20 \mu \mathrm{L}$ of resazurin $(0.85 \mathrm{mM}) 20 \mu \mathrm{L}$ of DDPG $(27.5 \mathrm{mM})$, and $20 \mu \mathrm{L}$ of enzyme solution $1.0 \mathrm{~J} / \mathrm{mI}$ PGM, $9.0 \mathrm{~J} / \mathrm{mL}$ G6PDH, 16 DCPIP U/mL diaphorase). The fluorescence of this solution was set to "zero", after phich $10 \mu$ of resorufin $(0.21 \mathrm{mM})$ was added and the RFI recorded. The GAIT reaction

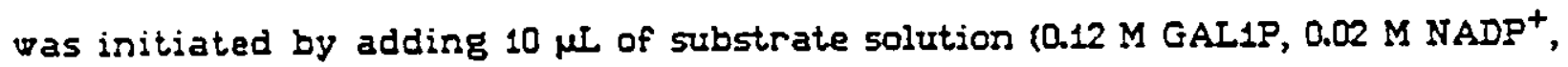
$1.0 \mathrm{mM} \mathrm{G1,6DP)}$ and followed at $37^{\circ} \mathrm{C}$ by monitoring the rate of increase of fluorescence $\left(\lambda_{\text {exc }}=565 \mathrm{~nm}, \lambda_{\text {emit }}=585 \mathrm{~nm}\right)$. Blank rates were determined by replacing JDPG with water, and were subtracted. 
$\checkmark$

FIGURE 15

-

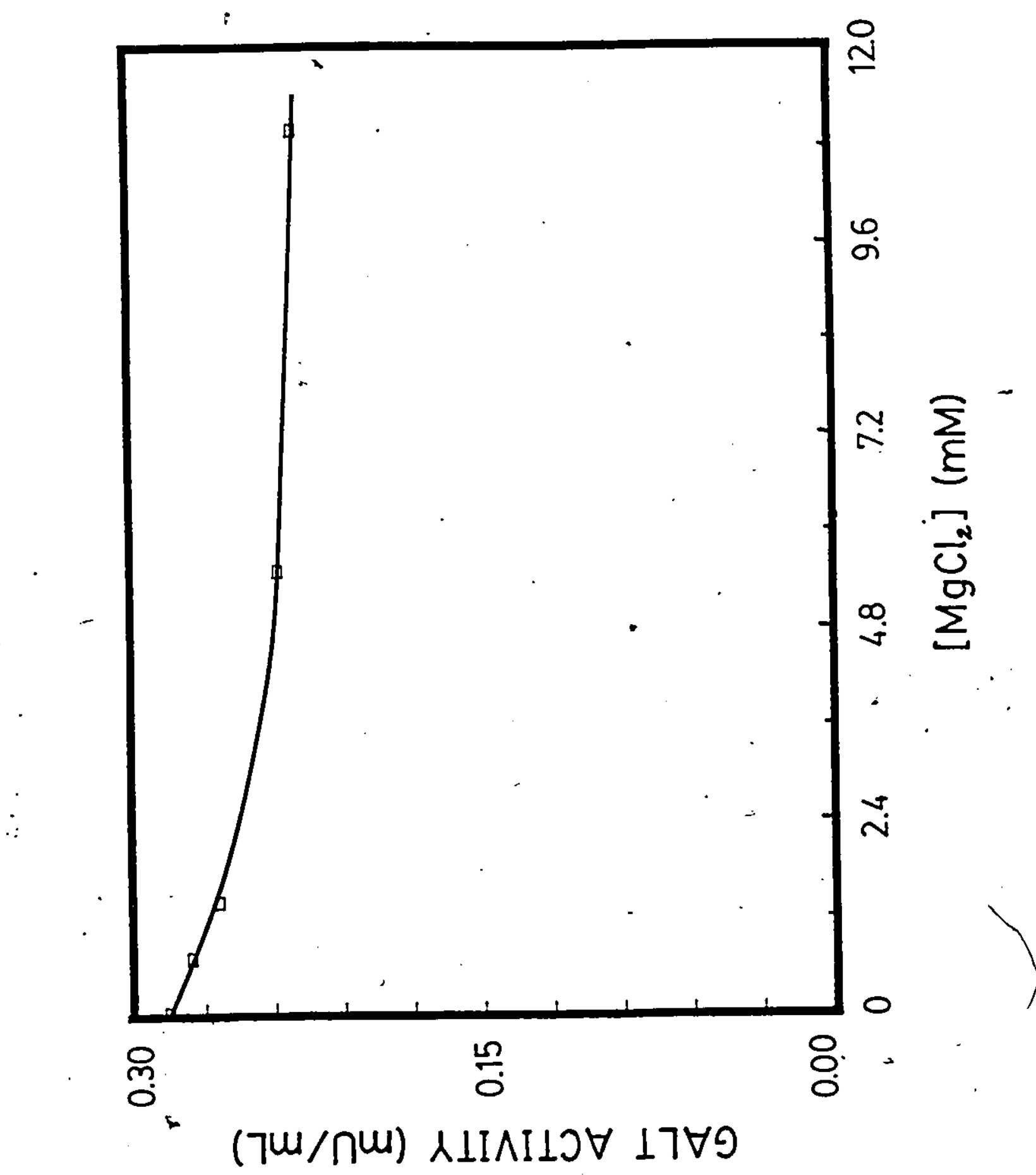




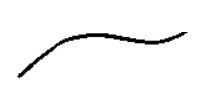

This was tested in our system by adding an amount of 6-PGADH (600 0/ I of hemolysate) which would cause minimum inhibition of GALT activity (25). GALT activity was about $8 \%$ lower than when 6-PGADE was omitted from the sample. This indicates that the endogenous 6-PGADE is sufficient to produce the second mole of NADPH; otherwise, the added 6-PGADH would have increased the GAIT activity.

Figure 16 shows the effetet of adding different amounts of diaphorase to the assay mixture. Maximum GAII activity was seen at diaphorase concentrations of $0.32 \mathrm{~J} / \mathrm{mI}$ for bokh normal and deficient samples.

\subsubsection{Substrates}

$\mathrm{NADP}^{+}$was varied from $0.03 \mathrm{mM}$ to $0.94 \mathrm{mM}$, and no significant difference in GAII activity was observed is that range.

Table IV shows the effect of resazurin concentration on GAIT activity. Maximum activits was seen at concentrations of $34 \mathrm{\mu M}$ and greater. At lower concentrations, the reduced GAITactivity is probably due to the decrease in diaphorase activity which becomes rate-limiting.

The Michaelis constants for UDPG and GALIP were determined using two different pooled hemolysates. By Hanes-woolf analysis (Figure 17), the $\mathrm{K}_{\mathrm{m}}$ for GAL1P was found to be $0.57 \mathrm{mM}( \pm 0.02 \mathrm{mM})$ and $0.84( \pm 0.19 \mathrm{mM})$. These values , $>$ are higher, but agree well vith values obtained by other workers (25). A concentratio, of $2.3 \mathrm{mM}$ GALIP (about $4 \times \mathbb{R}_{m}$ ) was chosen for the GALT assay. 
64

\section{Legend}

GALI activity in a normal sample $(a)$ and deficient sample ( $\Delta$ ) was determined in duplicate using the present coupled assay.

- To-410 $\mu L$ of buffer solution (100 mM glycine, $0.5 \mathrm{mM}$ EDTA, pH 8.7) at $37^{\circ} \mathrm{C}$, were added $10 \mu \mathrm{L}$ of sample, $20 \mu \mathrm{L}$ of resazurin $(0.85 \mathrm{mM}), 20 \mu \mathrm{L}$ of UDPG (27.5 mM) and $10 \mu \mathrm{L}$ of enzyme solution ( $1.5 \mathrm{~J} / \mathrm{mL}$ PGM, $20 \mathrm{U} / \mathrm{mL} \mathrm{G6PDH}$ ) and 10 $\mu L$ of diaphorase (varying concentratiops). The fluorescence of this solution was set to "zero", after which $10 \mu \mathrm{L}$ of resorufin $(0.23 \mathrm{mM})$ was initiated by adding . $10 \mu$. of substrate solution (0.12 M GAL1P, $0.024 \mathrm{M} \mathrm{NADP}^{+}, 0.64 \mathrm{mM} \mathrm{G1,6DP}$ ), and followed at $37^{\circ} \mathrm{C}$ by monitoring the rate of increase of fluorescence $\left(\lambda_{\text {exc }}=\right.$ $\left.520 \mathrm{~nm}, \lambda_{\text {emit }}=585 \mathrm{~nm}\right)$. Blank rates were determined by replacing UDPG with water, and were subtracted. 
FIGURE 16

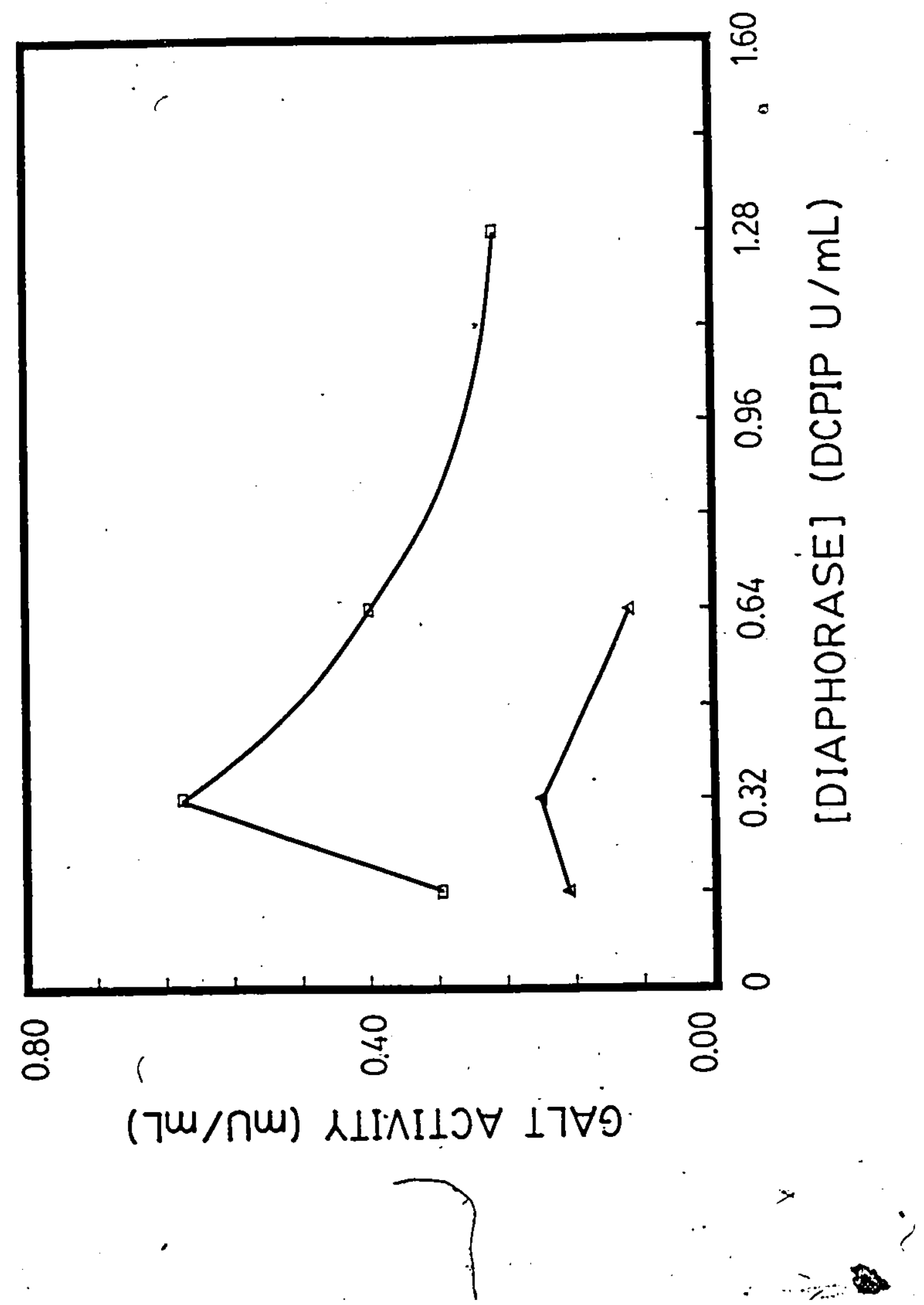




\section{TABLE IV}

\section{EFFECT OF RESAZURDS ON GALT ACTIVITY}

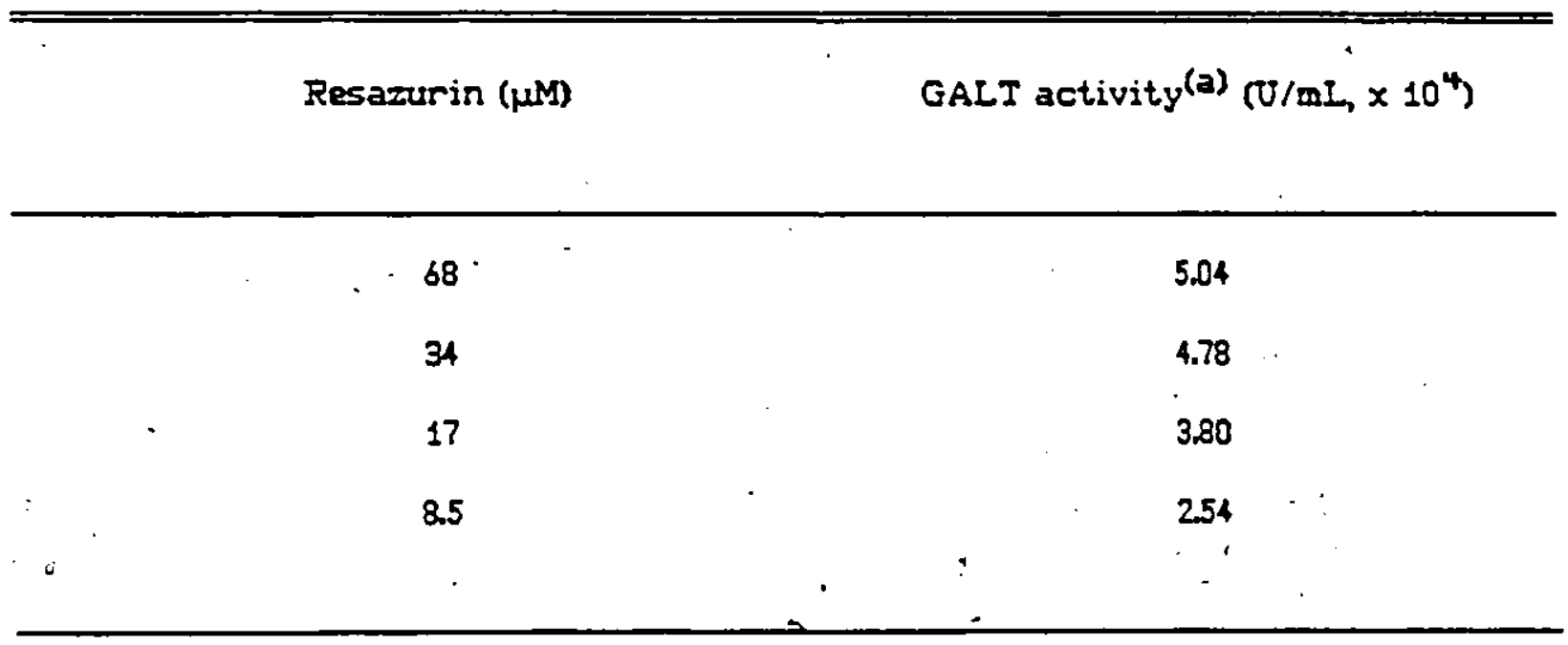

(a) Activity was determined in duplicate ysing the present coupled assay. To $410 \mathrm{\mu L}$ ' of buffer solution ( $100 \mathrm{mM}$ glycine, $0.5 \mathrm{mM}$ EDTA, pH 8.7 ) at $37^{\circ} \mathrm{C}$, - $\quad$ ere added $10 \mu \mathrm{L}$ of hemolysate, $20 \mu \mathrm{L}$ of resazurin (varying concentrations), $20 \mu \mathrm{L}$ of UDPG $(27.5 \mathrm{mM})$ and $20 \mu \mathrm{t} \times$ of enzyme solution $(0.75 \mathrm{U} / \mathrm{mL}$ PGM, $10 \mathrm{O} / \mathrm{mL}$ GGPDE, $8.0 \mathrm{DCPIP} \mathrm{O} / \mathrm{mI}$ diaphorase). The fluorescence of this solution was set to "zero", after which $10 \mu$ il of resorufin (0.20 mM) was. added and the RFI recorded. The GALI reaction was initiated by adding $10 \mu$ fl of substrate solution ( $0.12 \mathrm{M}$ GAIIP, $0.024 \mathrm{M} \mathrm{NADP}^{+}, 0.64 \mathrm{mM}$ G1,6DP), and followed at $37^{\circ} \mathrm{C}$ by monitoring the rate of increase of fluorescence $\left(\lambda_{\text {exc }}=520 \mathrm{~nm}, \lambda_{\text {emit }}=585 \mathrm{~nm}\right)$. Blank rates were determined by replacing ODPG with water, and were subtracted. 
67

FIGURE 17

HANES-WOOLF PLOT OF GAIT ACTIVITY

. WITE RESPECT TO GALACTOSE 1-PEOSPHATE

Legend

GAIT activity in two normal pooled samples was determined using the present coupled assay in the presence of $1.30 \mathrm{mM}$ UDPG and varying amounts of GAL1P. Blanks were determined at each GAL IP concentration. Procedure followed was that described in Chapter 2, Section 2.2.3.2 c., p. 23. 
FIGURE 17

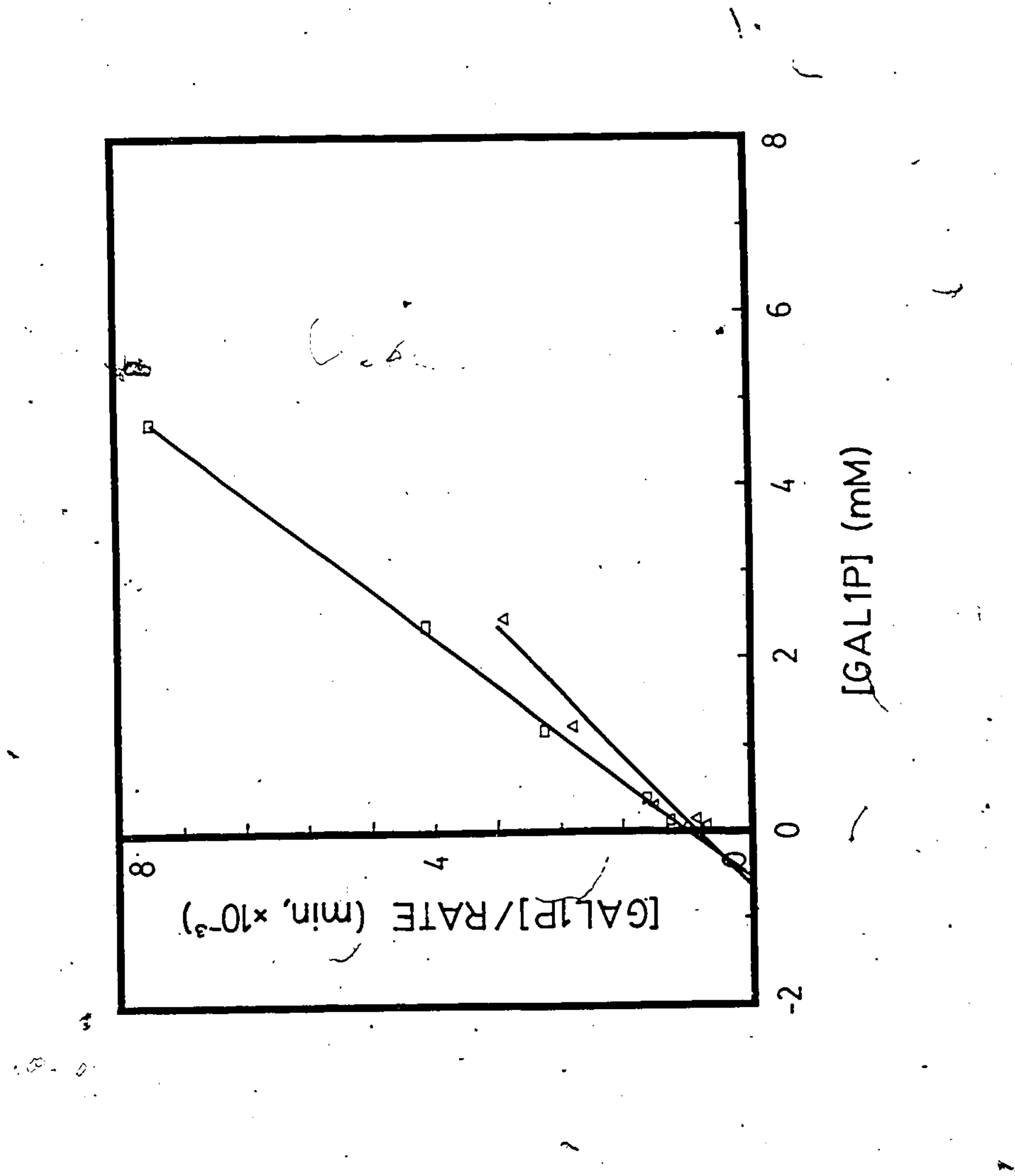


By Hanes-Woolf analysis (Figure 18), the $\mathrm{K}_{\mathrm{m}}$ for ODPG was found to be $0.081 \mathrm{mM}( \pm 0.002 \mathrm{mM})$ and $0.083 \mathrm{mM}( \pm 0.017 \mathrm{mM})$. This value is lower but agrees well,with the $\mathrm{K}_{\mathrm{m}}$ quoted by Tedesco and Mellman (2), but is significantly lower (2-fold less) than that quoted by others (25). A UDPG concentration of $110 \mathrm{mM}$ (about $14 \times \mathrm{K}_{\mathrm{m}}$ ) was chosen for our assay. At higher concentrations, GALT. activities were lower.

Table $V$ provides a summary of the optimum conditions of the present coupled assay for GAIT.

\subsubsection{The Internal Standard}

As discussed previously (see Preliminary Studies, Section 3.3.1, p. 53), the necessity of using an internal standard arose as a result of the variable quenching of the resorufin fluprescence caused by the variation of hemoglobin from sample to sample.

In-the initial stages of the optimization, the internal standard was made by adding the standard amount of resorufin to the assay mixture itself in order to make the procedure easier. The procedure followed was as described in CHAPTER 2, Section 2.3 .22 ca, p. 23 with the following modifications: 1) everything except the "substrate" solution was added to a curvette and allowed to incubate for several minutes at $\left.37^{\circ} \mathrm{C} ; 2\right)$ cuvette was placed in fluorometer and the instrument was "zeroed"; 3) the resorufin was added and the RFI measured; 4) the "substrate" solution was then added to the curette; 5 ) the mixture was allowed to incubate at $37^{\circ} \mathrm{C}$ for 3 minutes and then the rate of increase in fuorescence measured; 6) steps 1-5 were repeated for the blank by substituting water for UDPG. 
FIGURE 18

EANES-WOOLF PLOT OF GAIT ACTIVITY WITE RESPECT TO UDPG

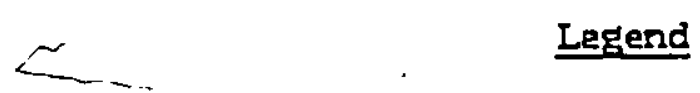

GAIT activity in two normal pooled samples was determined using the present coupled assay in the presence of $2.3 \mathrm{mM} \mathrm{GAL1P}$ and varying amounts of ODPG. Procedure followed was that described in CHAPTER 2, Section 2.2.3.2 c., p. 23.

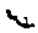


FIGURE 18

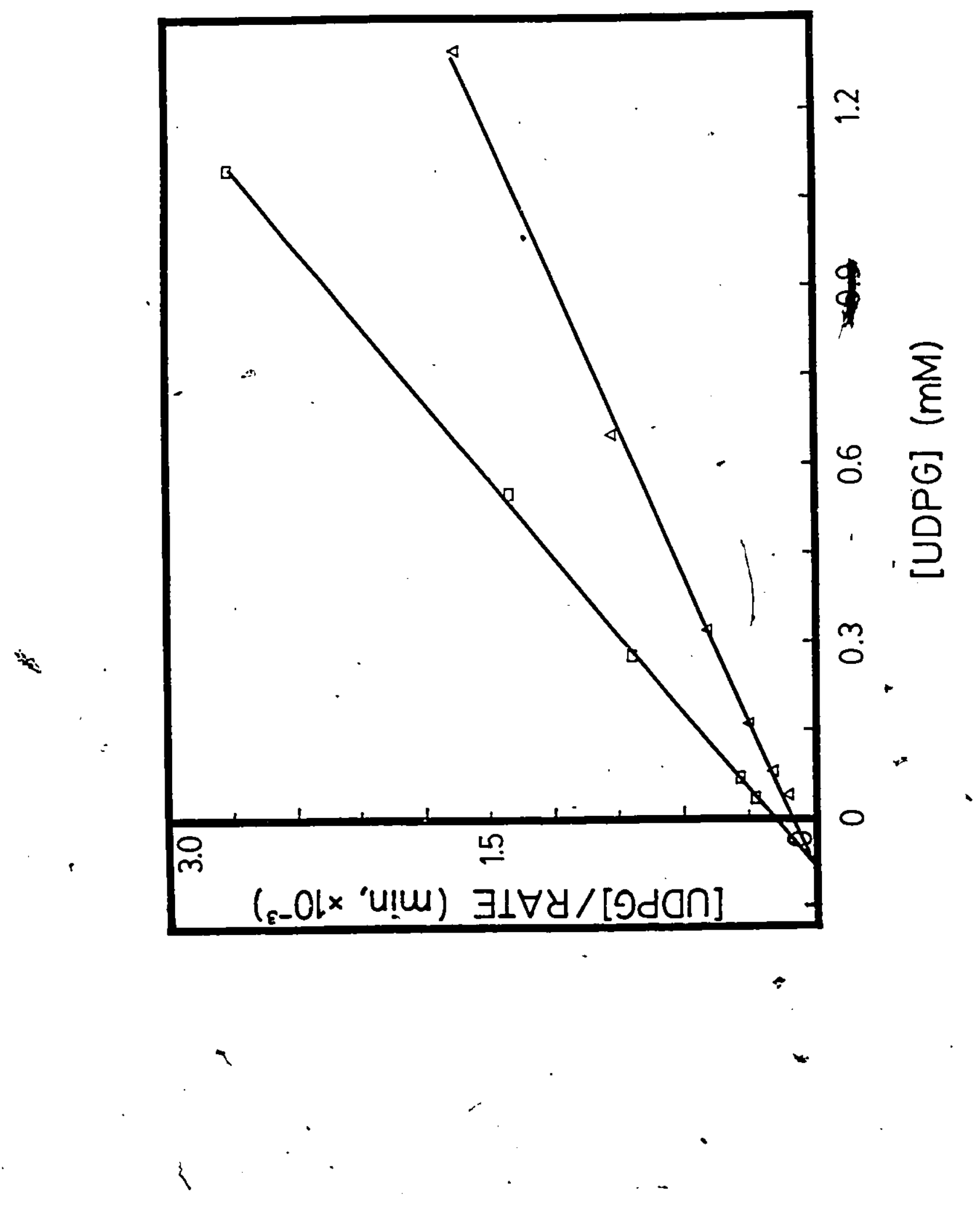


TABIE V

FINAL CONDITIONS FOR COUPLED ASSAY OF GALT

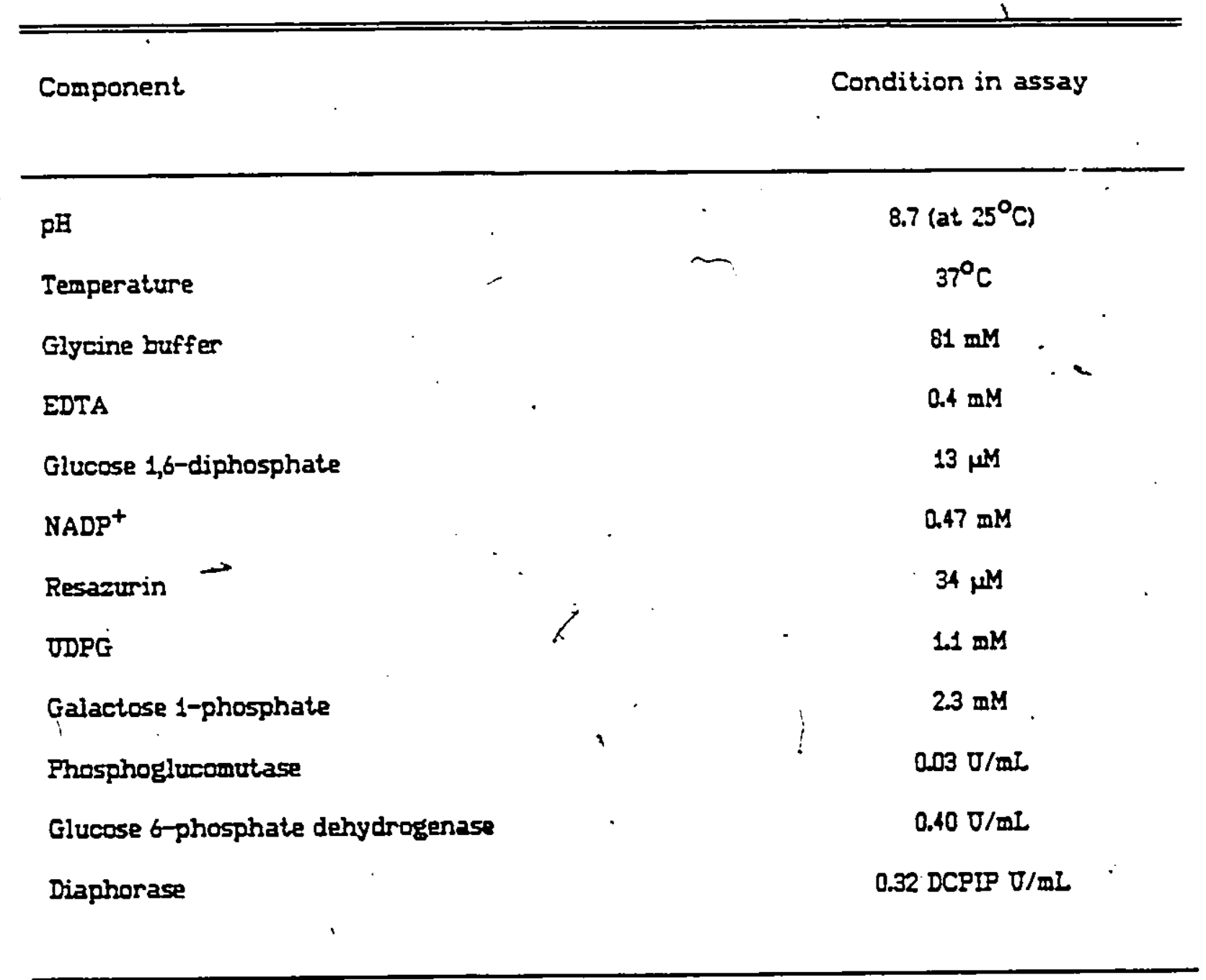

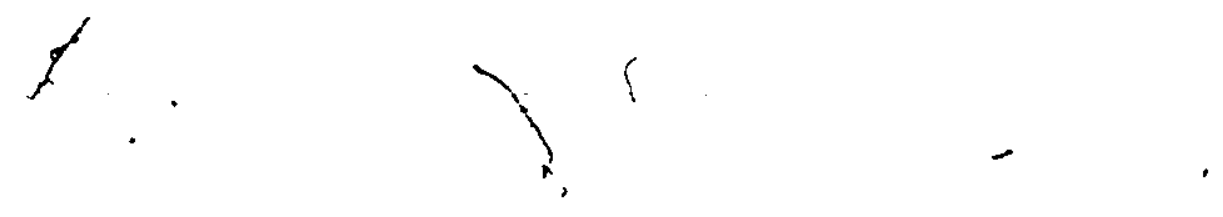


-

As the optimization proceeded, it became clear that lower GAIT activities than expected were being recovered. The ffect of adding different amounts of resorufin was, therefore, tested and the results are shown in Figure 19. As can be seen, adding resorufin to the assay mixture directly caused a decrease in GAII activity, proportional to the concentration of resorutin.

It was believed that the phenomenon was due to the effect of the resorufin on diaphorase activity and the hypothesis was tested. Inhibition of diaphorase activity was observed (Figure 20) which was proportional to the amount of resorufin added.

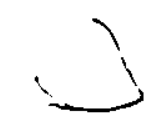

It was obvious then that the internal standard had to be prepared separately rather than by adding the resorufin to the assay mixture itself. It was known that the resazurin and the sample itself quenched the resorufin sigrial and had to be present in the internal standard. To see whether any other comporent of the assay mixture had to be included, the fluorescençe coefficient of resorufin in the presence of each of the UDPG, enzyme and substrate solutions pas compared to that when only resazurin and sample were present. The results shown in Table VI, indicate that there is no further quenching of resorufin by any other component of the GALT assay mixture. In studies, thereafter, only the sample and resazumin were present in the internal standard, as described in CHAPIER 2, Section 2.3.2.2. c.,p. 23. The amount of resorufin used in the internal standard was chosen so that,a reasonable RFI was obtained at the same fluorometer settings used to monitor the GAII activity. 


\section{FIGURE 19}

EFFECT OF ADDING RESORUFIN TO ASSAY MIXTURE ON GALT ACTIVITY

\section{Legend}

GAII activity in hemolysate was determined using the present coupled assay, as described in CHAPTER 3, Section 3.3.2.7, p. 69. To $410 \mu$ if of buffer solution ( $100^{\circ} \mathrm{mM}$ glycine, $0.5 \mathrm{mM}$ EDTA, $\mathrm{pH} 8.7$ ) at $37^{\circ} \mathrm{C}$, were added $10 \mu \mathrm{L}$ of hemolysate, $20 \mu \mathrm{L}$ of resazurin $(0.85 \mathrm{mM}), 20 \mu \mathrm{L}$ of UDPG $(27.5 \mathrm{mM})$, and $20 \mu \mathrm{L}$ of enzyme solution ( $0.75 \mathrm{U} / \mathrm{mL}$ PGM, to U/mL G6PDE, $8.0 \mathrm{DCPIP} U / \mathrm{mL}$ diaphorase). The fluorescence of this solution was set to "zero", after which $10 \mu$ of resorufin (varying concentrations) was added and the RFI recorded. The GAII reaction . Was initiated by adding $10 \mu[$ of substrate solution (0.12 M GAL1P, 0.024 M NADP+, $0.64 \mathrm{mM} \mathrm{G1,6DP}$, and followed at $37^{\circ} \mathrm{C}$ by monitoring the rate of increase of fluorescence $\left(\lambda_{\text {exc }}=520 \mathrm{~nm}, \lambda_{\text {emit }}=585 \mathrm{~nm}\right)$. Blank rates were determined by replacing UDPG with water, and were subtracted.
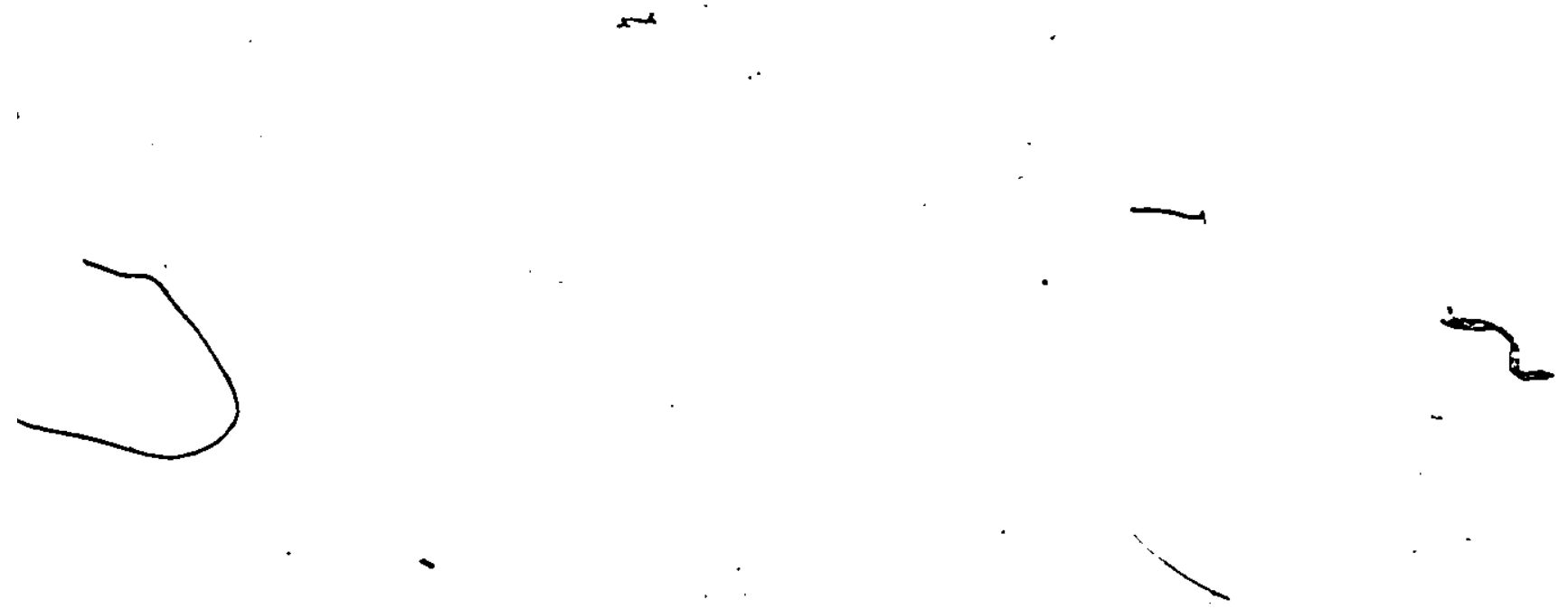
FIGURE 19

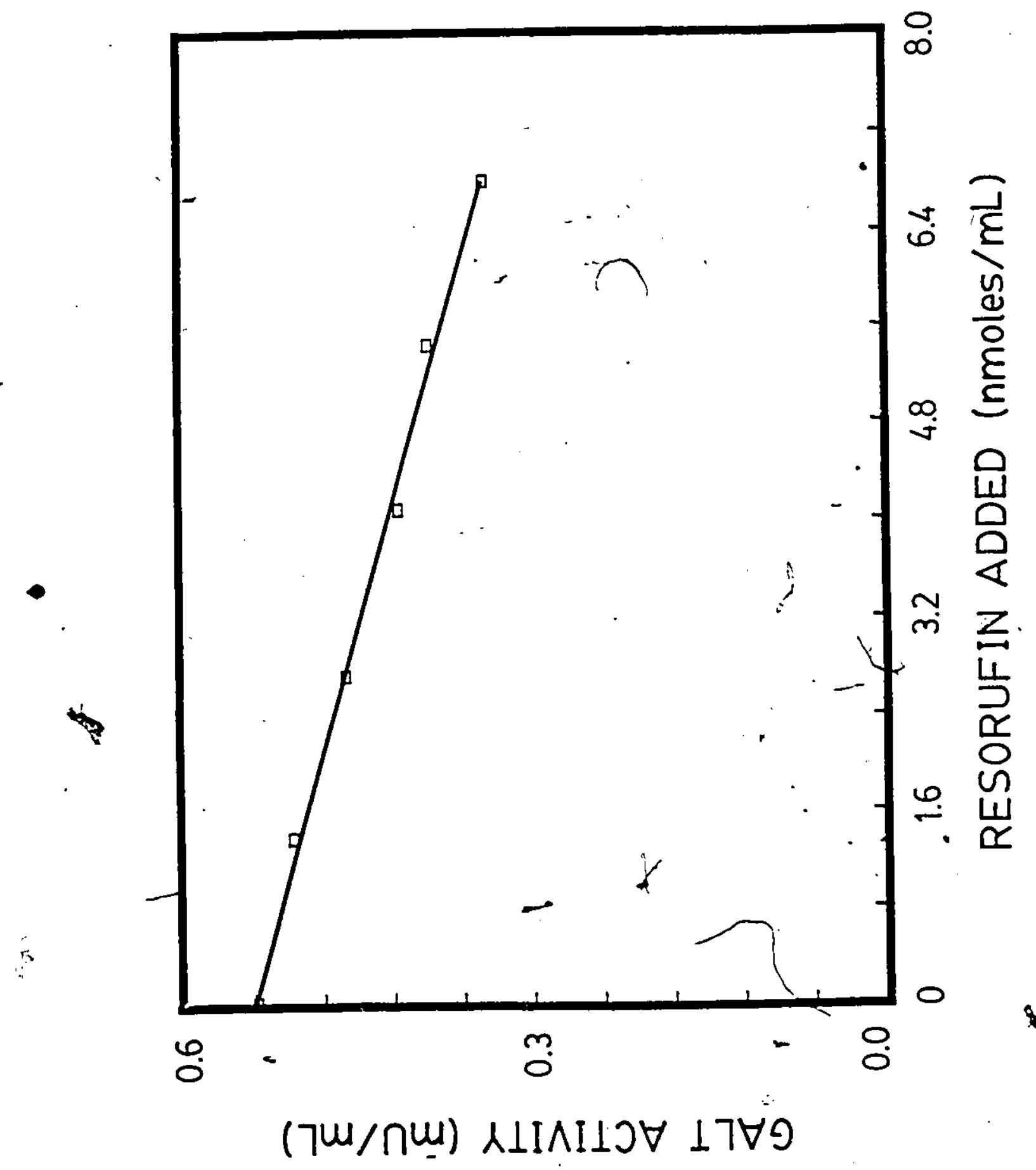


FIGURE 20

EFFECT OF ADDING RESORUFIN TO ASSAY MIXTURE ON DIAFHORASE ACTIVITY

\section{Leģend}

$r$

Diaphorase activity was determined at pH $8.7,37^{\circ} \mathrm{C}$, by monitorifig the rate of increase in fluorescence (nexe $=568$, hemit $=582 \mathrm{~nm}$ ).

To a solution containing $450 \mu \mathrm{L}$ buffer (100 mM glỵcine, $0.5 \mathrm{mM}$ EDTA), $20 \mu$ t resazurin $(0.85 \mathrm{mM})$ and $10 \mu$ NADPH $(1.0 \mathrm{mM})$, were added $10 \mu$. of resorufin solution (varying concentrations). The reaction was initiated by adding $20 \mu$ of diaphorase (8.0 DCPIP units/mL).

Rates of reaction are expressed as a percentage of that obtained when no resorufin was added.

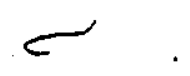


FIGURE 20

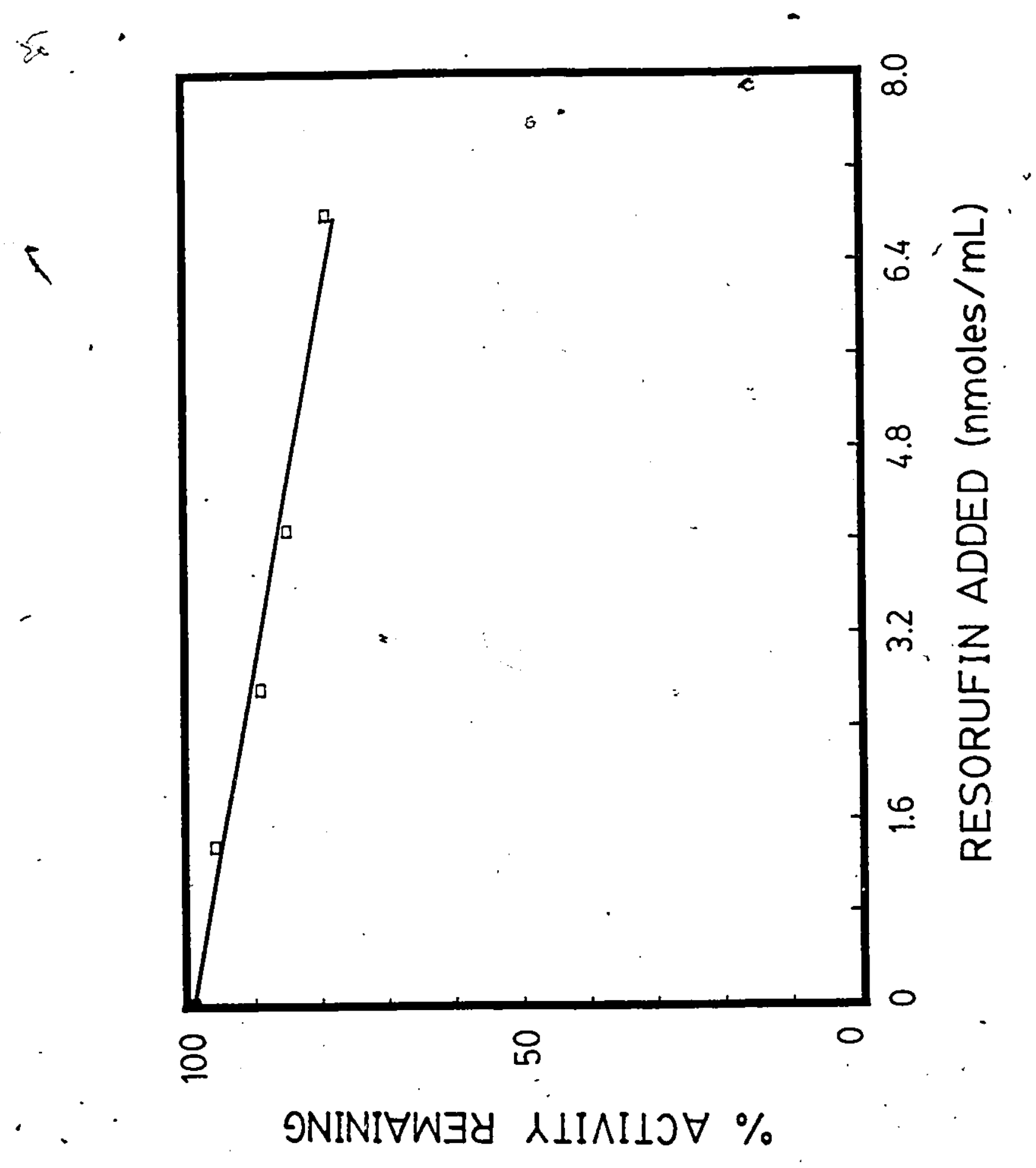


TABIE VI

FLUORESCENCE COEFFICIENT OF REŚOROFIS TN THE PRESENCE OF EACH COMPONEATT OF GALT ASSAT MIXTURE

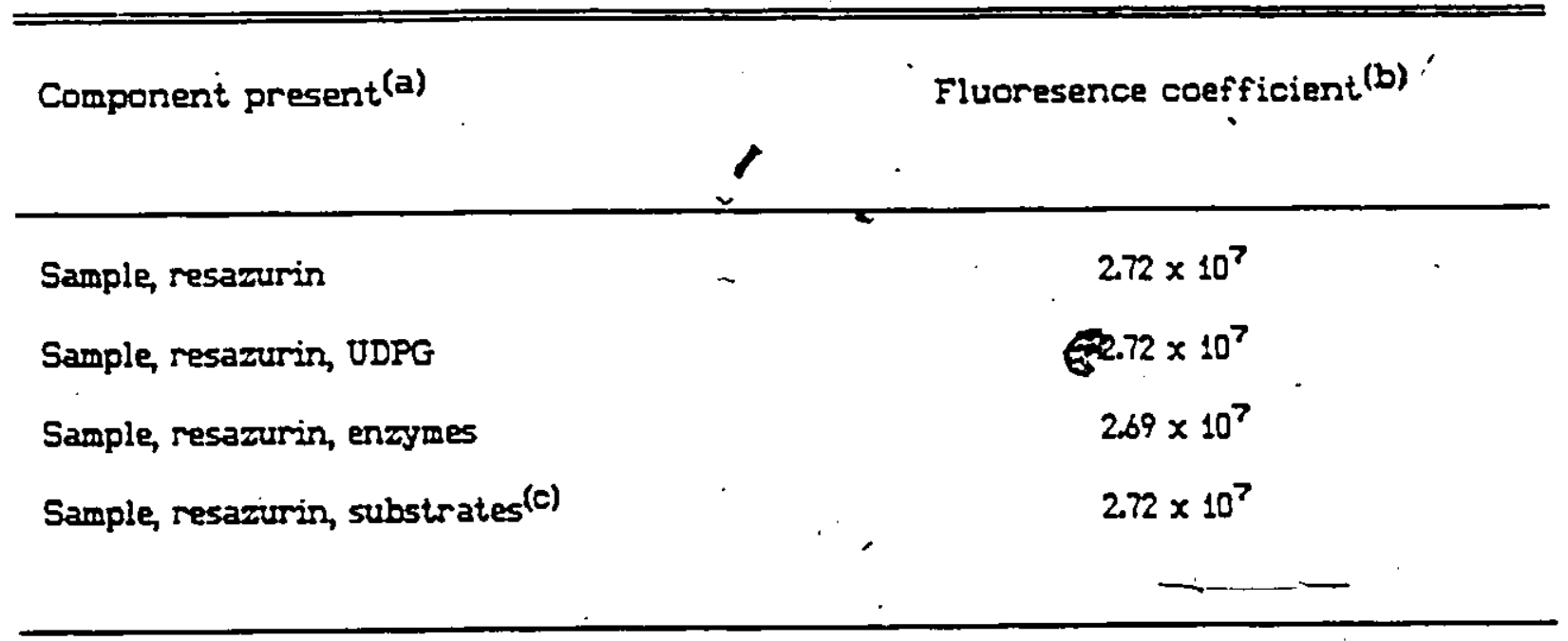

(a) Each component was present in the concentrations indicated in Table V.

(b) Fluorescence intensity was measured in duplicate at $(5, x 10)$ by first zeroing the instrument with mixture containing appropriate amounts of each component indicated, and then adding $10 \mathrm{\mu L}$ of $2.0 \times 10^{-4} \mathrm{M}$ resorufin.

(c) Substrates comprised of GAI1P, G1,6DP and NADP'. 


\subsection{3 - Einearity of GALT Assay}

The linearity of the ĠALT assay was determined using a commercial preparation of GAIT. Figure 21 shows that the assay is linear up to about i.4 $\times 10^{-3}$ units/mL and can detect less than $1 \times 10^{-4}$ units of GAIT. It should be noted that in this study, 6-PGADH was not present in the assay mixture.

\subsubsection{Precison}

The within-run $C V$ of the UDPG-consumption method (5), was $5.4 \%$ at 318 O/kg Hb. The within-run precision for the present GAIT assay at three different levels of GAIT activity is shown in Table VII. The higher CV seen for our assay is primarily due to the manner in which-the internal standard was prepared, i.e., the small volume of resorufin used led to large variability of fluorescence coefficient from run-to-rus.

The significantly higher $C V$ in the GAIT Deficient Ccritrol can be attributed to the fact that the commercial preparation contained a substarice or substances capable of reducing resazurin. Due to the dynamic blank, the determination of the fluorescenge coefficient of the internal standard was difficult.

\section{3 .5 Stability of GAIT}

The stability of GALT in hemolysates stored at $4^{\circ} \mathrm{C}$ and $-20^{\circ} \mathrm{C}$ is shown in Table VIII. The results indicate that GAIT is more stable at $4^{\circ} \mathrm{C}$, and should be assayed within one day after the preparation of the hemolysate. 
80

FIGURE 21

LINEARITY OF GAIT COUPLED ASSAY

Legend

Dilutions of a stock solution, containing a commercial preparation of GALT, were made with 1\% BSA and assayed.

GALT activity was determined by the present coupled assay as described in CEARIER 2, Section 2.2.3.2 c., p. 23. It should be noted that 6-PGADH was not present in the assay mixture for this study.

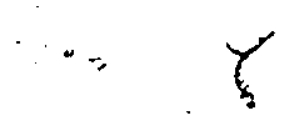

$\approx$

$\underbrace{2}$<smiles>CCCCCCC</smiles> 
FIGURE 21

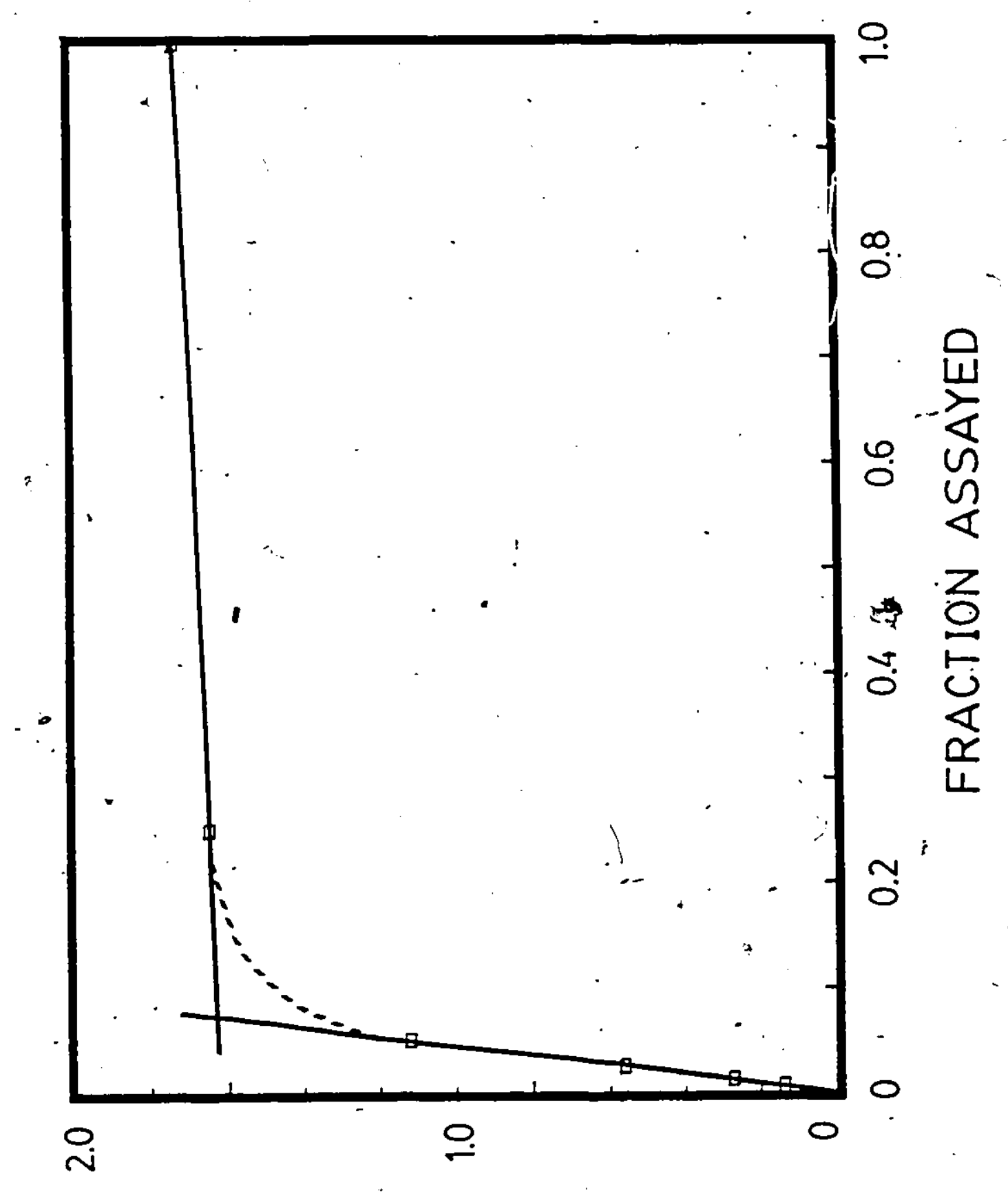

$(7 m / n m) \lambda \perp I \Lambda I \perp J \forall \perp 7 \forall 0$ 
TABLE VII

WITHIM-RUN PRECISION OF PRESENT COUPLED ASSAY FOR GALT ${ }^{(a)}$

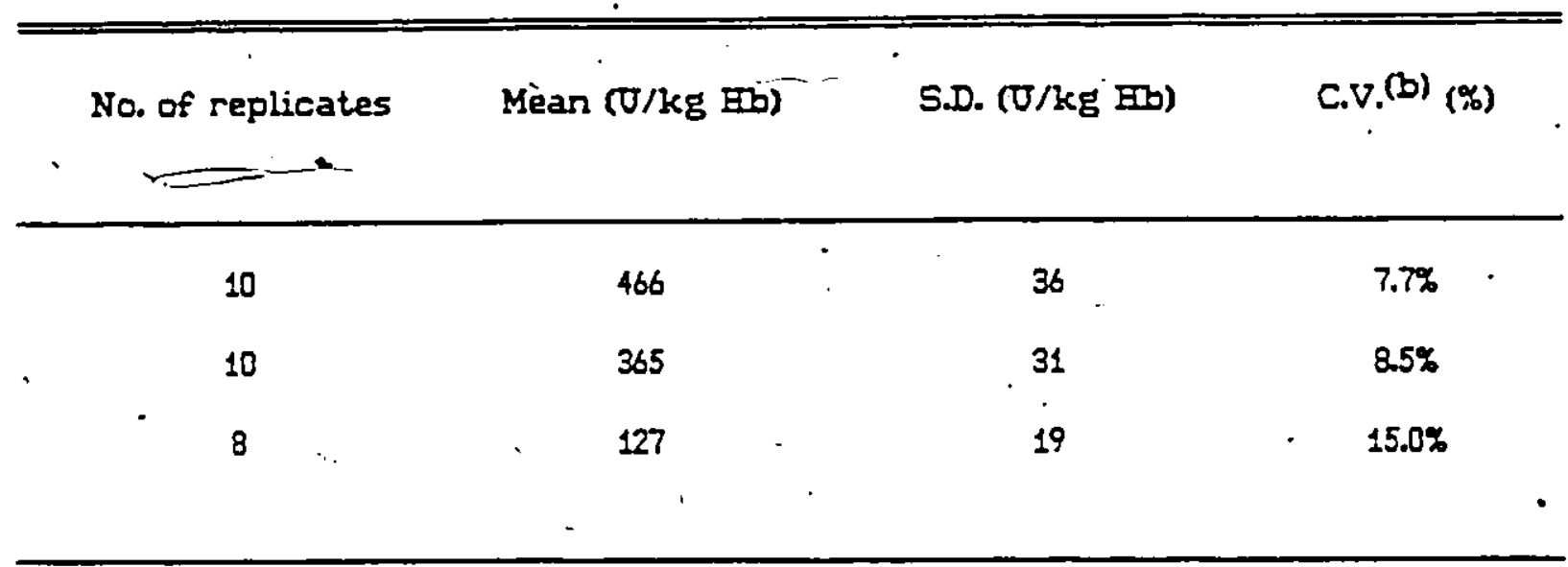

(a) GAIT activity was determined in $1: 1$ hemolysates, as described in CEAPTER 2, Section 2.2.3.2 c., p. 23 .

(b) C.V. = S.D.JMean $\times 100$

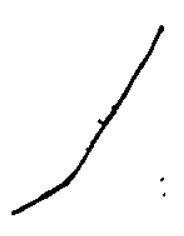


TABLE VIII

STABIITTY OF GALT IN HEMOLYPATES(a)

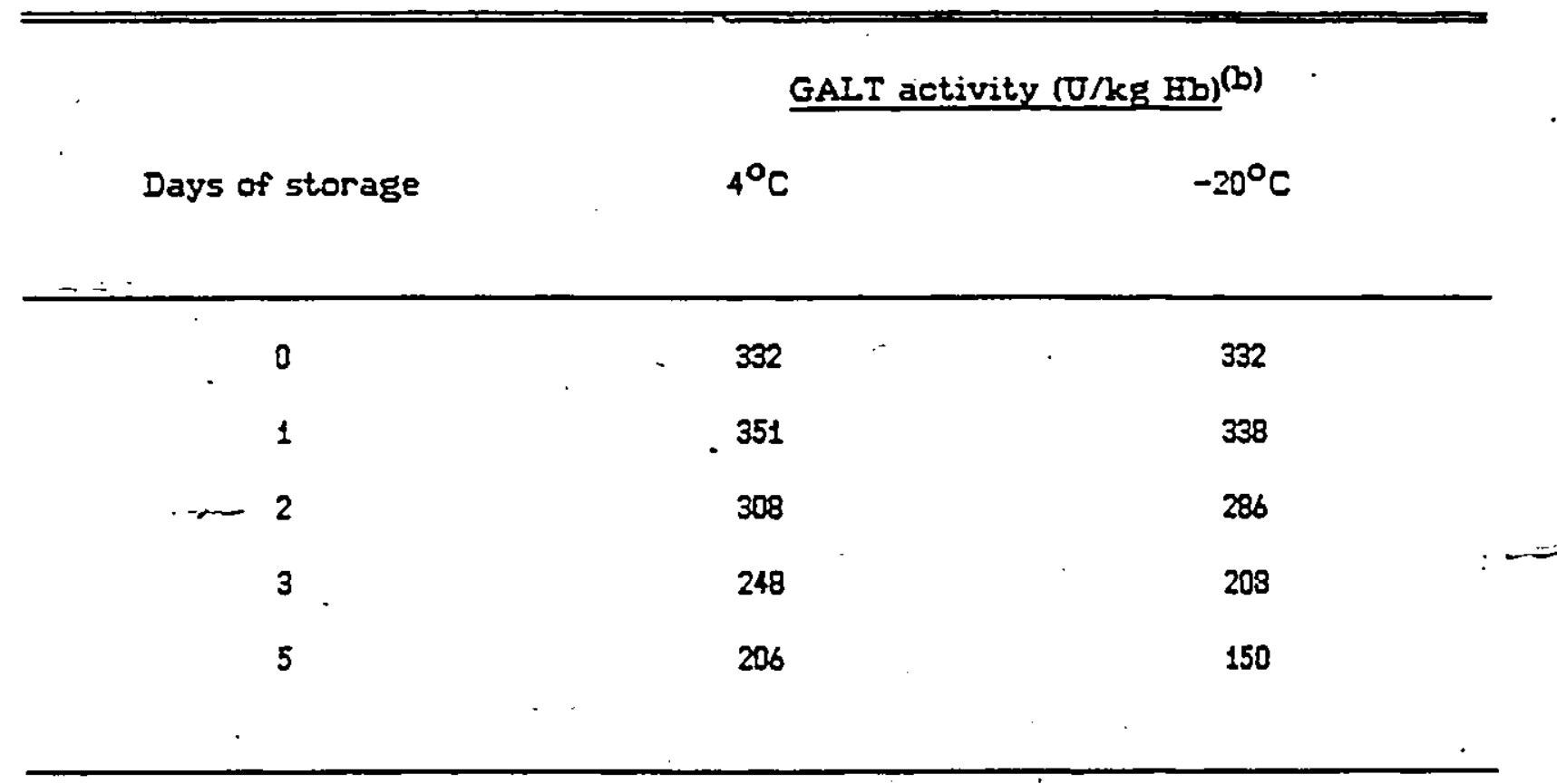

(a) Hemolysates pere 1:1 packed cell volume: water volume.

(b) GALI activity was determined in duplicate as Hescribed in CEAPTER 2, Section 2.2.3.2 c., p. 23. 
For samples which must be kept longer before analysis, it has been suggested by other porkers that the sample be stored as whole blood or packed calls at $4^{\circ} \mathrm{C}(14,25)$.

\section{3 .6 Comparison of Methods}

The present assay was compared with the reference ODPG-consumption method of Ibbott (5). There is good agreement $(r=0.977$ between the two methods (Figure 22). The equation of the line of best fit $(y=5.4+0.82 x)$ does not pass through the orifin, but:this is not clinically significant. It should be noted that one point was discarded as a statistical outlier (55). If this point is included; the statistical parameters are: $r=0.958, y=26.5+0.77 x$.

Analysis of the data using the t-test revealed that a statistically real bias exists between the two methods. Indeed, the slope of the regression line $(<1.0)$ suggests that a proportional error exists in our method (56).

The suggestion of a proportional error raised the possibility that there was an incomplete transfer of electrons from NADPE to resazurin. This idea was tested by converting known amounts of NADPE to resorufin using diaphorase and determining the percent recovered. Table IX shows that, indeed there is not an'equivalence between the amount of NADPH added and the arount of resorufin produced. In fact, there is only about a $40 \%$ efficiency in the presence of hemolysate. For this reason, GALT activity in our assay has been quoted as poles resorufin produced per minute.

If one considers our coupled assay, in which it is assumed that 2 moles of NADPE are produced per mole of' UDPG consumed, one would then expect about $40 \times 2 \times 2$ or 0.80 moles of resorufin are produced per mole of UDPG consumed. This value agrees fairly well with what was seen in the Comparison of Methods study, i.en a slope of 0.82 and explains the discrepancy between the two methods. 
85

FIGURE 22

COMPARISON OF PRESENT COUPLED ASSAY WITH UDPG-CONSUMPTION METHOD

\section{Legend}

Normal samples, the GALT Deficient Control and some samples, created by the combination of the two, were analyzed in duplicate by the present coupled assay (as described in CEAPTER 2, Section 2.2.3.2 c., p. 23) and the UDPGconsumption method of Ibbott (5).

GALT activity for the present assay is expressed as moles resorufin produced per minute/kg $\mathrm{Hb}$ at $\mathrm{pH} 8.7,37^{\circ} \mathrm{C}$. GALT activity for the UDPGconsumption method is expressed as umoles UDPG consumed per minute/kg Hb at $\mathrm{pE} 8.7,37^{\circ} \mathrm{C}$

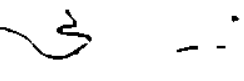


FIGURE 22

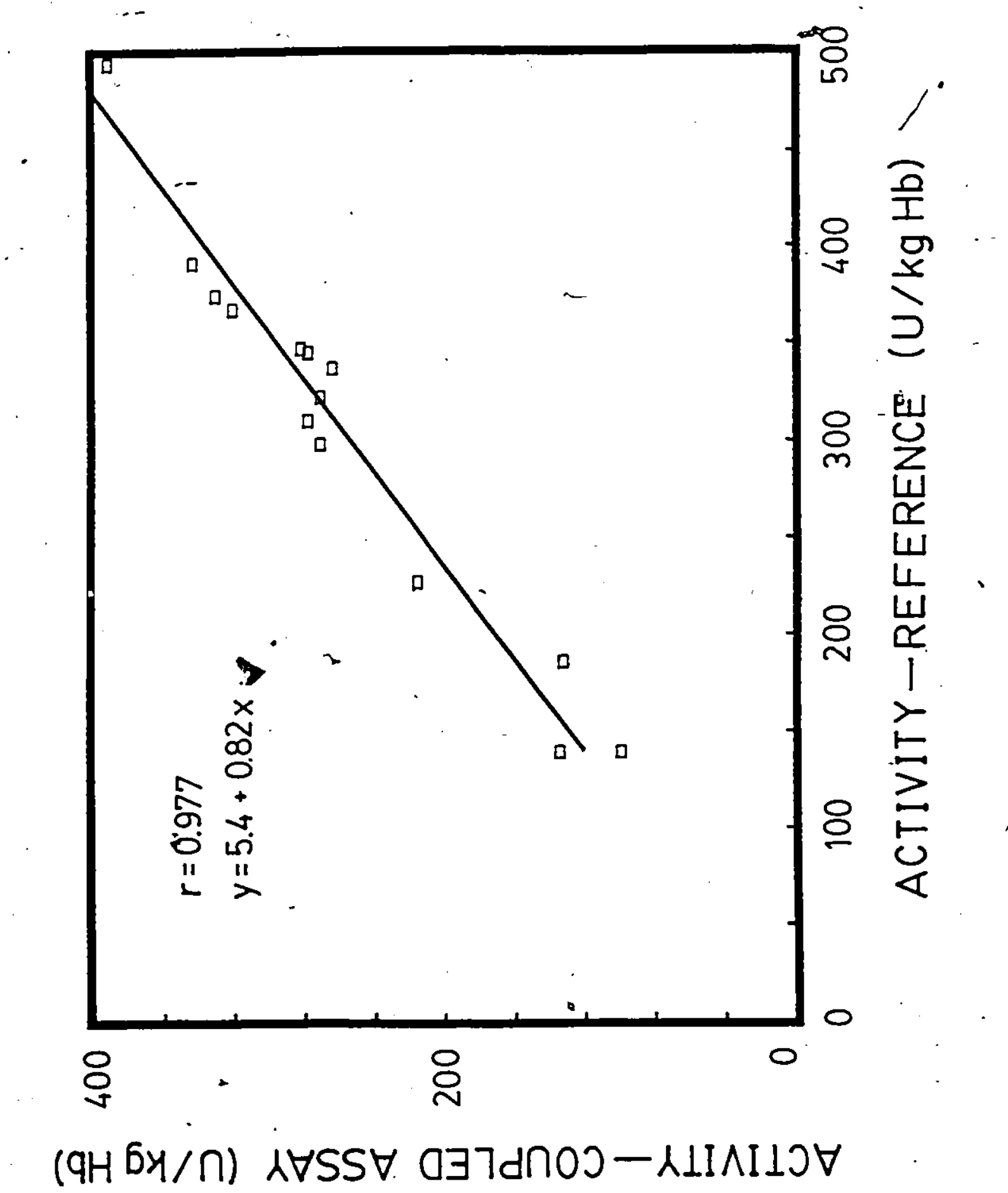


TABLE DX

PERCENT OF MADPH REDUCMC EQUTVALENTS

TRANSFERRED TO RESAZURN'(a)

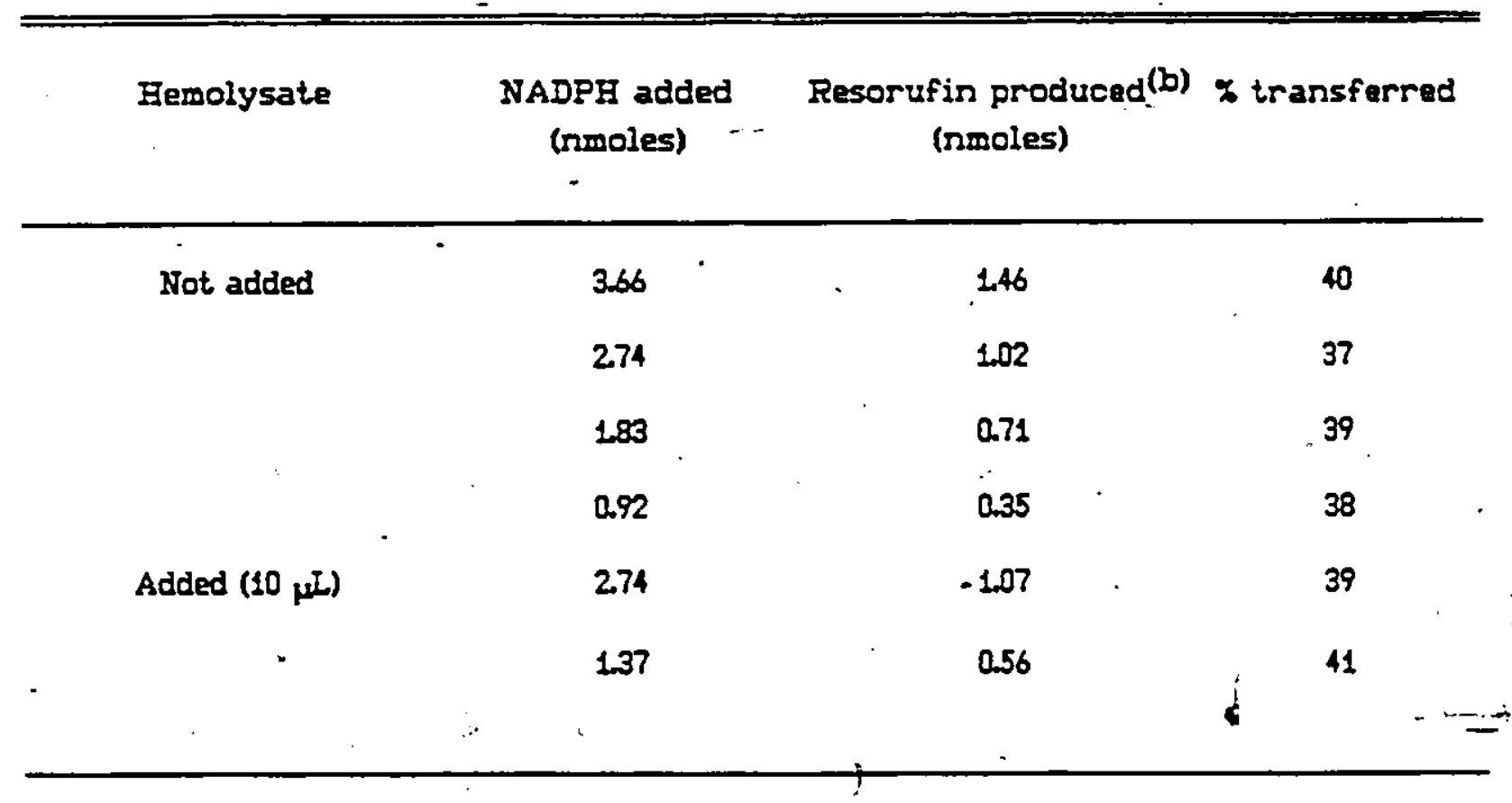

(a) Determined, in duplicate, at $\mathrm{pH} 8.737^{\circ} \mathrm{C}$, using $0.32 \mathrm{U} / \mathrm{mL}$ diaphorase, 34 M resazurin.

(b) Determined from a calibration curve, generated by measuring the RFI of known amounts of resorufin in the presence of diaphorase and resazurin (NADPH was omitted). A second calibration curve was generated for RFI of resorufin in the presence of $10 \mu$ of hemolysate. 
It is difficult to say what the exact cause of the inefficiency of the resazurin/NADPE/diaphorase system is, since it has not been discussed by previous workers using the system. Diaphorases, by their very nature, can transfer electrons to a variety of compounds.

It has besn shown by other workers $(57,58)$ that resorufin can undergo further reduction to a compound (dihydroresorufin), which is likely nonfluorescent. This fact, along with the observation that the addition of resorufin caused a decrease in the diaphorase activity, raised the question of whether resorufin, as it is produced, competes with resazurin for the electrons from NADPF. This was tested by trying to reduce resorufin using $0.32 \mathrm{DCPIP} \mathrm{U} / \mathrm{mL}$ diaphorase and $20 \mu \mathrm{M}$ NADPF at pE $8.7,37^{\circ} \mathrm{C}$. When $1.3 \mathrm{nmoles} / \mathrm{mL}$ of resorufin (on the order of what is produced in the GAIT assay) was used, a slow rate of decrease in fluorescence was observed. Howeyer, this corresponded to a rate on the order of $10^{-6}$ pmoles resorufin consumed per minyte, significantly lower than the rates encountered in the GII assay. This would suggest that resorufin does not cumpete with resazurin for the electrons.

Worsfold et 르. (59), using phenazine methosulfate as a catajyst for hydrogen transfer from NADPE to electron acceptors, noted that oxyger competes with the reaction to a significant extent. This raised the question of whether oxygen may act in the same way when using diaphorase as a catalyst. Kaplan et al. (60) performed the eariy studies on diaphorase from Clastridium kleryveri. They found that the rate of reaction using oxygen as an electron acceptor is only about $1 \bar{x} 10^{-3}$ times that when using DCPIP. In our assay, 0.32 DCPIP U/mL of diaphorase are used, which is the equivalent of about $0.3 \mathrm{~mJ} / \mathrm{mL}$ in terms of oxygen. This is on the same order of magnitude of GALT activity being measured and susfests that axygen may be a source of interference. This, however, 
would have to be proven experimentally under the conditions of our assay, namely pH 8.7 and $37^{\circ} \mathrm{C}$.

\subsubsection{Recovery Study}

The results from the recovery study are shown in Table-X. With the exception of one run, greater than $100 \%$ recoveries were obtained for the entire range of GAIT activity tested. It should be noted that the "added" GAIT was assayed in a mixture not containing 6-PGADF. It was assumed that when added to hemolysates, containing 6-PGADH, twice as much activity would be observed.

The work of Massa and Farias (61) showed that the-reduction of a tetrazolium salt (thiazolyl blue tetrazolium bromide) by NADH, in thé presence of phenazine methosulphate (PMS) was enhanced by the presence of erythrocyte membrane. This led us to wonder whether the erythrocyte membranes present in our hemalysate preparations were acting similarly, to enhance the reduction of resazurin.. A recovery study of NADPH, in the absence of hemolysate was, therefore, performed (Table IX). An average recovery of $38 \%$ was seen, as comparedto $40 \%$ in the presence of hemolysate. The difference does not seem significant enough to explain the greaterer than 100\% recoveries of FALT seen in hemolysates.

In the determination of the activity of "added" GALT, no activator was present in the assay mixture. The presence of reduced glutathione in erythrocytes (13) may have led to the activation of GAIT when added to the hemolysates and produced greater than $100 \%$ recoveries. This hypothesis, however, must be tested experimentally. 
TABIE $\mathbf{X}$

\section{RECOVERY OF GALT IN HEMOLYSATES}

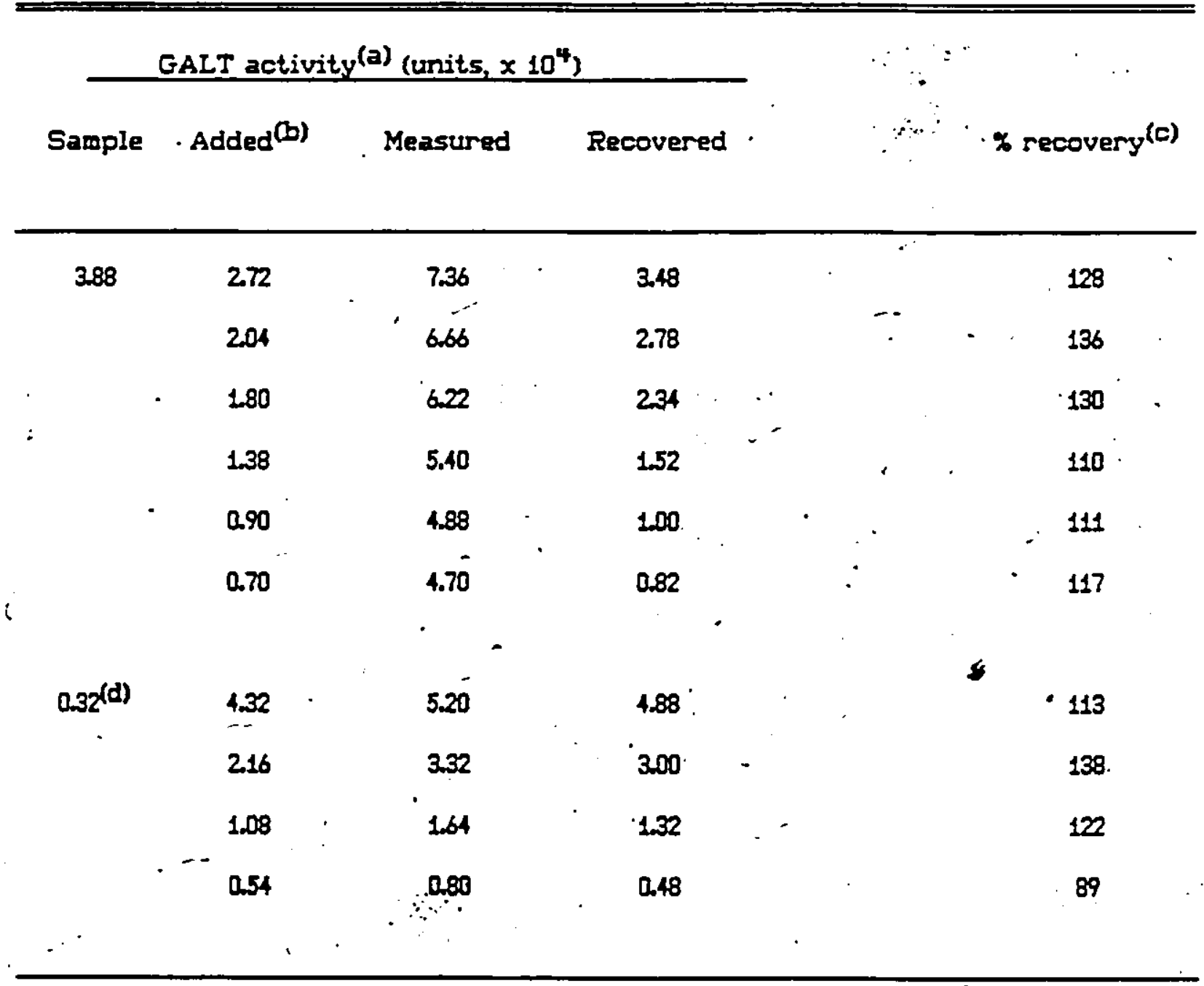

(a) Determined as described in CEAPTER 2, Section 2.2 .3 .2 c., p. 23.-

(b) Commercially prepared GALT was used.

(c) $\times$ Recovery $=$ Recovered/Added $\times 100$

(d) Sample was GAIT Deficient Control. 
3.3.8 Reference Range of GAIT in Erythrocytes

Figure 23 shows the time course of the present GALItissay for normal - and deficient samples. The assay clearly distinguishes between normal and deficient samples.

A small clinical study (23 samples) was carried out. The distribution of GAIT activity in patients is shown in Figure 24. Values of GAIT in normal samples ranged from 240-456 $\mathrm{O} / \mathrm{kg} \mathrm{Hb}$, with a mean value of $322 \mathrm{U} / \mathrm{kg} \mathrm{Fb}$ and standard deviation of $52 \mathrm{~J} / \mathrm{kg} \mathrm{Hb}$.

Q

I 
92

FIGURE 23

Legend

The increase in fluorescence $\left(\lambda_{\text {exc }}=520, \lambda_{\text {emit }}=585 \mathrm{~nm}\right)$ using the present coupled assay (as described in CHAPTER 2, Section 2.2.3.2 c., p. 23) is shown for hemolysates containing normal and deficient levels of GALT. UDPG was included in the SAMPLE and omitted from the BLANK. Reactions were initiated with the "substrate" solution, ie., GAL1P, NADP" and G1,6DP. 
)

$\checkmark$

FIGURE 23

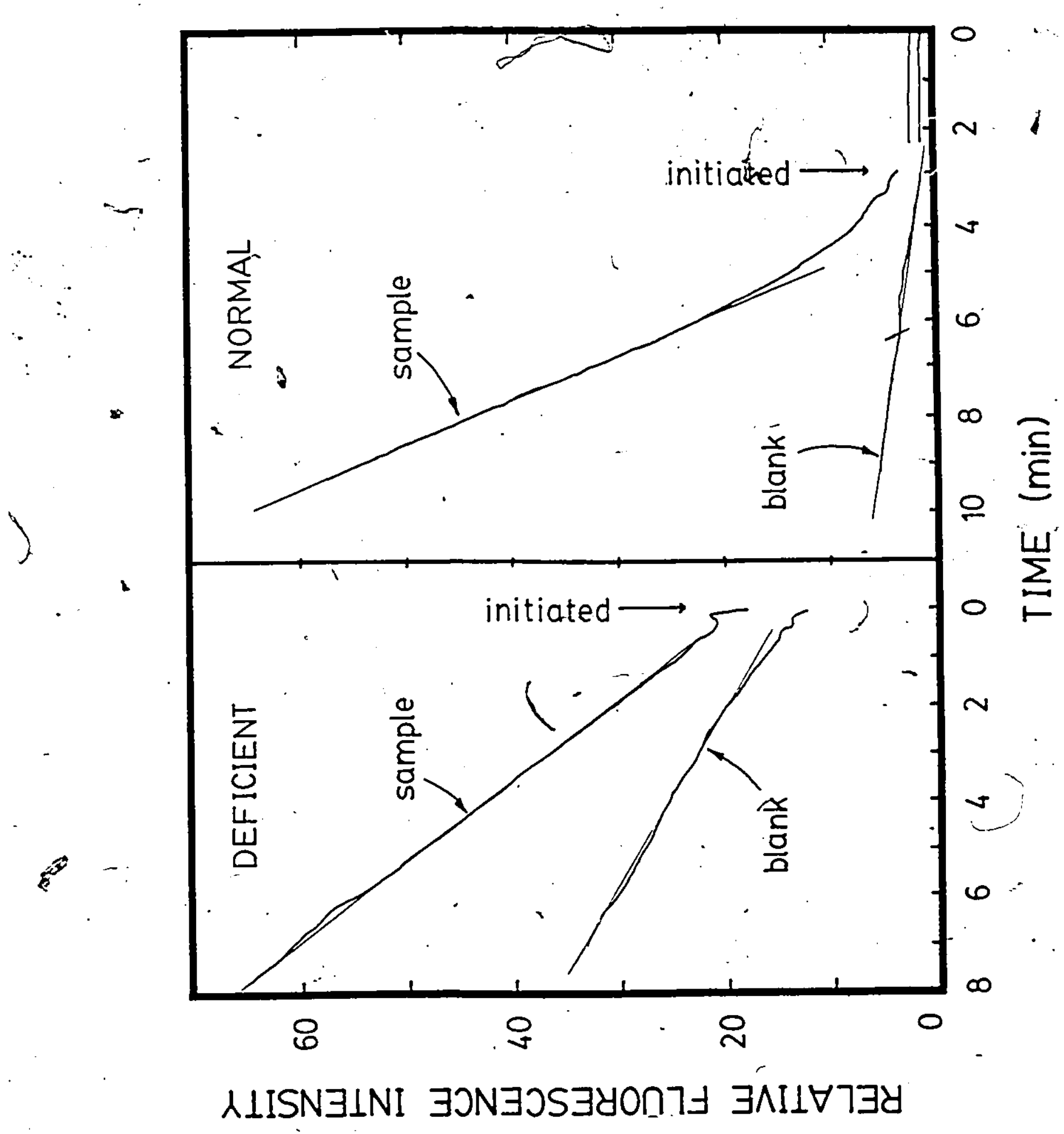




\section{FIGURE 24}

\section{DISTRIBUTION OF GALI ACTIVITY IN PATIENTS}

\section{Legend}

GALI activity was determined in hemolysates in duplicate using the present coupled assay as desctibed in CHAPTER 2, Section 2.2.3.2 c., p. 23. Deficient sample was the GALI Deficient Control.

1

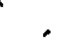


FIGURE 24

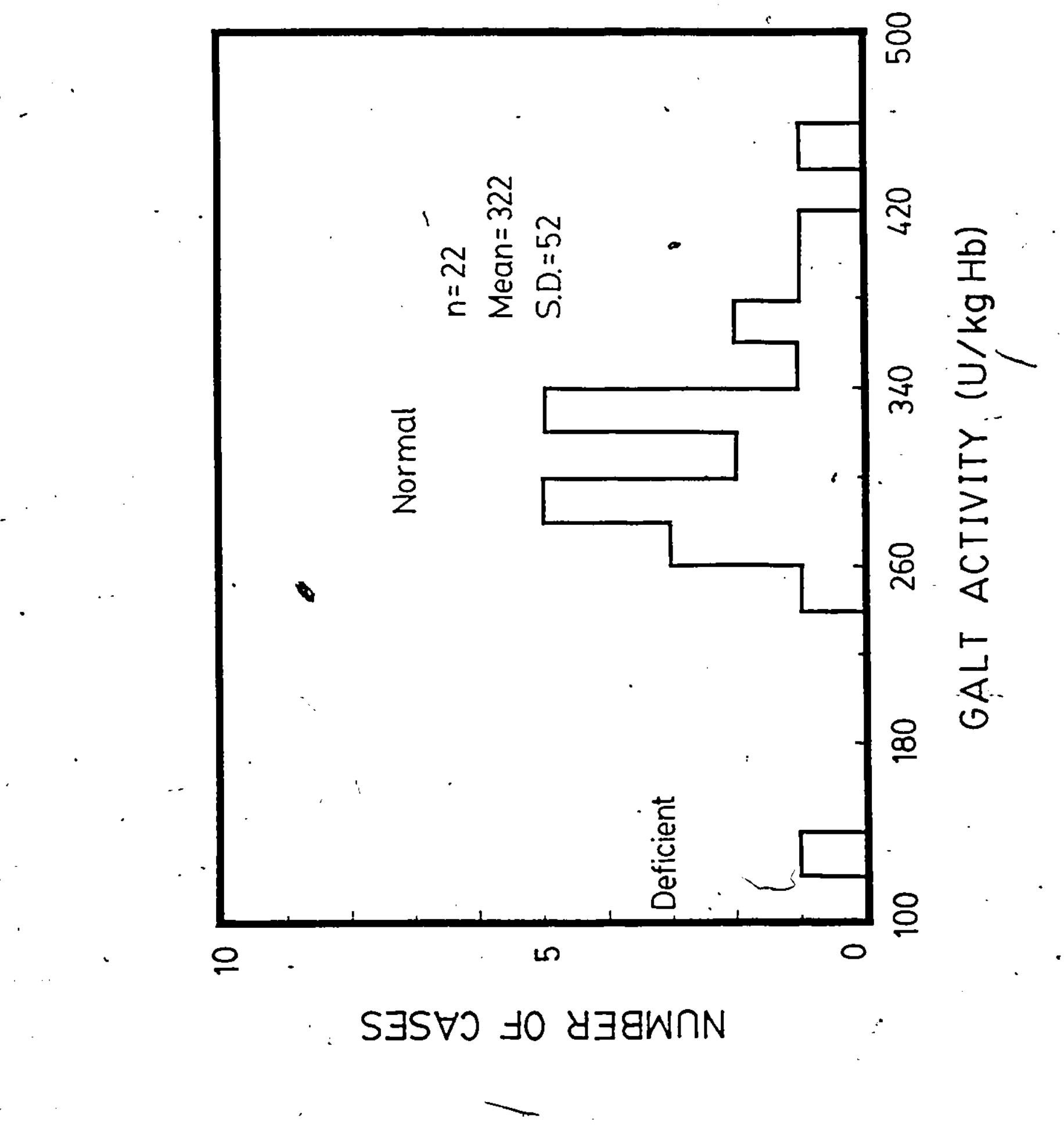




\section{CHAPTER 4}

\section{SUMMARI AND CONCLUSTOKS}

\subsection{The Resazurin/Diaphorase System}

1: We have found that the specific activity of diaphorase when using resazurin $(6.7 \mu \mathrm{M})$ as a substrate is only about $2 \times 10^{-3}$ that when using DCPIP as aísubstrate. This differs from the findings of Guilbault (53) who found thie factor to be only about $5 \times 10^{-2}$.

2. Specific activity of diaphorase can be increased by using higher concentrations of resazurin. The concentration chosen is influenced by the size of fluorometric cuvette used. In a 3.0-mL curette, concentrations above $13.4 \mathrm{\mu M}$ result in lower signals due to the quenching of the fluorescence by resazurin. In a 1.0-mL cuvette, the quenching effect is

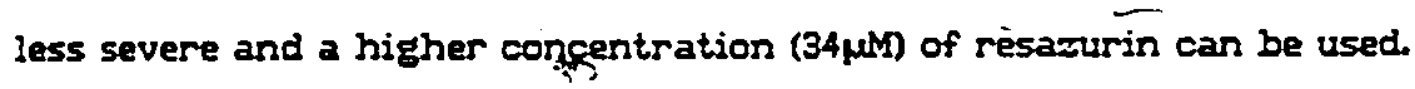

3. Diaphorase activity is first order in the concentration range up to 34 $\mu M$ of resazurin, and the $\mathrm{K}_{\mathrm{m}}$ could not be calculated from the range tested.

4. The- $\mathrm{K}_{\mathrm{m}}$ of diaphorase with respect to NADPE is dependent on the concentration of resazurin used. It is $0.78( \pm 0.04) \mu \mathrm{M}$ and 1.31 ( \pm 0.04$)$ $\mu M$ at resazurin concentrations of 6.7 and $34 \mu \mathrm{M}$, respectively.

5. We have improved on the kinetic assay of Guilbault et al. $(29,31)$ for determination of dehydrogenase activity by increasing both the amount of resazurin and diaphorase used. This has increased the sensitivity and produced calibration curves which have an extended linear range and better separation of points. 
6. Cellosolve should be replaced with water as a solvent for resazurin) solutions. This has two advantages: a) more concentrated isolutions of resazurin can be prepared; b) it eliminates the use of a teratogen.

\subsection{Present Coupled Assay for GALT}

\subsubsection{Advantages}

a. Due to the high fluorescence of resorufin, the assay is more sensitive than others, being able to detect less than $1 \times 10^{-4}$ units of CALT activity is hemolysates.

b. The present assay has a much shorter lag phase (about 3 minutes) than other wathods, which require anywhere from 15-20 minutes pre-incubation to generate enough product to be measured.

c. The procedure does not require the tedious separation steps required by UDPG-consumption and radioisotopic methods.

\subsubsection{Iimitations}

a. The method is primarily limited by the reagent blank, which is a result of the contamination of galactose 1-phosphate. Due to the low specific activity of diaphorase only very low blanks can be tolefated and this, in turn limits the amount of PGM and G6PDE that can be added to the assay mixture. This gives rise to the lag phase present in our assay.' However, if the purity of GAL1P could be improved, then the lag phase would be further reduced and possibly eliminated altogether.

b. The variable quenching of resorufin, from sample to sample, makes it necessary to include an internal standard for the assay of GALT. This is compticated by the fact that the internal standard cannot be added 
to the assay mixture itself, due to the inhibitory effect on diaphorase, but must be made up separately.

However, it may be possible to determine hemoglobin concentration in samples from calibration curves based on the quenching of resorufin. The intes

internal standard therefore could also be used for this purpose and eliminate the necessity of determining hemoglobin by a separate procedure.

c. The conversion of NADPH reducing equivalents to resorufin using . diaphorase is only about $40 \%$ in hemolysates. It is our belief that oxygen is the cause of this inefficiency, but further studies should be done in order to determine the exact cause and develop ways to counter its effect. In addition, although the inefficiency of the diaphorase/resazurin effects the sensitivity of the assay, the method correlates well with the UDPGconsumption method and is still clinically useful for the determination of GAIT activity in erythrocytes and ultimately the diagnosis of galactosemic patients. The assay clearly distinguishes between normal and deficient samples. ,

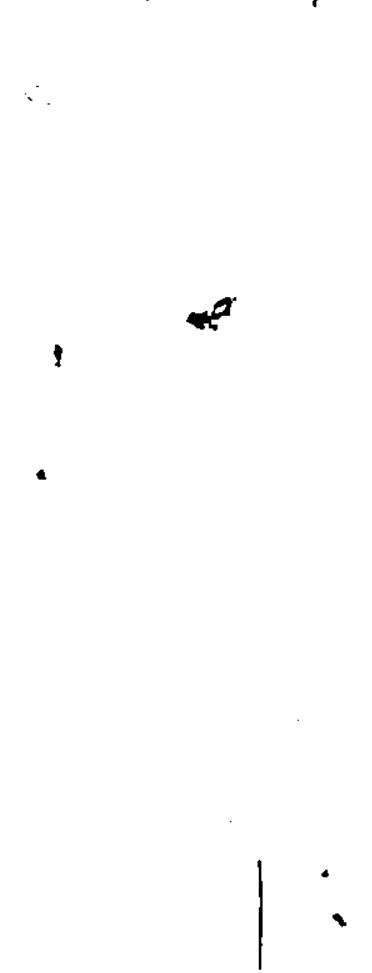


APPENDIX A

\section{CORRECTING OBSERVED-FLUORESCENCE INTENSITIES ON PERKIN-ELHER . - - FLOORESCENCE SPECTROPHOTOMETER}

The Perkin-Elmer 204 fluorescence spectrophotometer has 2 knobs which allow amplification of the observed fluorescence intensity.

The "sensitivity control" ranges from 1 to 12 . Increasing by one division approximately doubles the RFI. The "selector control" can be set at $\times 0.1, x$ 1, of $x$ 10, and this kngb causes the RFI to be multiplied exactly by the corresponding factor.

When an RFI is reported with a number in brackets beside it, this refers to the settings at which the above controls were at the time of recording. The first number in the brackets refers to the sensitivity control setting, and the second refers to the selector control setting.) (o compare RFI taken at different settings, one must take the differing amplification into consideration.

Therefore, to correct the RFI obtained at $(a, x$ b) to $(1, x$ 1) the following equation was used:

$$
\operatorname{RFI}(1, \times 1)=\operatorname{RFI}(a, x b) / 2^{(a-1)} \times b
$$

For example, a RFI of 80 at $(4, \times 10)$ would have a RFI $(1, x 1)$ of:

$$
\operatorname{RFI}(1, \times 1)=80 / 2^{(4-1)} \times 10=1
$$

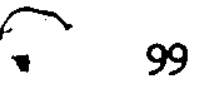




\section{APPENDIX B}

\section{CALCULATION OF GALT ACTIVITY USING AN INTERNAL STANDARD (IS)}

Activity (U/mL)

$=\mu$ moles resorufin produced $/ \mathrm{min} / \mathrm{mL}$

$\left.=\left[(\Delta F / \mathrm{min})_{\text {sample }}-(\Delta F / \mathrm{min})_{\text {blank }}\right)\right] \times \frac{\text { moles resorufin added }(1 S) / \mathrm{mL}}{\text { RFI (IS) }}$

$=\frac{\text { Net } \Delta F / \mathrm{min}}{R F I(\mathrm{IS})} \times \frac{\mathrm{mg} \text { reso. } \times 10^{-3} \mathrm{~g} / \mathrm{mg} \times 1 \mathrm{~mole} / 235 \mathrm{~g}}{100 \mathrm{~mL}} \times \frac{0.01 \mathrm{~mL}}{0.5 \mathrm{~mL}} \times \frac{1 \times 10^{6} \text { umole }}{\mathrm{mole}}$

$=$ Net $\Delta F / \min \times \mathrm{mg}$ resorufin $\times 0.852^{6} \times 10^{-3}$ unole

RFI (IS)

where, mg resorufin is the amount of resorufin weighed for stock solution;

100. $\mathrm{mL}$ is total volume of stock solution;

$0.01 \mathrm{~mL}$ is volume of resorufin solution used for IS;

$0.5 \mathrm{~mL}$ is total assay mixture volume.

To determine GAIT activity per kg of hemoglobin (Hb) in hemolysates, the following equation was used:

Activity $(\mathrm{U} / \mathrm{kg} \mathrm{Hb})=\quad$ Activity $(\mathrm{U} / \mathrm{mL}) \times 0.5 \mathrm{~mL}$ $[\mathrm{Fb}](\mathrm{g} / 100 \mathrm{~mL}) \times\left(1 \times 10^{-2}\right) \times\left(1 \mathrm{~kg} / 10^{3} \mathrm{~g}\right) \times\left(1 \times 10^{-2} \mathrm{~mL}\right)$

$=\quad$ Activity $(\mathrm{U} / \mathrm{mL})$ $[\mathrm{Hb}](\mathrm{g} / 100 \mathrm{~mL}) \times 2 \times 10^{-7}(\mathrm{~kg} \mathrm{Hb})$

where, $0.5 \mathrm{~mL}$ is volume of assay mixture;

$1 \times 10^{-2}$ is factor to convert $\mathrm{g} / 100 \mathrm{~mL}$ to $\mathrm{g} / \mathrm{mL}$;

$1 x^{\prime} 10^{-2} \mathrm{mI}$ is Nolume of hemolysate used for assay. 


\section{REFERENCE'}

1. Mayes, P.A. (1983) In: Earper's Revied of Biochemistry 19th edition Martin, D.W. Jr., Mayes, P.A. anc Rodwell, V.W. (editors). Lange Medical Publications, Los Altos. pp. 185-187.

2. Tedesco, T.A. and Mellman, W.J. (1969) In: Galactosemia. Hsia, Y.Y.D. (editor). Charles C. Thomas, Springfield. pp. 1-64.

3. Segal, S. (1972) In: The Metabolic Basis of Inherited Disease, 3rd edition. Stanbury, J.B., Wyngaarden, J.B. and Fredrickson, D.S. (editors). MeGrawHill, New York. pp. 174-195.

4. Cohn, R.M. and Roth, K.S. (1983) Metabolic Disease: A Guide to Early Recognition. W.B. Saunders Co, Toronto. pp. 276-280.

5. Ibbott, F.A. (1977) Clin. Chem. 로: 1348-1355.

6. Framier, P.D.M. and Summer, G.K. (1974) J. Lab Clin. Med. 83: 334-338̈.

7. Levy, H.L. (1973) In: Advances in Human Genetics. Harris, H. and Birschhorn, K. (editors). Plenum Fublic Corp, New York. pp. 1-104.

8. Ellis, G. and Goldberg, D.M. (1983) In: Methods of Enzymatic Analysis, 3rd edition. Volume III. Bergmeyer, H.J. (editor). Verlag Chemie Weinheim, Deerfield Beach. pp. 560-571.

9. Fensom, A.Zl and Benson, P.F. (1975) Clin. Chim. Acta 62: 189-194.

10. Ng, w.G., Donnell, G.N., Bergren, w.R., Alfi, O. and Golbus, M.S. (1977) Clin. Chim. Acta 74: 227-235. .

11. Wịlliams, V.P. (1978) Arch. Biochem. Biophys. 191: 182-191. 
12. Williams, V.P., Fried, C. and Popjak, G. (1981) Arch. Biochem Biophys. 206: 353-361.

13. Mellman, w.J. and Tedesco, T.A. (1965) J. Lab. Clin. Med. 60: 980-986.

14. Beutler, E. and Bajuda, M.C. (1966) Clin. Chim. Acta 13: 369-379.

15. Shin-Buehring, Y.S., Stuempfig, I., Pouget, E, Rahm, P. and Schaub, J. (1981)

- Clin. Chim. Acta 112: 257-265.

16. Fill, E.Z (1971) J. Cell. Physiol. 그: 419-430.

17. Mellman, W.J. and Tedesco, T.A. (1971) Science 172: 727-728.

18. Dale, G.I. and Popjałs, G. (1976) J. Biol. Chem. 251: 1057-1063.

19. Iang, A., Groebe, H., Hellkuhl, B. and von Figura, K. (1980) Pediatr. Res. 14: $729-734$.

20. Ng, W.G., Bergren, W.R. and Donnell, G.N. (1973) Ans. Buman Genet: 37: 1-8.

21. Anderson, E.P., Kalckar, H.M., Kurahashi, K. and Isselbacher, K.J. (1957) J. Lab. Glis. Med. 50: 469-477.

22. Bratthauer, R.K., Hansen, R.G., Donnell, G.N. and Bergren, W.R. (1959) Proc. Nati. Acad. Sci., U.S. 45: 328-336.

23. deBruyn, C.H.M.M., Reymakers, C., Wensing, A. and Oei, T.J. (1977) Clin. Chim. Acta 78: 145-150.

24. West.wood, A. and Raine, D.N. (1973) Clin Chim. Acta 19: 435-443.

25. Pesce, M.A, Bodourian, S.H, Barris, R.C, and Nicholson, J.F. (1977) Clin. Chem. 23: $1711-1717$.

26. Schutgens, R.B.E., Berntssen, w.J.M. and Pool, L. (1978) Clin. Chim. Acta 86: 301-305. 
27. Ng, W.G, Bergren, w.R. and Donnell, G.N. (194) Clin. Chim. Acta 10: 337-343.

28. Grodzka, Z. and Choinacki, T. (1976) Biochem. Med. 16: 182-186.

29. Guilbault, G.C. and Kramer, D.N. (1964) Anal. Chem. 36: 2497-2498.

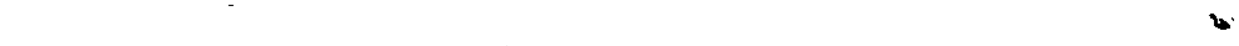

30. Udenfriend, S. (1962) In: Fluorescence Assay in Biology and Medicine. Academic Press, New Yorks p. 312.

31. Guilbult, G.C. and Kramer, D.N. (1965) Anal. Chem. 37: 1219-1221.

32. Caines, P.S.M., Thibert, R.J. and Draisey, T.F. (1985) Microchem. I. 31: 161-169.

33. Caines, P.S.M., Thibert, R.J. and Draisey, T.F. (1984) Microchem. J. 29: 168-181.

34. Caines, P.S.M, Thibert, R.J. and Draisey, T.F. (1986) Microchem. ‥ 34: 151-157.

35. Mashige, F., Imai, K. and Osuga, T. (1976) Clin. Chim. Acta 70: 79-86.

36. Barnes, S. and Spenney, J.G. (1980) Clin. Chim. Acta 102: 241-245.

37. Guilbault, G.C. and Kramer, D.N. (1965) Anal. Chem. 377: 120-123.

38. Sigma Chemical Co. (1980) Sigma Technical Bulletin, Diaphorase. เ

39. Sigma Chemical Co."(1977) Sigma Technical Bulletin, Glucose 6-Phosphate Dehydrogenase.

40. Sigma Chemical' Co. (1976) Sigma Technical Bullátin, Phosphoglucomutase.

41. Sigma Chemical Co. (1977) Sigma Technical Bulletin, 6-Fhosphogluconic Dehydrogenase.

42. Sigma Chemical Co. (1976) Sigma Technical Bulletin, UDPG Dehydrogenase.

43. Bergmeyer, H.U. (ed.) (1985) In: Methods of Enzymatic Analysis, 3rd edition. Volume VII. Verlag Chemie Weinheim, Deerfield Beach. pp. 634-635. 
44. Haid, E, Lehmann, P. and Ziegenhorn, J. (1975) Clin Chem. 21: 884-887.

45. Willard, E.H., Merritt, I.I. Jr. and Dean, J.A. (1965) In: Instrumental Methods of Analysis, 4th edition. D. Van Nostrand Company, Inc., Toronto. pp. 390-391.

46. Perkin-Elmer Corp. (1974) Instruction Manual for Model 204 Fluorescence Spectrophotometer. Norwalk, Conn.

47. Bergmeyer, H.U. (ed.) (1974) In: Methods of Enzymatic Analysis, 2nd English edition. Volume 1. Verlag Chemie Weinheim, New York. p: 555.

48. van Kampen, EJ. and Zijjlstra, W.G. (1961) Clin. Chim. Acta b: 538-544.

49. International Committee for Standardization in Hematology (1978) J. Clin. Path. 31: 139-143.

50. Bergmeyer, H.ण. (ed.) (1983) In: Methods of Enzymatic Analysis, 3rd edition. Volume 1. Verlagi Chemie Weinheim, Deerfield Beach. pp. 114-142.

51. Dävis, J.E. and Pevnick, J. (1979) Anal. Chem. 51: 529-533.

52. Brooks, S.P.J., Espinola, T. and Suelter, C.\#. (1984) Can. J. Biochem. Cell Biol 62: 945-955.

53. Guilbault, G.C., Kramer, D.N. and Goldberg, P. (1965) J. Phys. Chem. 69: $3696-3699$.

54. Fairbanks, V.F. and Ilee, G.G. (1986) In: Textbook of Clinical Chemistry. Tietz, N.w. (editor) W.B. Sinders Company, Toronto. pp. 1532-1533.

55. Weisbrat, I.M. (1985) Statistics for the Clinical Laboratory. J.B. Lippincott, Company, New York. pp. 139-140.

56. Carey, R.N. and Garber, C.C. (1984)-In: Clinical Chemistry: theory, analysis and correlation. Kaplan, I.A. and Pesce, A.J. (edjtors). The C.V. Mosby 
. Company, Toronto. pp. 346-347.

57. Ruzicka, E, Adamek, J. and Andree, J. (1966) Monatsh. Chem. 97: 1558-1567.

58. Ruzickea, E., Adamek, J. and Andree, J. (1966) Mikrochim. Acta 6: 975-982.

59. Worsfold, M., Marshall, M.J. and Ellis, E.E. (1977) Anal. Biochem. 79: 152-156.

60. Kaplan, F, Setlow, P. and Kaplan, N.0. (1969) Arch. Biochem. Biophys. 132: 91-98.

61. Massa, E.M. and Farias, R.N. (1982) Biochem. Biophys. Res. Com. 104: 1623-1629.
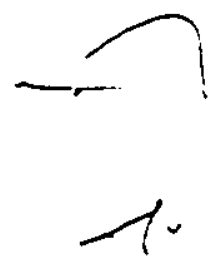


\section{ADDITIORAT REFERENCES}

Principles of Kinetic Enzyme Assays

Cousins, C.L. (1976) Principles of Enzymology. Clin. Biochem. 9: 160-164.

Henderson, A.R. (1976) Errors in Measuring Enzyme Activity by Reaction-Rate Methods. Clin. Biochem. ㅇ: 165-167.

Pardue, H.L. (1977) A Comprehensive Classification of Kinetic Methods of Analysis Used in Clinical Chemistry. Clin. Chem. 23: 2189-2201.

Ingle, J.D. and Crouch, S.R. (1971) Theoretical and Experiment Factors Influencing the Accuracy of Analytical Rate Measurements. Anal. Chem. 43: 697-701.

Maclin, E., Rohlfing, D. and Ansour, M. (1973) Relationship Between Variables in Iristrument Parformance and Results of Kinetic Enzyme Assays - A System View. Clin. Chem. 19: 832-837.

Iondon, J.W., Shä,-L.M., Fetterolf, D. and Garfinkel, D. (1975) A Systematic Approach to Enzymé Assay Optimization, Illustrated by Amirgtransferase Assays. Clin. Chem. 21: 1939-1952.

\section{- Analysis of Enzyme Kinetics Data}

Segel, J.H. (1976) Biochemical Calculations, 2nd edition: John wiley and Sons, Toronto. pp. 214-246.

Method Evaluation

Weisbrot, J.M. (1985) Statistics for the Clinical Laboratory. J.B. Iippincott Company, New York. pp. 129-149.

Carey, R.N. And Garber, C.C. (1984) In: Clinical Chemistry: theory, analysis and correlation. IJaplan, L.A. and Pesce, A.J. (editors). The C.V. Mosby Company, 
Toronto. pp. 346-347.

Properties of Auxiliary Enzymes

Corie, G.T., Colowick, S.P. and Cori, C.F. (1938). The Enzymatic Conversion of Glucose 1-Phosphoric Ester to 6-Ester in Tissue Extracts. J. Eiol. Chem. 124: 543.

Lowry, O.H. and Passoppneau, J.V. (1969) Phosphoglucomutase Kinetics with the Phosphates of Fructose, Glucose, Mannose, Ribose and Galactose. ‥ Biol. Chem. 244: 910-916."

Glaser, L. and Brown, D.F. (1955) Purification and Properties of D-Glucose 6-Phosphate Dehydrogenase, J. Biol. Chem. 216: 67-79.<smiles>CC=CC</smiles>

Gella, F.J., Olivella, M.T., Pegueroles, F. and Gener, J. (1981) Colorimetry of Diaphorase in Commercial Preparations and Clinical Chemical Reagents by Ise of Tet $\mathrm{F}$ azolium Salts. Clin. Chem. 27: 1686-1689.

\section{Properties of Substrates}

Kosterlitz, H.W. (1943) The Structure of the Galactose-phosphate Present in the Liver During Galactose Assimilation. Biochem. ‥ 37: 318-321.

Caputto, R., Leloir, L.F., Cardini, C.E. and Palladini, A.C. (1950) Isolation of the Coenzyme of Galactose Phosphate-Glucose Phosphate Transformation. J. Biol. Chem. 184: 333-350.

Lowry, O.Y., Passonneau, J.V. and Rock, M.K. (1961) The Stability of Pyridine Nuclècotides. J. Biol. Chem. 236: 2756-2759. 
VITA AUCTORIS

PETER CATOMERIS

Birth:

April 15, 1960

Toronto, Ontario, Canada

Education:

1984-Present Master of Science

Clinical Chemistry

University of Windsor, Windsor, Ontario

1979-1983 Bacheior of Science

Biochemistry Major

University of Toronto, Toronto, Ontario

Awards:

1987 University of Windsor Iuition Scholarship

Work Experience:

\author{
1984 Research Trainee \\ Department of Defence, Toronto, Ontario \\ 1982, 1983 Technical Assistant \\ Centre of Forensic Sciences, Toronto, Ontario
}

\title{
Presentations:
}

October 22, 1987 "An Improved Kinëtic Fluorometric Enzymatic Coupled Assay $n$ for the Determination of Galactose 1-Phosphate Uridylyltransferase in Erythrocytes". A seminar presented to the Michigan Section of the American Association for Clinical Chemistry, Windsor, Canada.

Juna 8, 1987 "An Improved Direct Fluorometric Enzymatic Coupled Assay for the Determination of Galactose 1-Phosphate Tridylyltransferase in Erythrocytes". A poster presented at the Annual Meeting of the Canadian Society of Clinical Chemists, Ottara, Canada. 


\section{Professional Memberships:}

- Canadian Society of Clinical Chemists

American Association for Clinical Chemistry

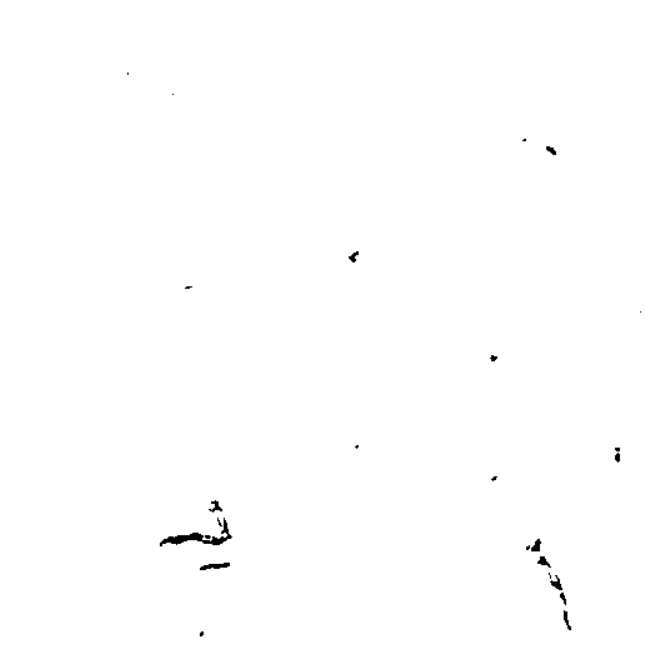

